\title{
REVISIÓN DEL GÉNERO STIPA L. Y NASSELLA DESV. (POACEAE) EN LA PENÍNSULA IBÉRICA E ISLAS BALEARES
}

\author{
Francisco M. VÁZQUEZ y Juan Antonio DEVESA
}

\begin{abstract}
RESUMEN. Revisión del género Stipa L. y Nassella Desv. (Poaceae) en la Península Ibérica e Islas Baleares. Se ha efectuado un estudio taxonómico de los géneros Stipa L. y Nassella Desv. en la Península Ibérica e Islas Baleares. Para el primero se reconocen en el territorio 27 taxones: 18 especies y el resto taxones infraespecíficos, mientras que el segundo está representado sólo por $N$. mucronata. Se aportan claves para la identificacion de los taxones, que se acompañan además de descripción, principales sinonimias comprobadas e información sobre su número cromosómico y distribución en el territorio. Se efectúan ocho combinaciones: Stipa sect. Inaequiglumes, Stipa sect. Jarava, Stipa sect. Macrochloa, Stipa sect. Giganteae, S. iberica var. pseudodasyphylla, S. iberica var. austro-iberica, S. parviflora var. pilosa y $S$. pauneroana, y se describen además los siguientes taxones $S$. apertifolia var. nevadensis, $S$. juncea var. cabanasii y $S$. gigantea subsp. donyanae.
\end{abstract}

Palabras clave. Spermatophyta, Stipa, Nassella, Poaceae, Gramineae, taxonomía, nomenclatura, número cromosómico, distribución, Península Ibérica, Baleares.

ABSTRACT. A revision of Stipa L. and Nassella Desv. (Poaceae) genera in Iberian Peninsula and Balearic Islands.. A taxonomic study of the genus Stipa L. and Nassella Desv. at the Iberian Penisula has been made. 27 taxa of the genus Stipa are recognized, 18 of which are species and the remaining infraspecific taxa. Nassella mucronata is the only species of the genus Nassella in the studied area. Keys to identification of the taxa are given, together with descriptions, the most important synonimies and information concerning to their cromosomic numbers and geographical distribution. Eight combinations have been made: Stipa sect. Inaequiglumes, Stipa sect. Jarava, Stipa sect. Macrochloa, Stipa sect. Giganteae, S. iberica var. austro-iberica, S. iberica var. pseudodasyphylla, S. parviflora var. pilosa and S. pauneroana. The following taxa are new : S. apertifolia var. nevadensis, $S$. juncea var. cabanasii y $S$. gigantea subsp. donyanae.

Key words. Spermatophyta, Stipa, Nassella, Poaceae, Gramineae, Taxonomy, Nomenclature, Chromosomic number, Chorology, Iberian Peninsula, Balearic Islands.

\section{INTRODUCCIÓN}

El género Stipa L. está integrado por alrededor de 400 especies (Freitag, 1985;
Barkworth \& Everett, 1987; Barkworth, com.pers.), aunque algunos autores estiman tan sólo 300 (Tzvelev, 1989), discrepancia que pone de manifiesto la dificultad taxonómica 
del grupo. En apoyo de estas ideas baste recordar que en la tribu Stipeae, a la cual pertenece el género Stipa, se reconocen unos 12 géneros con cerca de 450 taxones (Clayton \& Renvoize, 1986; Tzvelev, 1989; Barkworth com.pers.), lo que da idea de la alta variabilidad existente, de cuya valoración taxonómica depende la cuantificación de las especies (Barkworth, 1990).

El género se incluye en la tribu Stipeae, un grupo originado tal vez en el antiguo continente Gondwana y que se habría diversificado tras la separación de los continentes (Barkworth \& Everett, 1987), conociéndose de él fósiles miocénicos procedentes del norte de América (Thomasson, 1980; Barkworth \& Everett, 1987) y afines a los géneros Stipa (Berriochloa, Elias, 1942; Stebbins, 1975; Thomasson, 1979) y Nassella Desv. (Paleoeriocoma; Thomasson, 1980).

Sus representantes son mayoritariamente perennes y cespitosos (sólo se conocen las anuales S.capensis Thunb., S.annua Mez, S.eremophila Reader, S.macalpinei Reader y S.compresa R.Br.). Se encuentran distribuidos principalmente por las zonas templadas de ambos hemisferios (De Winter, 1965; Hartley, 1973; Barkworth \& Everett, 1987; Tzvelev, 1989), siendo máxima su representación en el sur de Australia (c.50 especies, sec. Vickery et al., 1986; Barkworth \& Everett, 1987), en la Región Mediterránea (más de 60, sec. Martinovsky, 1980; Freitag, 1985; Moraldo, 1986), en América del Sur (c.100, sec. Hitchcock, 1925; Matthei, 1965; Caro \& Sánchez, 1973; Tovar, 1988; Torres, 1993; Rojas, 1994) y en las regiones meridionales de Norteamérica (c.40, Hitchcock, 1935; Barkworth, com. pers.). Exceptuando algunos representantes de la sect. Lasiagrostis (v.g. Stipa calamagrostis (L.)Wahlenb.), la mayoría de las especies de Stipa están particularmente adaptadas a vivir en enclaves muy secos
(Matthei, 1965; De Winter, 1965; Vickery et al., 1986), una condición considerada evolucionada dentro del grupo (Freitag, 1985) y que comparten la mayor parte de las estipeas, salvo algunos representantes de los géneros Oryzopsis Michx. (Barkworth \& Everett, 1987) y Piptatherum Beauv. (Freitag, 1975).

En Europa el género Stipa está representado por unos 42 taxones (Martinovsky, 1980), siendo bien conocidos sobre todo los taxones centroeuropeos de la sect. Stipa y en particular los afines a S.pennata L., que han sido objeto de diversos estudios (Martinovsky, 1966, 1967b, 1970 b \& c, 1980, etc.; Martinovsky \& Skaliscky, 1969; Dihoru \& Roman, 1969; Scholz, 1982, 1989 \& 1990; Moraldo, 1986, etc.). Sin embargo, si se exceptúa la aportación de Martinovsky (1980) para Flora Europaea, el conocimiento del género en la Península Ibérica se fundamenta sólo en estudios corológicos (Cebolla \& López, 1994) o taxonómicos puntuales de los representantes de la sección Stipa (Martinovsky, 1967b \& 1970c; Bolòs et al., 1987), de la sección Leiostipa Dumort. (Talavera, 1987; Scholz, 1989; Viera \& Vázquez, 1991) o de algunas especies en particular, como S.setigera Presl (García, 1946), S.tirsa Steven (Paunero, 1960) y S.papposa Nees (Casasayas \& Farras, 1985), persistiendo no obstante problemas taxonómicos importantes que han sido abordados en el presente estudio.

Finalmente, respecto de Nassella, género descrito por Desvaux en 1854 y recientemente validado por Barkworth (1990) y Jacobs. et al. (1995), destacar su escasa representación en Europa, pues de sus aproximadamente 80 especies -todas americanas-sólo siete aparecen como adventicias en nuestro continente: N.neesiana (Trin. \& Rupr.) Barkworth, en Francia (Kerguélen, 1975; Martinovsky, 1980) e Italia (Martinovsky, l.c.; Pignatti, 1982; 
Moraldo, 1986); N.trichotoma (Nees) Hackel, en Italia (Pignatti, 1982; Moraldo, 1986) y Francia (Kerguélen, 1975); N.brachychaeta (Godron) Barkworth, en Francia (Godron, 1853; Kerguélen, 1975); N.filiculmis (Delile) Barkworth, en Francia (Delile, 1849; Kerguélen, 1975); N.formicarum (Delile) Barkworth, en Francia (Delile, 1840; Kerguélen, 1975); N.hyalina (Nees) Barkworth, en Italia (Martinovsky, 1980; Moraldo, 1986) y N.mucronata (Humb., Bonpl. \& Kunth) Pohl en España (García, 1946, sub Stipa setigera C.Presl).

Revisión histórica. Aunque en las obras de muchos autores prelinneanos es posible reconocer algunas de las especies que actualmente se incluyen en el género (v.g. Clusius, 1601; Bauhini, 1623; Grisley, 1660; Boccone, 1697; Tournefort, 1700; Scheuchzer, 1719; Van Royen, 1740), la primera referencia a Stipa se debe a Linneo (1753), quien efectuó una descripción formal del género en la quinta edición de su Genera Plantarum (1754).

Inicialmente Linneo (1753) reconoció sólo cuatro especies, dos europeas (S.juncea y S.pennata) y una americana, S.avenacea, además de su S.membranacea de «Hispania» que figura en la addenda y que actualmente se incluye en el género Vulpia (V.membranacea (L.)Dumort.; Stace \& Jarvis, 1985). En aportaciones posteriores este autor describió nuevos taxones, varios de ellos representados en la Península Ibérica: S.tenacissima (Linneo, 1755, a partir de material recolectado por Loefling en España); Agrostis calamagrostis (Linneo, 1759, =Stipa calamagrostis); S.capillata (Linneo, 1762); Agrostis bromoides (Linneo, 1767, =Stipa bromoides) y Stipa aristella (Linneo, 1768, =Stipa bromoides).

Con posterioridad, a finales del siglo XVIII y en la primera mitad del siglo XIX, fueron muchas las aportaciones de interés para el conocimiento de la tribu Stipeae y del género Stipa en particular, buena parte de ellas centradas en taxones americanos. De este período merece destacarse a Beauvois (1812), quien segregó parte de los taxones incluidos en Stipa en tres géneros nuevos: Chaetaria, Achnatherum y Piptatherum, así como el trabajo de Dumortier (1823), el primer autor que define los límites de la tribu Stipeae y reconoce en el género Stipa dos secciones, en base a las características de la arista de la lema: Eriostipa («Arista plumosa vel pubescens»; S.pennata L.) y Leiostipa («Arista glabra»; S.capillata L.).

De gran interés fue la aportación de Kunth (1829), tanto para la comprensión y delimitación de la tribu como por el tratamiento del género Stipa, que desdobló en dos géneros en base a las características del ápice de la lema y la pálea: entero en Stipa y bífido o dentado en Macrochloa (para el que reconoce dos representantes de la Península Ibérica, M.arenaria y M. tenacissima). A Bertoloni (1833) se debe la segregación de Stipa del género Aristella, en base a características de la inflorescencia (fusiforme) y de la lema (dentada y con callo obtuso), género donde incluye un solo representante, Aristella bromoides, basado en el taxón descrito por Linneo (1767, Agrostis bromoides). Previamente, Trinius (1820) había utilizado el mismo criterio para el reconocimiento de la sección Aristella dentro del género Stipa.

No obstante, las principales aportaciones monográficas sobre el género durante el siglo XIX se debieron a Trinius (1820), Trinius \& Ruprecht (1842) y Steudel (1854). Al primero se debe la segregación de parte de los taxones americanos de Stipa en el género Urachne (Trinius, l.c.) y, ya en colaboración (Trinius \& Ruprecht, l.c.), el reconocimiento dentro de Stipa de 5 subgéneros basados, 
fundamentalmente, en caracteres de la espiguilla: Oreostipa, Jarava (Ruiz \& Pavón), Neostipa, Schizachne y Eustipa. Este criterio es seguido también por Steudel (1854), quien reconoce además los subgéneros Aristella (Trin.) («..Panicula depauperata racemosa; aristae rectae non tortae breves...»; incluye S.aristella), Orthoraphium («...Flosculo glumis paulo longiore, arista recta»), Lasiagrostis (Link) («...Valvula inferior glumis paulo firmior (nec tamen coriacea) apice bidentata; arista raro plerumque vix torta...»; incluye Stipa calamagrostis, entre otras especies) y Macrochloa (Kunth) («...Spiculae 9-12 lineales; arista long a nuda vel inferne barbata manifeste torta et geniculata...»; donde incluye S.tenacissima y S.arenaria (=S.gigantea)). También de este período son las aportaciones de Endlicher (1836-1840) y Bentham \& Hooker (1883). El primero reconoce para Stipa las secciones Stipa («Floris stipitulus conicus. Paleae cylindraceae»), Aristella Trin. ( Floris stipitulus planiusculus. Paleae cylindraceae») y Nassella (Desv.) («Floris stipitulus planiusculus, brevissimus. Paleae oblongae»), esta última inicialmente descrita bajo el género Urachne (Trinius, 1820). En su Genera Plantarum Bentham \& Hooker (1883) ubican el género Stipa en la tribu Agrostideae y reconocen en él 5 grupos basándose en caracteres relativos a la espiguilla, y a los que no asignan categoría taxonómica alguna: Macrochloa (incluyen aquí S.tenacissima y S.arenaria), Aristella (incluyen entre otras a Stipa aristella), Streptachne, Jarava (donde incluyen entre otras a Stipa papposa) y Lasiagrostis (sólo para Stipa calamagrostis).

Ya en el siglo XX destacar el tratamiento efectuado por Rouy (1913) en su Flore de France, donde reconoce para Stipa dos subgéneros: Eustipa y Aristella (Bertol.), incluyendo en este último sólo Stipa bromoides. No obstante las aportaciones más interesantes de este período se centran en Australia (Hughes,
1921 \& 1922) y sobre todo en el continente americano, pudiéndose señalar las monografías de Spegazzini (1901), Hitchcock (1925) y las recientes de Barkworth (1990 \& 1993) y Torres (1993), así como las contribuciones de Parodi (1946 \& 1960), Matthei (1965), Caro (1966), Cabrera \& Torres (1968) y Caro \& Sánchez (1973). De todas ellas destacar la de Barkworth (1990), quien segrega los géneros Stipa y Nassella, criterio taxonómico seguido en el presente trabajo para ubicar taxonómicamente Stipa mucronata (=Nassella mucronata), la única especie de este género detectada hasta la fecha en la Península Ibérica. Posteriormente, Barkworth (1993) redefine el concepto del género Achnatherum en America del Norte, incluyendo dentro de ese concepto a taxones hasta entonces incluidos en los géneros Stipa, Oryzopsis y Eriocoma.

El conocimiento taxonómico del género Stipa en Europa a partir de la aportación de Steudel (1854) ha sido más fragmentario, pues a esta suceden sobre todo contribuciones puntuales (Steven, 1857; Celakovsky, 1883 \& 1884; Smirnov, 1925 \& 1929; Rouy, 1913). A mediados de siglo los estudios taxonómicos en el género cobran un nuevo impulso, destacando los trabajos de Roshevits (1934), Martinovsky (1965, 1966, 1967 a \& b, 1976, etc.), Martinovsky \& Scholz (1968); Scholz (1968, etc.) y Tzvelev (1973, 1974 \& 1989), la mayor parte de ellos centrados en la problemática del grupo de S.pennata (sect. Stipa). Entre ellos merece destacarse el de Roshevits (1934), quien reconoce para Stipa (incluida en la tribu Agrostideae) 7 series en función de características relativas a la espiguilla: Sibiricae, Brevigeniculatae, Barbatae, Pennatae, Tortiles, Pseudocapillatae y Capillatae, mientras que Tzvelev (1974), además de segregar los géneros Stipa y Achnaterum Beauv. (incluye dentro de este la sección Aristella, entre otras) reconoce en el primero 8 secciones, algunas de ellas 
reconocidas igualmente en este estudio (Leiostipa, Stipella y Barbatae). A Martinovsky (1976) se debe el reconocimiento de diversas series dentro del género (Pulcherrimae, Tirsae, Dasyphyllae, Epilosae, Bromoides y Penicillatae) y una vez más la segregación del género Macrochloa, previamente descrito por Kunth (1829), donde reconoce M.tenacissima (=Stipa tenacissima) y M.arenaria (=Stipa gigantea), taxón este último que incluye en una nueva serie, Giganteae, caracterizada por las espiguillas con arista bigeniculada y páleas bífidas.

A partir de la década de los sesenta se intensifican los estudios del género Stipa en la Región Mediterránea y el SW de Asia (Bor, 1960; Freitag, 1985; Scholz, 1968, 1975, 1988 \& 1991; Moraldo, 1986), así como en Australia (Everett \& Jacobs, 1983 \& 1990; Vickery et al., 1986), pudiéndose destacar entre ellos el de Freitag (l.c.), ampliamente documentado y cuyo tratamiento en secciones ha sido el adoptado en el presente estudio (tab. I).

\section{MATERIAL Y MÉTODOS}

El estudio morfológico ha sido llevado a cabo a partir de material de herbario procedente de Centros muy diversos (B. BC, BC-Costa, BC-Cadevall, BC-Vayreda, BC-Sennen, BPU, COI, COI-Willk, COFC, FI, G, GDA, GDAC, GOET, H, JACA, KASS-Freitag, LE-Trin., LINN, LISU, LISU-Van, LISU-Wel, MA, MAF, MAF-Pourret, MGC, P, P-Co, P-Desf, P-Humb, P-Poiret, PR, PRC, SALF, SEV, SGO, UNEX, UPS, UPS-Thumb, VAB, abreviaturas según Holmgren et al., 1981) y del que sólo se recogen en el texto aquellos especímenes de interés para la tipificación de los taxones. En el Anexo 1 se recoge, no obstante, una selección de material representativo de cada taxón.

El estudio cariológico se ha efectuado a partir de botones florales recogidos en poblaciones silvestres o bien en raíces obtenidas tras germinación de cariópsides en condiciones de laboratorio. En el primer caso se empleó como fijador una mezcla de alcohol de $90^{\circ}$ y acetato férrico (3:1), y como colorante carmín-alcohólico-acético siguiendo la técnica de Snow (1963). Para el estudio de las mitosis en meristemos radicales se utilizó como antimitótico una solución acuosa de 8 hidroxiquinoleína $(0,002 \mathrm{M}$; Tjio \& Levan, 1950) actuando durante 4-6 horas y a temperatura no superior a $4^{\circ} \mathrm{C}$ (Pretel, 1976); el fijador utilizado aquí fue el líquido de Farmer (Löve \& Löve, 1975), y el colorante y montaje como en el caso anterior.

\section{CARACTERES TAXONÓMICOS}

Entre los caracteres con mayor interés taxonómico en el género destacan la morfología foliar y, sobre todo, los relativos a las espiguillas y flores.

Hojas. Los taxones peninsulares estudiados presentan hojas con limbo conduplicado (Stipa calamagrostis, S.bromoides, S.capensis, S.parviflora, Nassella mucronata y ocasionalmente en S.gigantea) o más generalmente convoluto, siendo de interés también en él su pubescencia (permite discriminar taxones infraespecíficos) y la morfología del ápice, carácter este que diferencia S.tirsa del resto de los taxones, al prolongarse aquí en una seta apical de hasta 20 $\mathrm{mm}$.

De especial interés es la morfología de la lígula, que en los taxones peninsulares puede estar sustituida por pelos (en S.tenacissima, sect. Macrochloa) o constituida por una estructura membranosa (en Nassella y los restantes taxones de Stipa), entera o lacerada, a menudo auriculada (S.bromoides, 


\begin{tabular}{|c|c|c|c|c|c|c|c|c|c|c|c|}
\hline 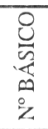 & $\overline{\bar{x}}$ & $\overline{\vec{x}}$ & $\overline{\overrightarrow{\|}}$ & $\prod_{x}$ & $\underset{*}{\pi}$ & $\overline{\underline{\pi}}$ & $\underset{*}{\pi}$ & $\underset{\times}{\pi}$ & $\frac{7}{\pi}$ & $\underset{\pi}{\pi}$ & $\begin{array}{l}= \\
\frac{0}{11} \\
x\end{array}$ \\
\hline 㣢 & $\mathrm{N}$ & $\mathrm{N}$ & $\begin{array}{l}\vec{r} \\
\dot{0} \\
\stackrel{i}{i}\end{array}$ & $\mathrm{~N}$ & $\mathrm{~N}$ & $\mathrm{~N}$ & $\mathrm{~N}$ & $\mathrm{~N}$ & $\mathrm{~N}$ & $N$ & $\alpha$ \\
\hline 旡 & 兽 & 总 & 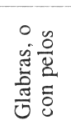 & 恣 & 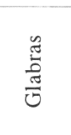 & $\begin{array}{l}\stackrel{\mathscr{E}}{\tilde{E}} \\
\frac{\tilde{J}}{\tilde{J}}\end{array}$ & 思 & 总 & 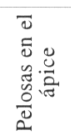 & 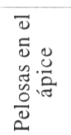 & 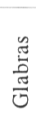 \\
\hline 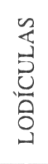 & & & & & & & & & & & \\
\hline 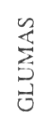 & 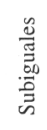 & 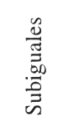 & 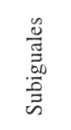 & 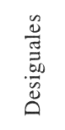 & 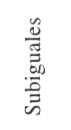 & 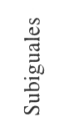 & 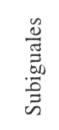 & 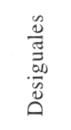 & 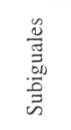 & 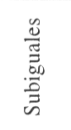 & 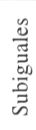 \\
\hline 焉 & 莺 & $\begin{array}{l}\text { 莺 } \\
\text { 岦 }\end{array}$ & $\begin{array}{l}\text { 壹 } \\
\text { 苫 }\end{array}$ & $\begin{array}{l}\text { 苛 } \\
\text { 吉 }\end{array}$ & 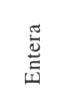 & $\begin{array}{l}\text { 密 } \\
\text { 密 }\end{array}$ & $\begin{array}{l}\text { 苞 } \\
\text { 屆 }\end{array}$ & 莺 & $\begin{array}{l}\text { 苛 } \\
\text { 童 }\end{array}$ & 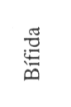 & $\begin{array}{l}\text { 苟 } \\
\text { 壱 }\end{array}$ \\
\hline 完 & 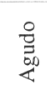 & 总 & 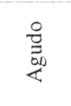 & 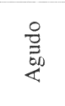 & $\begin{array}{l}\stackrel{\circ}{0} \\
\stackrel{0}{00}\end{array}$ & 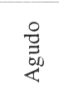 & 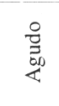 & $\begin{array}{l}0 \\
\stackrel{0}{2} \\
0\end{array}$ & 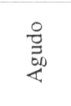 & 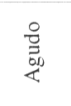 & $\begin{array}{l}\stackrel{0}{0} \\
\stackrel{\bar{g}}{<}\end{array}$ \\
\hline 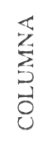 & $\frac{\pi}{\frac{\pi}{0}}$ & 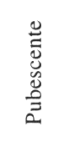 & & & & & & 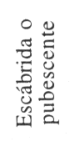 & 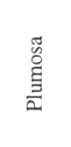 & & \\
\hline$\overleftrightarrow{\frac{5}{x}}$ & 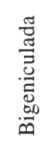 & 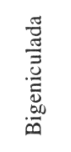 & 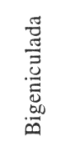 & 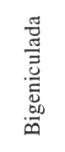 & 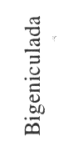 & 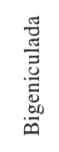 & $\begin{array}{l}\frac{\pi}{0} \\
\frac{\pi}{3} \\
\bar{J} \\
5 \\
5\end{array}$ & & $\begin{array}{l}\frac{\tilde{J}}{\tilde{J}} \\
\bar{\Xi} \\
\bar{\Xi} \\
\tilde{\Xi}\end{array}$ & 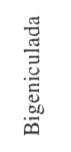 & 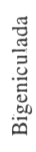 \\
\hline 莺 & 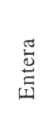 & 莺 & 䇺 & 䓌 & 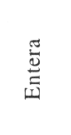 & 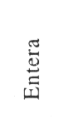 & 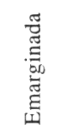 & 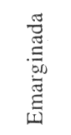 & 总 & 苟 & $\begin{array}{l}\text { 丞 } \\
\text { 힘 }\end{array}$ \\
\hline 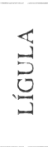 & 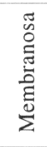 & 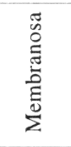 & 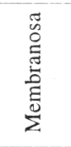 & 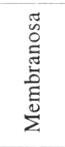 & 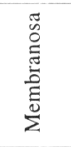 & 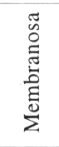 & 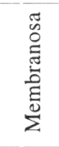 & 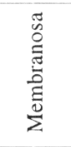 & 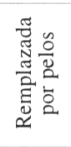 & 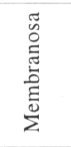 & 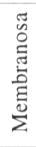 \\
\hline 里 & & 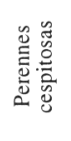 & 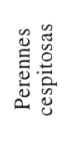 & 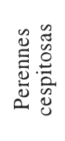 & 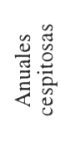 & 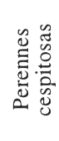 & 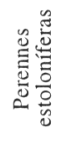 & 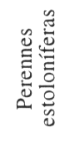 & 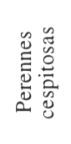 & 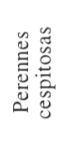 & \\
\hline 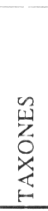 & 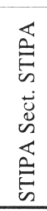 & 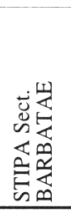 & 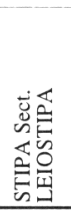 & 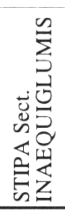 & 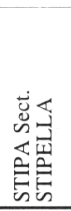 & 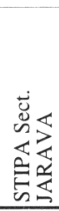 & 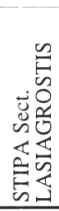 & 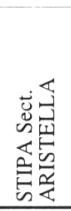 & 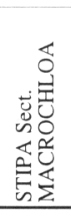 & 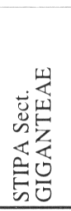 & 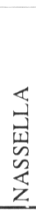 \\
\hline
\end{tabular}


S.calamagrostis, etc.), aguda o truncada (v.g. S.gigantea), con márgenes glabros (v.g. S.offneri) o ciliados (v.g. S.lagascae).

Flores y espiguillas. La inflorescencia típica en las especies estudiadas de Stipa es una panícula de dimensiones muy variables (desde c. $10 \mathrm{~cm}$ en S.papposa a más de $50 \mathrm{~cm}$ en S.gigantea) y cuya morfología puede ser fusiforme (S.bromoides) o más comúnmente oblongo-lanceolada u ovado-lanceolada en el resto de los taxones peninsulares de Stipa y Nassella.

Las flores se disponen en espiguillas unifloras, y son precisamente las características de sus piezas los caracteres que mayor información aportan para la segregación de los taxones.
A. Glumas. Son siempre dos, de consistencia membranosa, iguales o subiguales salvo en S.parviflora, donde la inferior es notablemente mayor. En general muestran una pubescencia laxa en el dorso (suelen depilarse en la madurez) y pueden aparecer recorridas por 1 (S.papposa), 1-3 (Stipa sects. Stipella e Inaequiglumis), 3 (Stipa sects. Lasiagrostis, Aristella y Macrochloa, y Nassella mucronata), 3-5 (S. gigantea) o 3-7 nervios longitudinales (Stipa sects. Stipa y Leiostipa). Su ápice puede ser obtuso (S.parviflora) o más frecuentemente agudo y terminado en una pequeña seta.

\section{B. Lemas. Constituyen un carácter} excepcional, no sólo por su variabilidad de tamaño (útil en la segregación de taxones, como S.lagascae y S.juncea) sino también por el interés de sus caracteres cualitativos y el
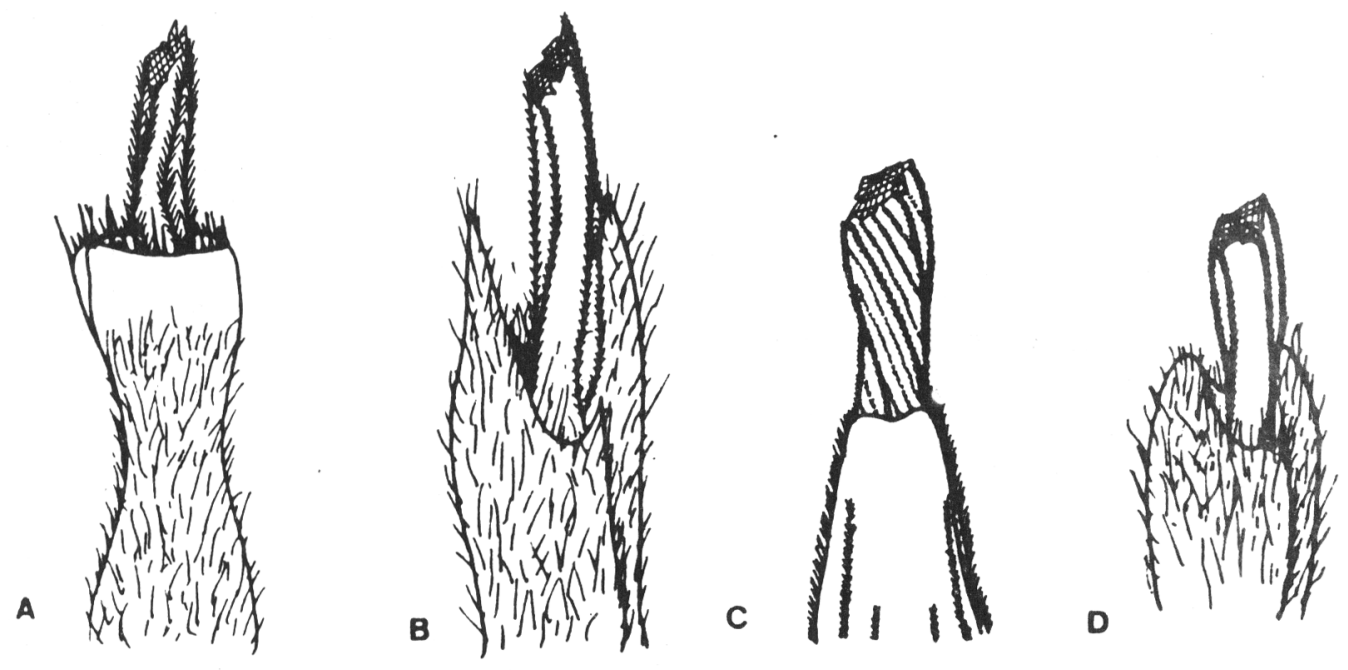

Figura 1. Morfología del ápice de la lema en las especies peninsulares de los géneros Stipa y Nassella. A, Nassella mucronata. B, Stipa sect. Macrochloa y Giganteae. C, Stipa sect. Stipa, Barbatae, Leiostipa, Stipella, Inaequiglumis y Jarava. D, Stipa sect. Lasiagrostis y Aristella. Morphology of the lemma apex in the peninsulars species of the Stipa and Nassella genera. 
tipo de arista.

Poseen forma generalmente fusiforme y consistencia subcoriácea, siendo muy variable su indumento. Así, pueden aparecer recorridas longitudinalmente por 7 líneas desiguales de pelos (Stipa sects. Stipa, Leiostipa y Barbatae), concentrarse éstos en la mitad distal (S.papposa) o bien aparecer distribuidos homogéneamente por el dorso (en Nassella mucronata y el resto de los taxones estudiados de Stipa). Las lemas son enteras, como ocurre en la mayoría de los representantes peninsulares de Stipa (fig. 1C), o bien presentan el ápice emarginado (S.bromoides y S.calamagrostis; fig. 1D) o bidentado (S.gigantea y S.tenacissima; fig. 1B), siendo muy diferente el caso de Nassella mucronata, en que las lemas portan en el ápice una corona ciliado-dentada (fig. 1A).
En todas las especies las lemas portan una arista apical (fig. 2), retorcida helicoidalmente y generalmente con dos partes bien definidas: la columna, o parte basal recta, y el pico o porción terminal, muy alargada y a menudo fácilmente distinguible de aquella por su doble inflexión (salvo en S.calamagrostis, S.bromoides y S.tenacissima, donde presenta una sola genícula). Las aristas presentan una sección tetrágona, siendo precisamente en los ángulos donde se disponen en general los pelos (en S.capillata también en los lados); en los representantes de la sección Stipa la columna es glabra y el pico plumoso (fig. 2B), y en el resto de los taxones la arista es pelosa 0 escábrida en toda su longitud.

En la base de la lema se distingue el callo, o cicatriz de inserción, cuya forma es de interés

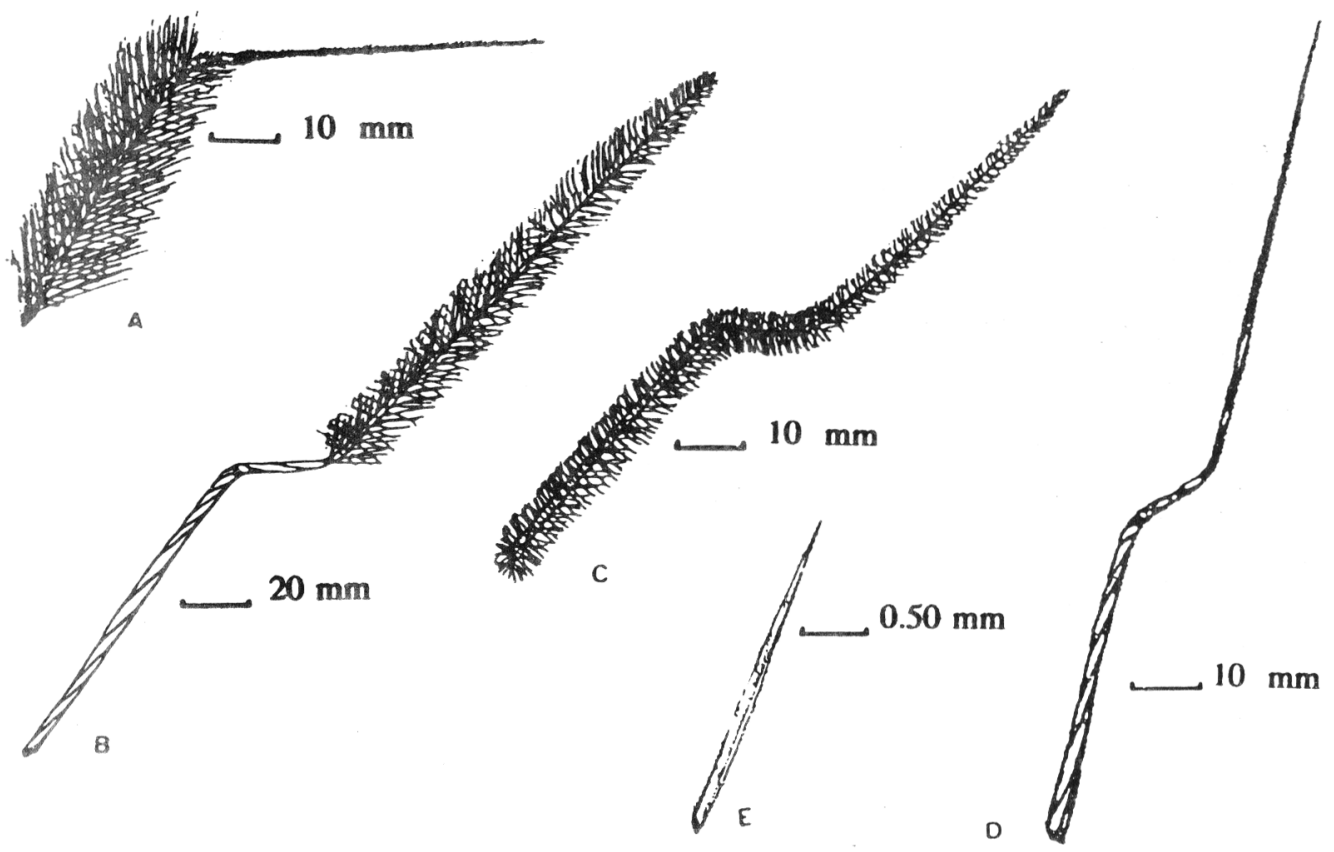

Figura 2. Morfología de la arista en las especies peninsulares de los géneros Stipa y Nassella. A, Stipa sect. Macrochloa. B, Stipa sect. Stipa. C, Stipa sect. barbatae. D, Nassella mucronata, Stipa sect. Leiostipa, Giganteae, Jarava, Inaequiglumis y Stipella. E, Stipa sect. Lasiagrostis y Aristella. Morphology of the awn in the peninsulars species of the Stipa and Nassella genera. 
taxonómico en el grupo. En los taxones peninsulares estudiados de Nassella y Stipa es siempre agudo, salvo en S.bromoides que 10 presenta obtuso, siendo en todos los casos peloso y mostrando excepcionalmente dos líneas laterales glabras en S.capensis.

C. Páleas. Su valor taxonómico es muy inferior al de las lemas, pues aparecen siempre como una estructura lanceolada y bicarenada, subigual o ligeramente mayor que la lema (claramente mayor en S.gigantea). En ella es de interés tan solo la morfología del ápice, que puede ser bífido (sect. Giganteae) o entero (en el resto de los taxones estudiados), así como su pubescencia, de utilidad en la segregación de algunos taxones de la sección Leiostipa (S.lagascae subsp. lagascae, S.juncea, S.offneri).

D. Lodículas. Las lodículas son siempre 3 , una de ellas contigua a la pálea (la posterior) y dos enfrentadas (las anteriores; fig. 3), estas últimas mayores que aquella salvo en S.gigantea (fig. 3C). Presentan consistencia membranosa, forma generalmente lanceolada (salvo en S.tenacissima, donde son ovadas) y ápice agudo y setoso, excepto en S.eriocaulis donde es ciliado (fig. 3B).

Verticilos sexuales y fruto. El androceo lo integran 3 estambres de anteras generalmente glabras, aunque a veces portan un penacho apical de pelos conspicuos (en Stipa tenacissima y S.gigantea) o bien algunos pequeños y esparcidos, como sucede en algunos representantes de Stipa sect. Leiostipa (S.lagascae, S.offneri y S.clausa).

El ovario es súpero y monocarpelar, y puede estar rematado por 2 (la mayoría de los taxones peninsulares de Stipa y Nassella), 3 (S.lagascae y S.juncea) ó 4 estilos (S.clausa); glabros (S.capensis) o plumosos (v.g.
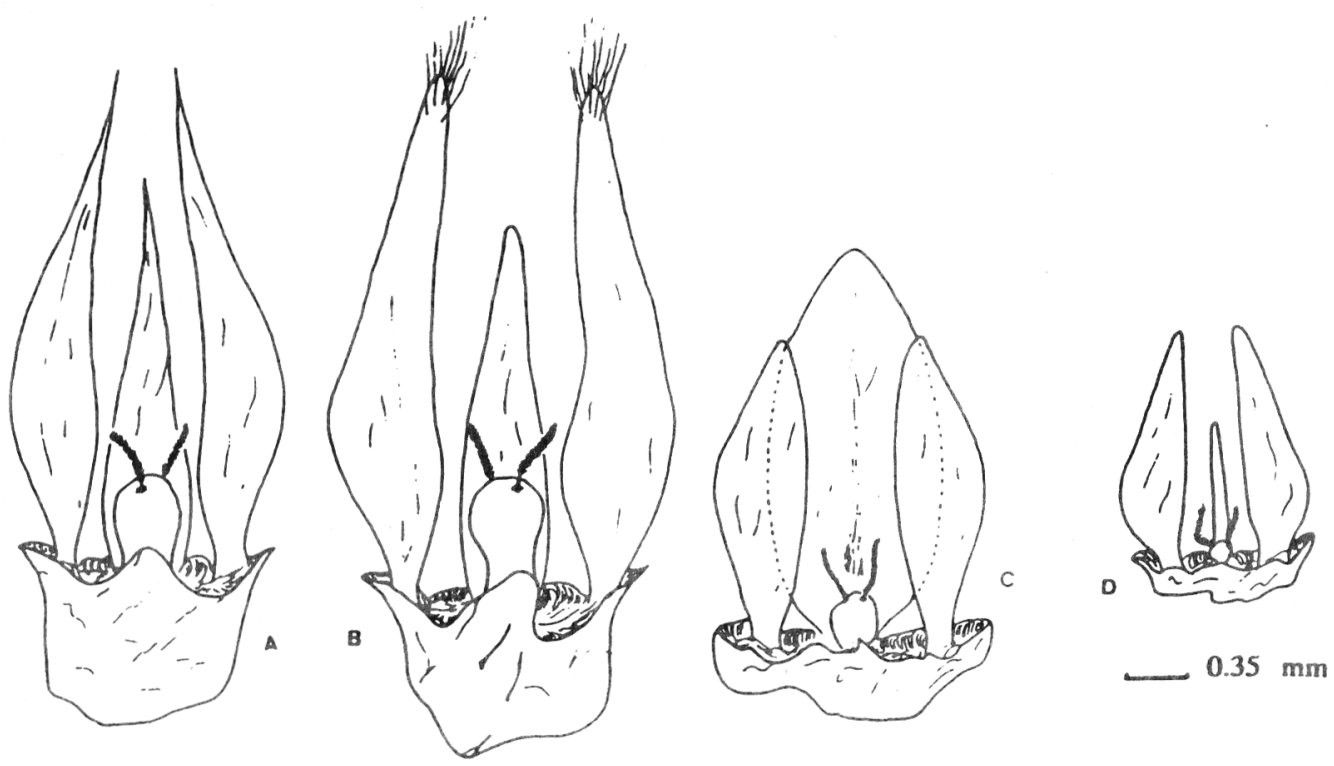

Figura 3. Tipología de las lodículas en las especies peninsulares de los géneros Stipa y Nassella. A, Stipa pauneroana. B, S.eriocaulis. C, S.gigantea. D, S.papposa y Nassella mucronata. Typology of the lodicules in the peninsulars species of the Stipa and Nassella genera. 
S.gigantea, S.tenacissima, S.lagascae). En la madurez da lugar a un fruto cariópside típico, glabro y generalmente fusiforme, adnado o no a la pálea (Nassella mucronata).

\section{ECOLOGÍA Y DISTRIBUCIÓN GEOGRÁFICA}

La mayoría de los taxones estudiados se asientan sobre sustratos calcáreos, con $\mathrm{pH}$ básico o neutro. Sólo S.gigantea ocupa habitualmente sustratos silíceos con $\mathrm{pH}$ ácido, y S.capensis es indiferente a la naturaleza del sustrato.

Suelen ocupar zonas subesteparias desde el nivel del mar hasta más de $2.000 \mathrm{~m}$. Algunos taxones de la sect. Stipa viven por encima de los 600 m.s.m., aunque la mayoría aparecen habitualmente entre los 1.000 y 2.500 m.s.m.; otros, como los de las sects. Inaequiglumis, Stipella, Macrochloa y Aristella, no superan generalmente los 700 m.s.m. Sólo los representantes de las secciones Leiostipa, Giganteae y Lasiagrostis (género Stipa) tienen un comportamiento errático en lo relativo a su distribución en función de la altura, viviendo desde el nivel del mar hasta los 2.000 m.s.m.

Los parámetros climáticos (temperatura y pluviosidad) limitan la distribución de algunas especies. Así, los representantes de la sect. Stipa permanecen algunos meses del año cubiertos por la nieve, e igual sucede en algunos enclaves en los representantes de las secciones Giganteae y Lasiagrostis; otros, como los representantes de la sect. Macrochloa, no suelen ocupar enclaves propensos a las heladas. Las áreas donde se asientan estos taxones presentan una precipitación por debajo de los 600 $\mathrm{mm}$ anuales, muy frecuentemente comprendida entre 300 y $500 \mathrm{~mm}$, aunque algunas especies como S.calamagrostis ocupan hábitats con precipitación por encima de los $600 \mathrm{~mm}$ anuales.
La distribución del genero Stipa en la Península Ibérica e islas Baleares es muy amplia y está asociada en la mayoría de los casos a la presencia de sustratos calcáreos. Es fácil encontrar representantes de Stipa en el centro, sur y este peninsular, y más esporádicamente en el norte y oeste del territorio, donde son frecuentes no obstante S.gigantea (ligada a sustratos silíceos) y S.capensis (indiferente edáfica).

\section{DESCRIPCIÓN DE LOS TAXONES Y CLAVES DE IDENTIFICACIÓN}

\section{Clave de géneros}

1. Lema sin corona distal, prolongada en una arista apical I. Stipa

1 '.Lema con una corona cupuliforme apical, de cuyo interior parte la arista ..... II. Nassella

I. Stipa L., Sp. Pl. 78 (1753) [Gen. Pl. ed.5: 34, 1754]

Jarava Ruiz y Pavón, Prodr. Fl. Perú 2 (1794) (Especie tipo: J.ichu Ruiz y Pavón; Caro \& Sánchez, 1973)

Achnatherum Beauv., Agrost. 146 (1812)

(Especie tipo: Achnatherum calamagrostis

(L.)Beauv., = Agrostis calamagrostis L.; Niles \& Chase, 1925)

Lasiagrostris Link, Hort. Berol. 1: 99 (1827)

(Especie tipo: Lasiagrostis calamagrostis

(L.)Link, = Agrostis calamagrostis L.; Swallen, 1979)

Macrochloa Kunth, Revis. Gram. 1: 58 (1829)

(Especie tipo: Macrochloa tenacissima (Loefl. ex L.)Kunth, = Stipa tenacissima Loefl. ex L.)

Aristella (Trin.)Bertol., Fl. Ital. 1:690(1833)

(Especie tipo: Aristella bromoides (L.)Bertol, = Agrostis bromoides L.; Chambers et al., 1979) 
Plantas perennes, estonolíferas o cespitosas, menos frecuentemente anuales. Hojas con vaina de márgenes libres, glabra, escábrida o pubescente. Lígula membranosa, aguda, truncada u obtusa, glabra, escábrida o ciliada, menos frecuentemente sustituida por una línea de pelos. Limbo convoluto o conduplicado, rara vez plano, glabro, escábrido o pubescente. Panícula densa o laxa. Glumas 2, iguales, subiguales o desiguales, con 3-7 nervios. Lemas fusiformes, homogéneamente pubescentes en el dorso o con 7 líneas de pelos, provistas de una arista apical recta o con 1 ó 2 genículas, escábrida, pubescente o plumosa. Callo agudo u ocasionalmente obtuso, más o menos pubescente. Páleas membranosas y bicarenadas, glabras o pubescentes. Estambres 3. Lodículas 3, con sección plana, glabras o ciliadas en el ápice, las anteriores generalmente de mayor tamaño que la posterior. Estilos 2, rara vez 3 ó 4 , glabros o plumosos. Cariópside fusiforme. $x=7,11$ y 12 .

Especie tipo: Stipa pennata L. (Nash, 1913).

\section{Clave para las secciones}

1. Hojas con lígula reemplazada por pelos... J. Sect. Macrochloa

1'. Hojas con lígula membranosa, endurecida hacia la base.

2. Lemas con 7 líneas desiguales de pelos 3

2'. Lemas uniformemente pubescentes, o con pelos sólo en la porción apical

3. Arista de la lema con columna glabra y pico plumoso

A. Sect. Stipa

3'. Arista de la lema pubescente en toda su longitud

4. Arista con pelos de 0,5-3 mm

B. Sect. Barbatae

4'. Arista con pelos de hasta $0,4 \mathrm{~mm}$

C. Sect. Leiostipa
5. Anteras conspícuamente pelosas en el ápice. Páleas bífidas.... K. Sect. Giganteae

5'. Anteras glabras o glabrescentes. Páleas enteras

6. Arista bigeniculada. Anual o perenne, cespitosa ...................................................... 7

6'. Arista recta o geniculada. Estolonífera. 9

7. Dorso de la lema parcialmente escábrido en la mitad basal ............. F. Sect. Jarava

7'. Dorso de la lema uniformemente pubescente 8

8. Glumas desiguales. Perenne

D. Sect. Inaequiglumes

8'. Glumas iguales o subiguales. Anual

E. Sect. Stipella

9. Lemas con callo agudo y dorso con pelos patentes. Panícula oblongo-lanceolada ...

G. Sect. Lasiagrostis

9'. Lemas con callo obtuso y dorso adpresopubescente. Panícula fusiforme

H. Sect. Aristella

\section{Clave para las especies}

(La medida de la lema no incluye la longitud del callo).

1. Lígula reemplazada por pelos

16. S.tenacissima

1'. Lígula membranosa, a veces muy estrecha, glabra, ciliada o pubescente ................... 2

2. Anteras con un penacho apical de pelos de más de $0,4 \mathrm{~mm}$. Páleas bífidas

17. S.gigantea

2'. Anteras glabras, o con pelos apicales de hasta $0,2 \mathrm{~mm}$. Páleas enteras 3

3. Lemas con arista recta o monogeniculada. Perenne, estolonífera 4

3'. Lemas con arista bigeniculada. Anual o perenne, cespitosa 5 
4. Callo agudo. Lemas con pelos patentes.... 14. S.calamagrostis

4'. Callo obtuso. Lemas con pelos adpresos. 15. S.bromoides

5. Lemas con dorso escábrido u homogéneamente pubescente .................. 6

5'. Lemas con dorso recorrido por 7 líneas de pelos de distinta longitud . 8

6. Lemas con dorso escábrido y pelos patentes de hasta $6 \mathrm{~mm}$ en el ápice, prolongadas en una arista de hasta $3 \mathrm{~cm}$..... 13. S.papposa

6'. Lemas con dorso adpreso-pubescente, con pelos de menos de $3 \mathrm{~mm}$ y sin pelos apicales patentes, prolongadas en una arista de más de $3,5 \mathrm{~cm}$

7. Glumas desiguales. Lemas con callo de (0,7-)1-1,5(-2) mm, homogéneamente pubescente. Perenne....... 11. S.parviflora

7'. Glumas iguales o subiguales. Lemas con callo de (1-)1,5-3,5(-4) mm, con 2 líneas laterales glabras. Anual .... 12. S.capensis

8. Arista con columna glabra o escábrida, y pico plumoso. 9

8'. Arista escábrida o pubescente en toda su longitud 13

9. Limbo foliar con ápice prolongado en una seta. Glumas de 3,5-5,2 cm..... 18. S.tirsa

9'. Limbo foliar con ápice agudo u obtuso, mútico. Glumas de $(4,5) 4,7-10 \mathrm{~cm}$..... 10

10. Lodículas anteriores abundantemente ciliadas en el ápice 1. S.eriocaulis

$10^{\prime}$.Lodículas anteriores glabras o rara vez con algún pelo apical. 11

11. Lemas de 12-17(-18) mm y páleas de 10$15(-17) \mathrm{mm}$.

3. S.iberica

11'.Lemas de (15-)16-22(-24) mm y páleas de (14-)16-21 mm 12
12. Anteras de 6-8,5(-9,5) mm. Limbo de las hojas inferiores de 0,7-1,5 mm de diámetro, con cara abaxial generalmente lisa

2. S.apertifolia

12. Anteras de 8-14(-16) mm. Limbo de las hojas inferiores de 0,4-1 mm de diámetro, con cara abaxial densamente escábrida....

4. S.pauneroana

13. Arista de las lemas con al menos algunos pelos de 0,5-3 $\mathrm{mm}$ 5. S.barbata

13'.Arista de las lemas escábridas, o con pelos de menos de $0,5 \mathrm{~mm}$ 14

14. Arista con pelos setosos en los ángulos e inconspícuamente adpreso-pubescente en las zonas interangulares, al menos hacia la base

6. S.capillata

14 '.Arista sólo con pelos setosos en los ángulos 15

15. Lemas de 7-10,5(-11) $\mathrm{mm}$, con arista de (5) 8-16(-18) mm. Páleas de 6-10(-11) mm ...

$15^{\prime}$.Lemas de (10-)10,5-14(-15) mm, con arista de (16-)18-30(-35) mm. Páleas de 10-13(14) $\mathrm{mm}$ 17

16. Lígula de las hojas caulinares de 5-10(-12) $\mathrm{mm}$, glabra y aguda. Aristas de (5-)8-12(15) $\mathrm{cm}$ 10. S.offneri

16'.Lígula de las hojas caulinares de 0,5-2,5(3) $\mathrm{mm}$, generalmente truncada, escábrida o pubescente. Arista de (10-)12-16(-18) cm

7. S.lagascae

17. Hojas caulinares con limbo pubescente en la cara adaxial. Lemas de (11-)12-14(-15) $\mathrm{mm}$, con arista de (19-)23-30(-35) cm ......

9. S.clausa

17 '.Hojas caulinares con limbo escábrido en la cara adaxial. Lemas de 10-12(-12,5) mm, con arista de (16-) $18-25(-28) \mathrm{cm}$

8. S.juncea 


\section{A. Sect. Stipa}

Stipa sect. Eriostipa Dumort., Observ. Gram. Belg. 134 (1823) (Especie tipo: S.pennata L.; Dumortier, 1823)

Stipa ser. Pennatae Roshev. in Komarov, Fl. URSS 2: 92 (1934) (Especie tipo: S.pennata L.)

Stipa ser. Pulcherrimae Martinovsky, Webbia 20: 718 (1965) (Especie tipo: S.pulcherrima C.Koch; Martinovsky, 1965)

Stipa ser. Pulcherrimae subser. Eriocaules Martinovsky, Preslia 39: 272 (1967) (Especie tipo: S.eriocaulis Borbás; Martinovsky, 1967b)

Stipa ser. Tirsae Martinovsky, Preslia 48: 186 (1976) (Especie tipo: S.tirsa Steven; Martinovsky, 1976)

Plantas perennes, cespitosas. Glumas subiguales o desiguales. Lemas enteras, o si emarginadas con dientes de menos de $0,4 \mathrm{~mm}$, recorridas por siete líneas desiguales de pelos; callo agudo; arista bigeniculada, diferenciada en una columna glabra y un pico plumoso. Páleas enteras. Lodículas 3, las dos anteriores de mayor tamaño. Cleistógamas. $x=11$.

1. Stipa eriocaulis Borbás, Math. Term. Közl. 15: 311 (1877)

Stipa pennata subsp. eriocaulis (Borbás) Martinovsky \& Skalicky, Preslia 41: 331 (1969)

Stipa pennata auct. pl., non L. (1753)

Tallos de hasta $85 \mathrm{~cm}$, erectos, con nudos violáceos glabros. Hojas con vaina glabra 0 escábrida, ciliada en los márgenes; lígula de (1,5-)3-5,5(-7) mm, aguda y escábrida; limbo glabro en la cara abaxial y escábrido en la adaxial; el de las hojas inferiores de hasta 80 $\mathrm{cm} \times 0,8-1,5 \mathrm{~mm}$ y el de las superiores de hasta
$35 \mathrm{~cm}$ de longitud. Panícula de hasta $27 \mathrm{~cm}$, laxa, de contorno sublanceolado, con ramas y pedúnculos escábridos. Glumas desiguales, la superior de (45-)55-75(-80) mm, con 5-7 nervios, y la inferior de (60-)70-85(-90) mm, con 3-5 nervios. Lemas de (13-)14-15,5(-16,5) $\mathrm{mm}$, a veces con dientes apicales de hasta 0,4 $\mathrm{mm}$; callo de (3-)3,5-5,5(-6) mm; arista de (1820-26(-29) cm, con pelos de hasta 6,5 mm. Páleas de (12)14-16 mm, glabras. Lodículas anteriores de 1,7-3 $\mathrm{mm}$, ciliadas en el ápice, la posterior de hasta $2 \mathrm{~mm}$. Anteras de 5,5-7,5(8,5) mm. Estilos 2, plumosos. Cariópsides de 8,8-12,5 mm. Florece entre Mayo y Agosto.

Número cromosómico: $\quad 2 \mathrm{n}=44$ (Tarnavschi, 1970, Rumanía; Vázquez, inéd., en plantas de Huesca, UNEX 14591).

Ind.loc.: «... ad stationem viae ferreae Buccari et in rupestribus infra Kosztrema exadversus Portum regium Litoralis HungaricoCroatici».

Tipo: No estudiado.

Ecología: En pastos psicroxerófilos desarrollados sobre suelos ricos en bases, junto a caméfitos pulviniformes. Desde 1800 a 2500 m.s.m. Festucion scopariae.

Distribución general: Endémica de Europa, desde Alemania hasta los Pirineos (fig. 4).

2. Stipa apertifolia Martinosvky, Preslia 39: 274 (1967)

Tallos de hasta $85 \mathrm{~cm}$, erectos, con nudos violáceos glabros. Hojas con vaina glabra 0 escábrida, ciliada en los márgenes; lígula de (1,5-)3-5,5(-7) mm, aguda y escábrida; limbo convoluto, glabro o suavemente escábrido en la cara abaxial y escábrido o pubescente en la 
adaxial, el de las hojas inferiores de hasta 50 $\mathrm{cm} \times 0,7-1,5 \mathrm{~mm}$ y el de las superiores de hasta $18 \mathrm{~cm}$ de longitud. Panícula de hasta $24 \mathrm{~cm}$, laxa, de contorno sublanceolado, con ramas y pedúnculos escábridos. Glumas desiguales, glabras, escábridas en los nervios; la superior de (48-)57-72(-80) mm, con 5-7 nervios, y la inferior de (54-)65-85(-90) mm, con 3-5 nervios. Lemas de (15-)16-19(-20) $\mathrm{mm}$; callo de (3-)3,5-5,5(-6) mm; arista de (22-)25-29(32) $\mathrm{cm}$, con pelos de hasta $7 \mathrm{~mm}$. Páleas de (14-)15-18 mm, glabras u ocasionalmente pubescentes hacia la base. Lodículas anteriores de 1,4-3 $\mathrm{mm}$, la posterior de hasta $2 \mathrm{~mm}$. Anteras de 6-8,5(-9,5) mm. Estilos 2, plumosos. Cariópsides de 10-13,5 mm. Florece entre Mayo y Agosto.

Ind. loc.: «Montes in vicinitate urbis Cuenca in Hispania».

Holótipo: PRC 388, ejemplar izquierdo (v.s.).

\section{Et.1.-HERB ARIUM \\ UNIVERSITATIS} CAROLINAE PRAHA (impr.).

Et.2.- Typus!/S.apertifolia Martinovsky / Srov. Martinovsky, Preslia 39: 260-275 (1967). / Martinovsky (manuscr.) / Dr. Jan O. Martinovsky profesor / Praha XVI., U Nikolajky 17 (impr.).

Et.3.- BOTANISCHES INSTITUT DER DEUTSCHEN UNIVERSITÄT IN PRAG (impr.).

Et.4.- Stipa pennata L. / Hisp. Cuenca/ -6.1898. / M.Gandoger (manuscr.).

Ecologia: En comunidades cespitosas desarrolladas sobre suelos poco profundos crioturbados, de naturaleza calcárea o dolomítica. Desde 1800 a 2500 m.s.m. Minuartio-Poion ligulatae.

Observaciones: Taxón bastante constante en sus caracteres morfológicos y del que, no

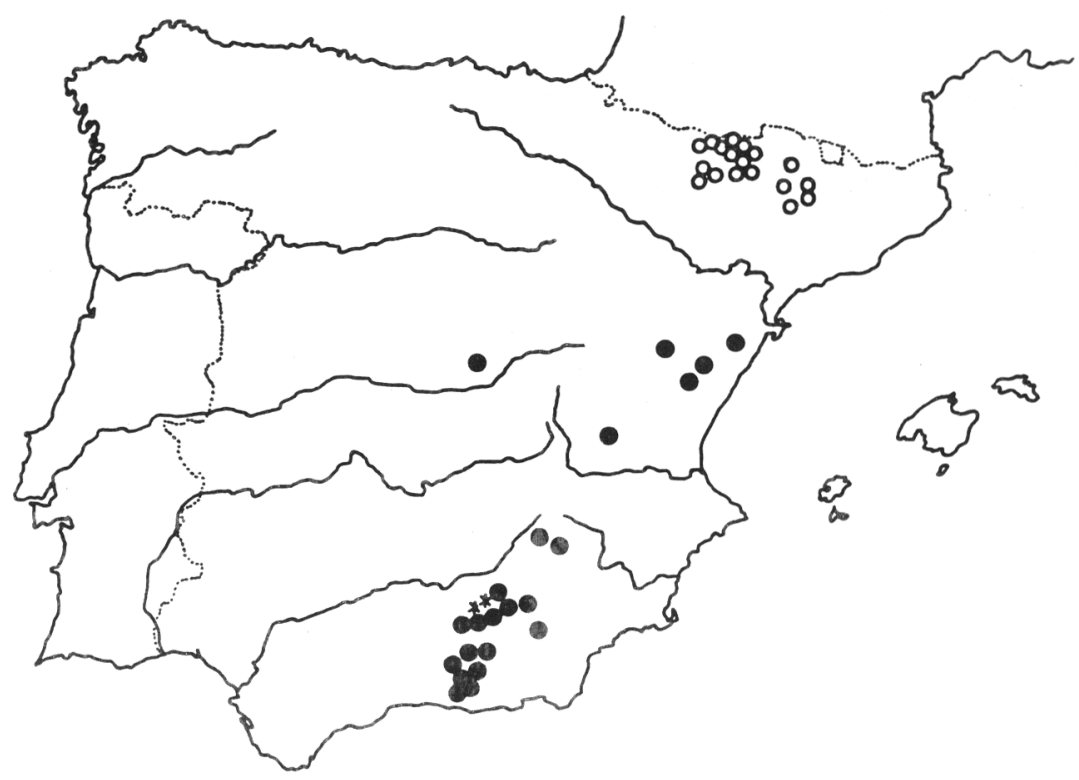

Figura 4. Distribución peninsular de : $\bigcirc$, Stipa eriocaulis; apertifolia var. nevadensis. Peninsular distribution.

- S. apertifolia varapertifolia; *, S. 
obstante, se han detectado poblaciones en las estribaciones de Sierra Nevada (Granada) cuyos individuos se segregan de los especímenes típicos por presentar el limbo foliar pubescente en su cara adaxial, mientras que lo normal en aquellos es que sea glabro o a lo sumo escábrido. Esta pauta de variación se considera en este estudio con categoría de variedad.

\section{Clave para las variedades}

1. Hojas con limbo glabro o escábrido en la cara adaxial a. var. apertifolia

1'. Hojas con limbo pubescente en la cara adaxial b. var. nevadensis

\section{a. var. apertifolia}

Stipa dasyvaginata Martinovsky, Anal. Inst. Bot. Cavanilles 27: 61 (1970) (Ind.loc.: «Mons Dornajo in Sierra Nevada, ubi a M.WINKLER collecta est». Holótipo: PRC 219007, ejemplar izquierdo. (v.s.) Et.1.- Polius st. grafiana Steven (Martinovsky) (manuscr.2)/ Riese durch das sudliche Spanien 1873/ HERBARIUM MUSEI NATIONALIS PRAGAE 219007 (impr.)/ Stipa pennata L. / Monte Dornajo, S ${ }^{a}$ Nevada 20 July (manuscr.l) / M.Winkler (impr.)/ b.australis (gallica) (manuscr.2). Et.2.Stipa dasyvaginata Martinovsky (Planta hac in Mte Dornajo/ M. Sierra Nevada/ a M.Winkler collectam, in Herbarium Musei Nationalis Pragae Depositum / sicut speciem novam in An. del Inst. Bot. Cavanilles t. 27: 6-63/ 1969-70./ descripsit et specimen hac sicut typum nomenclatorierum designavit (impr.)/ J.O.Martinovsky (manuscr.2); Martinovsky, 1970c).

Stipa pennata auct. pl., non L. (1753)

Stipa eriocaulis auct. pl., non Borbás (1877)
Tallos de hasta $85 \mathrm{~cm}$. Hojas con limbo glabro o ligeramente escábrido en ambas caras; el de las hojas inferiores de hasta $50 \mathrm{~cm}$ x 0,8 $1,5 \mathrm{~mm}$ y el de las superiores de hasta $18 \mathrm{~cm}$.

Distribución general: Norte de Africa, Italia y Península Ibérica (fig. 4).

\section{b. var. nevadensis F.M.Vázquez \& Devesa,} var. nov.

Tallos de hasta $45 \mathrm{~cm}$. Hojas con limbo glabro en la cara abaxial y pubescente en la adaxial; el de las hojas inferiores de hasta 15 $\mathrm{cm} \times$ 0,7-1,2 $\mathrm{mm}$ y el de las superiores de hasta $12 \mathrm{~cm}$.

Laminae foliae subtus glabris, supra pubescentis.

Holótipo: ESPAÑA: Granada, Sierra de Baza, sin fecha, J. Torres, G. Blanca \& C. Morales (GDAC 26143). Ejemplar único.

Distribución general: Endémica de la Sierra de Baza y Sierra Nevada (fig. 4).

3. Stipa iberica Martinovsky, Feddes Repert. 73: $150(1966)$

Stipa pennata subsp. iberica (Martinovsky) O.Bolòs, Masalles \& Vigo, Collect. Bot. (Barcelona) 17(1): 96 (1987)

Tallos de hasta $70 \mathrm{~cm}$. Hojas con vaina escábrida o pubescente; lígula de (3-)5-7(-9) $\mathrm{mm}$; limbo convoluto, escábrido o pubescente en ambas caras, el de las hojas inferiores de hasta $50 \mathrm{~cm} \times 0,2-0,7(-1) \mathrm{mm}$ y el de las superiores de hasta $20 \mathrm{~cm}$ de longitud. Panícula de hasta $22 \mathrm{~cm}$, de contorno lanceolado. Glumas subiguales, glabras; la superior de (44-)50$80(-87) \mathrm{mm}$, con 5-7 nervios, y la inferior de 
(45-)50-80(-85) mm, con 3-5 nervios. Lemas de (12-)14-17(-18) mm; callo de (3-)4-6,5(7,5) mm, pubescente; arista de (19-)21-30(32) $\mathrm{cm}$, con pelos de hasta $6,5 \mathrm{~mm}$. Páleas de (10-)12-15(-17) mm. Lodículas anteriores de 2-3 $\mathrm{mm}$, la posterior de hasta $2 \mathrm{~mm}$. Anteras de 9-13 mm. Estilos 2, plumosos. Cariópsides de (9-)10-13 mm. Florece de Abril a Junio

Número cromosómico: 2n=44 (Vázquez inéd., en plantas de Cuenca, UNEX 14438).

Ind.loc.: «Herdam in Hispania; legit R. Agelet».

Holótipo: FI 1877 ejemplar único (v.s.). Et.1.- Stipa iberica Martinovsky (manuscr.)/ Dr. Martinovsky 1964 (impr.).

Et.2.- SOCIETAS BOTANICA BARCINONENSIS (impr.)/ Stipa pennata L. (manuscr.)/ Habitat (impr.) incultis (manuscr.) / Regiones (impr.) Hispa. (manuscr.) / Lecta (impr.) / prés Herdam (manuscr.) / Die Mayo ann 18 (impr.)75 (manuscr.) / Locus (impr.) R.Agelet (manuscr.) / SOC BARCINON. (impr.).

Distribución general: Endémica del centro y este de la Península Ibérica y sur de Francia (fig. 5).

Observaciones: Los individuos que se ajustan al tipo (var. iberica) presentan hojas con limbo escábrido en la cara abaxial y pubescente en la adaxial, a diferencia de lo que sucede con los de muchas poblaciones del cuadrante suroriental de la Península Ibérica, cuyas hojas presentan la cara adaxial escábrida, segregándose en este trabajo con categoría de variedad: var. austro-iberica. Por otro lado, en el noreste del territorio estudiado se localizan poblaciones cuyos individuos presentan hojas con la cara abaxial pubescente, a diferencia de los de las variedades anteriores, considerándose aquí esta pauta de variación también con categoría de variedad: var. pseudodasyphylla .

\section{Clave para las variedades}

1. Limbo y vaina de las hojas con cara abaxial pubescente ........ b. var. pseudodasyphylla

1'. Limbo y vaina de las hojas con cara abaxial escábrida ..... 2

2. Limbo de las hojas con cara adaxial escábrida ................. c. var. austro-iberica

2'. Limbo de las hojas con cara adaxial pubescente a. var. iberica

\section{a. var. iberica}

Stipa pennata var. mediterranea Trin. \& Rupr., Spec. Gram. Stirp. 1: 82 (1842) (Ind.loc.: "Tergesti!; Gallia merid. (Czernajeff!); Hispania in aridis montium Granatensium altit. circa 5-6000 ped. (Boissier! ...)». Lectótipo: LE-TRINIT, ejemplar izquierdo (vidi microf.), designado en este trabajo. Et.1.- Herb. Trinit. (impr.). Et.2.- Herbarium Academiae Scientiae Petropol. (impr.). Et.3.- Stipa pennata ex Gallia merid. Com. Czernajef a 1825 (manuscr. 1) Hb. Acad flosculo (?) piloso (manuscr.2). Otro material (ejemplar derecho) contenido en el pliego y no identificado: Et.4.Stipa pennata (manuscr. 3) (?) (manuscr.4).

Stipa [Stupa] pennata subsp. mediterranea (Trin. \& Rupr.) Ascherson \& Graebner, Syn. Mitteleur. Fl. 2:106 (1899)

Stipa iberica var. pygmaea Martinovsky, Anal. Inst. Bot. Cavanilles 27: 74 (1970) (Ind.loc.: «In Montserrat, in pratis aridis in altitudine 300-350 m.s.m. a S. VAYREDA collecta in herbario MA sub 
numero 4963 conservatur.». Holótipo: MA 4963 ejemplar único (v.s.) Et.1.HERBARIUM STANISLAI VAYREDA / Hab. (impr.) Montserrat (manuscr.) / Stat. (impr.) in pratis aridis (manuscr.) / Alt. (impr.) 300-350 m. / Leg. (impr.) Jun. 1896 (manuscr.) OBSERV. (impr.). Et.2.- Stipa pygmaea sp.n. Et.3.- ?. Et.4.m. (impr.) Martinovsky (manuscr.)»).

Stipa iberica var. pygmaea fma. levis Martinovsky, Anal. Inst. Bot. Cavanilles 27: 74 (1970) (Ind.loc.: «Specimen examinatum in $\mathrm{Val}$ de Llo in rupibus calcareis (1980 m s.m.) a F. Sennen collectum in herbario LD depositum est.». Tipo: no estudiado)

Hojas con vaina escábrida y limbo escábrido en la cara abaxial y pubescente en la adaxial.
Ecología: En claros de matorrales seriales de bosques mediterráneos, sobre suelos calcáreos o margosos. Desde 400 a 1200 m.s.m. Aphyllantion.

Distribución general: Endémica del centro y este de la Península Ibérica y sur de Francia (fig. 5).

b. var. pseudodasy phylla (Martinovsky) F.M. Vázquez \& Devesa, comb. in stat. nov.

Stipa iberica subsp. pauneroana fma. pseudodasyphylla Martinosvky, Anal. Inst. Bot. Cavanilles 27: 75 (1970)

Hojas con vaina pubescente y limbo pubescente en ambas caras.

Ind.loc.: «Specimen formae in statione calcarea, lapidosa in altitudine $900 \mathrm{~m} \mathrm{s.m.} \mathrm{ad}$

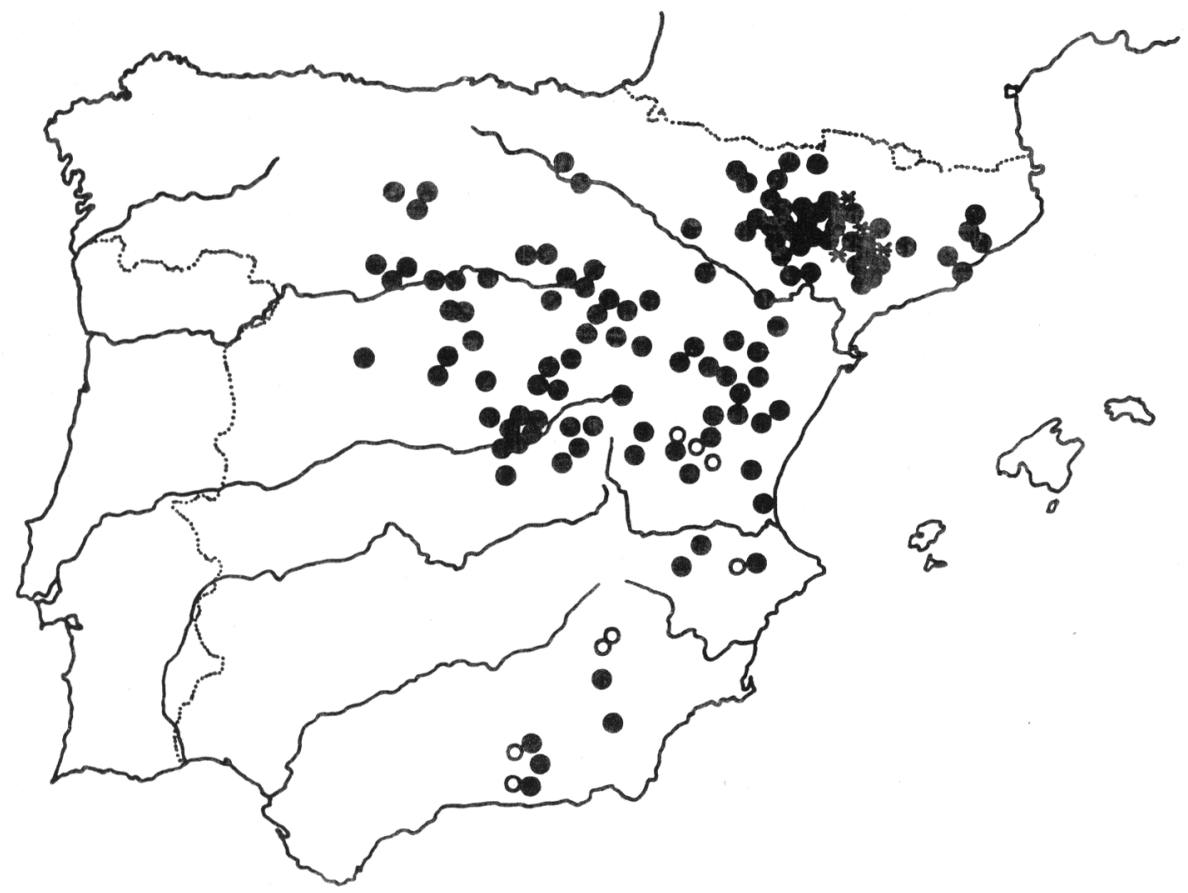

Figura 5. Distribución peninsular de: - Stipa iberica var. iberica; O, S. iberica var. austro - iberica; * , S.iberica var. pseudodasyphylla. Peninsular distribution. 
Renera (La Alcarria) a J.R. DEL CASTILLO collecta est.».

Tipo: No estudiado.

Ecología: En matorrales abiertos sobre sustratos calizos o margosos. Desde 800 a 1400 m.s.m. Aphyllantion.

Distribución general: Endémica del centro y noroeste de la Península Ibérica (fig. 5).

c. var. austro-iberica (H.Scholz)F.M.Vázquez \& Devesa, comb. in stat. nov.

Stipa iberica subsp. austro-iberica H.Scholz, Willdenowia 19: 129 (1989)

Hojas con vaina escábrida y limbo escábrido en ambas caras.
Ind.loc.: «Spanien: Jaen, Sierra Secca, El Chaparral, 1800 m, 29.6.1988, Ursula Matthäs al 2657 (B, G, PAL, SEV); Granada, Huesca, Sierra de Moncayo, 22.6.1988, Ursula Matthäs 1644 (B, G, PAL, SEV); Jaen, Sierra de Mágina bei Huelma, $1500 \mathrm{~m}$, steinige triften, mit PinusAufforstungen, auf Osthang, 8.7.1979, H.Ern $3713(\mathrm{~B}) »$.

Holótipo: B (Scholz, 1989; v.s.).

Et.1.-MUSEUMBOTANICUMBEROLINENSE / Gramineae Stipa (impr.) iberica Martinovsky / (Basalblätter mit kahlen Rippenscheitely !) (manuscr.) / leg.: H.Ern, 8.VII.1979/Nr. 3713 / Spanien, Prov. Jaen, Sierra de Mágina bei Huelma / $1500 \mathrm{~m} /$ ü. M. / steinige Triften, mit Pinus-Aufforstungen, / auf Osthang (impr.) det.: H.Scholz (manuscr.). Et.2.- Stipa iberica Martinovsky / subsp. austro-iberica H.Scholz / Typus / det. confirm. (impr.) (Scholz, 1989).

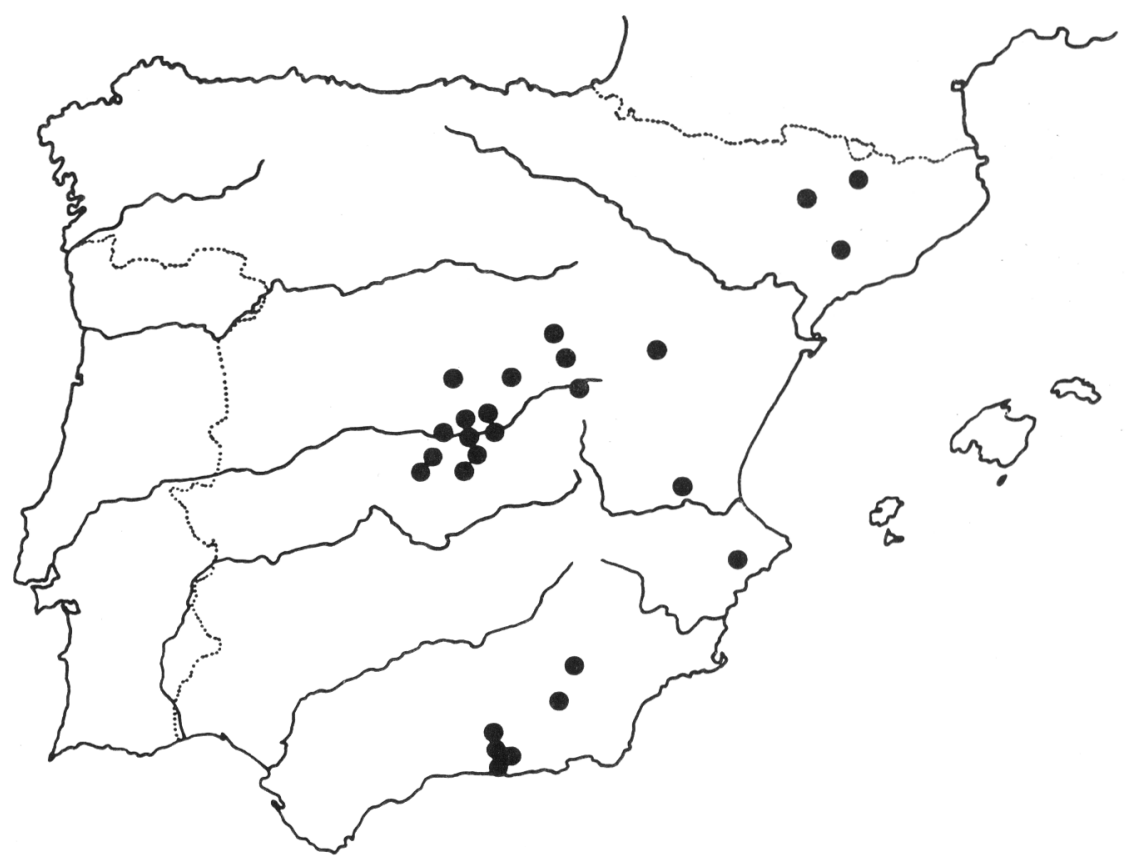

Figura 6. Distribución peninsular de Stipa pauneroana. Peninsular distribution. 
Ecología: En tomillares y ahulagares sobre suelos margo-arcillosos. Desde 1000 a 1800 m.s.m. Lavandulo-Echinospartion boissieri.

Distribución general: Endémica del cuadrante suroriental de la Península Ibérica (fig. 5).

4. Stipa pauneroana (Martinovsky) F.M. Vázquez \& Devesa, comb. et stat. nov.

Stipa iberica subsp. pauneroana Martinovsky, Anal. Inst. Bot. Cavanilles 27: 74 (1970)

Tallos de hasta $100 \mathrm{~cm}$. Hojas con vaina escábrida; lígula de (4)6-10(-12) mm; limbo convoluto, escábrido en ambas caras, el de las hojas inferiores de hasta $70 \mathrm{~cm} \times 0,4-1 \mathrm{~mm}$. y el de las superiores de hasta $20 \mathrm{~cm}$ de longitud. Panícula de hasta $26 \mathrm{~cm}$, de contorno lanceolado. Glumas subiguales, la superior de (50-)60-90(-95) mm, con 5-7 nervios, y la inferior de (50-)60-100(-110) mm, con 3-5 nervios. Lemas de (16-)17-22(-24) mm; callo de (3-)4-6,5(-7,5) mm, pubescente; arista de (24-)28-40(-45) cm, con pelos de hasta 8,5 mm. Páleas de (15-)16-19(-21) mm. Lodículas anteriores de 2-4 $\mathrm{mm}$, la posterior de hasta 2 mm. Anteras de 8-14(-16) mm. Estilos 2, plumosos. Cariópsides de (10-)12-16 mm. Florece de Abril a Junio.

Número cromosómico: 2n=44 (Vázquez inéd., en plantas de Toledo, UNEX 14466).

Ind.loc.: «Locus classicus Aranzueque (La Alcarria), quo typus, in herbario MA conservatus, a F.BUENDíA collectus est».

Holótipo: MA 184491 (v.s.).

Et.1.- Stipa pennata L. / Aranzueque (La Alcarria)/28.V.1965 F.Buendía (manuscr.). Et.2.- HERBARIUM HORTI BOTANICI
MATRITENSIS / Stipa pennata L./ Aranzueque (La Alcarria) / 28-V-1965 / F.Buendía (impr.). Et.3.- Stipa iberica Martinovsky subsp. pauneroana Martinovsky.

Et.4.- specimen sicut typus / proc subspecie hac electum (impr.).

Et.5.- J.Martinovsky (manuscr.) / Dr. J.O. Martinovsky (impr.) / Pragae 12.XII.1966. (manuscr.).

Ecología: En romerales y tomillares basófilos. Desde 600 a 1600 m.s.m. Aphyllantion.

Distribución general: Centro, este y sureste de la Península Ibérica (fig. 6).

B. Sect. Barbatae Junge, Bull. Jard. Bot. Pétersb. 10: 130 (1910)

Perennes, cespitosas. Lígula membranosa. Glumas subiguales. Lemas enteras, recorridas por siete líneas desiguales de pelos, con arista bigeniculada y provista de pelos de más de 1 mm en toda su longitud. Callo agudo. Páleas enteras. Lodículas 3, las dos anteriores de mayor tamaño. Parcialmente cleistógamas. $\mathrm{x}=11$.

Especie tipo: S. barbata Desf. (Tzvelev, 1974).

5. Stipa barbata Desf., Fl. Atl. 1: 97, Tab. 27 (1798)

Stipa barbata var. hispanica Trin. \& Rupr., Spec. Gram. Stirp. 1: 77 (1842) (Ind.loc.: «Castella nova (Boissier)». Tipo. No estudiado)

Stipa plumosa Pourret ex Willk., Prodr. Fl. Hisp. 1: 60 (1861), pro syn.

Stipa barbata var. longiaristata Martinovsky, Preslia 42(4): 373 (1979) (Ind.loc.: «ab E.Hadac in Shaqlava 
11.4.1960». Holótipo: PR. (v.s.) Et.1.Herbarium Musei Nationalis Pragae/ Flora of Iraq/ Herbarium Hadac 594658 (impr.)/ typus (manuscr.)/ Stipa barbata Desf. var. longiaristata Martinovsky / Loc. Shaqlava / Date: 11.4.60 / coll. E.Hadac / Number: 1390. Det. J.Martinovsky / Notes: Hab. APC. $n^{\circ} 44 /$ 1963 (impr.)

Tallos de hasta $80 \mathrm{~cm}$, erectos 0 ligeramente curvados en la fructificación, con nudos violáceos y escábridos. Hojas con vaina glabra o escábrida; lígula de (1-)3-6,5(-7) mm, aguda y escábrida; limbo convoluto, glabro en la cara abaxial y pubescente en la adaxial, el de las hojas inferiores de hasta $37 \mathrm{~cm} \times 0,3-0,9$ $\mathrm{mm}$ y el de las superiores de hasta $35 \mathrm{~cm}$ de longitud. Panícula de hasta $35 \mathrm{~cm}$, laxa, de contorno lanceolado, con ramas y pedúnculos escábridos. Glumas glabras, con 3-5 nervios escábridos; la superior de (22-)28-40(-45) mm y la inferior de (23-)27-39(-47) mm. Lemas de (8-)9-12(-13) mm; callo de 1,8-5 mm; arista de (10-)12-16(-20) cm, con pelos de 0,5-3 mm. Páleas de (8-)9-12 mm, glabras. Lodículas anteriores de 1-2,5(-3) mm, la posterior de hasta 1,5 mm. Anteras de (2-)2,5-7(-8) mm. Estilos 2, plumosos. Cariópsides de 5-8,5(-9) $\mathrm{mm}$. Florece de Abril a Junio.

Número cromosómico: 2n=44 (Vázquez inéd., en plantas de Ciudad Real, Granada, Murcia y Toledo: UNEX 14505, 14510, 14514 \& 14519, respectivamente). Recuentos previos: Moraldo (1986, Italia).

Ind. loc.: «HABITAT in collibus incultis circa Mascar et Tlemsen.».

Lectótipo: P-DESF ejemplar único (vidi microf.); designado en este trabajo.

Et.1.- Stipa barbata (impr.).

Et.2.- Herbier de la Flore Atlantique/donné au Museúm par M. Desfontaines / $\mathrm{N}^{0}$ (impr.) n.3

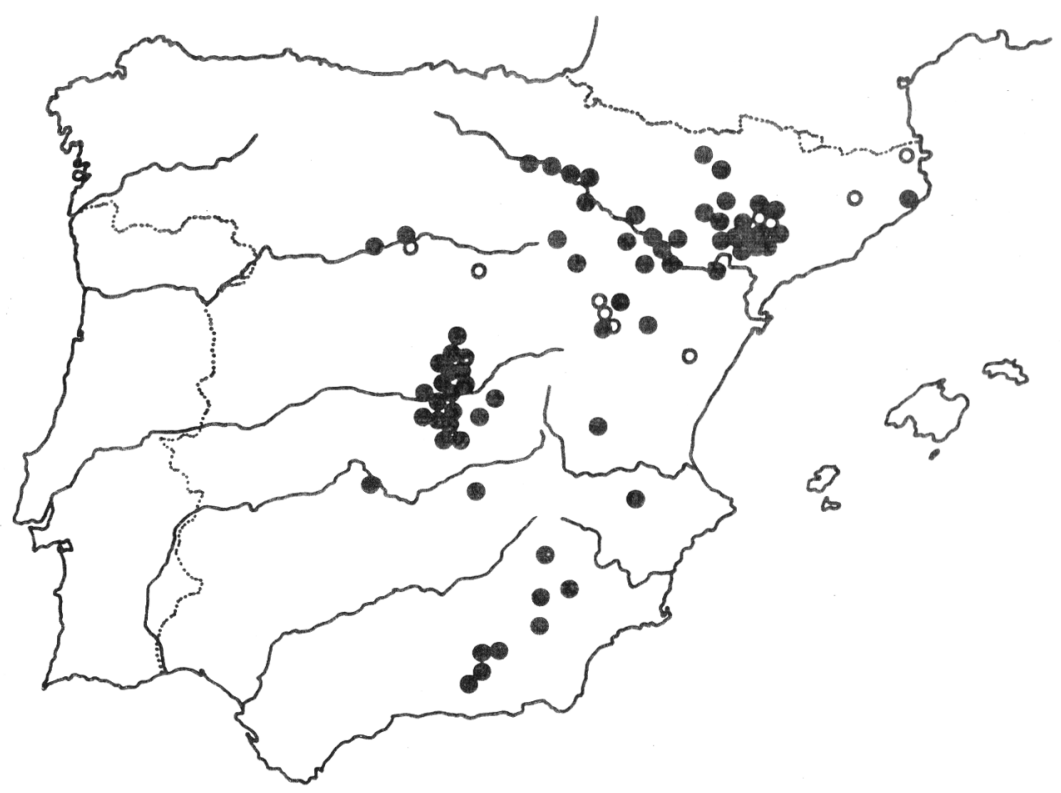

Figura 7. Distribución peninsular de: - Stipa barbata; $\bigcirc$, S.capillata. Peninsular distribution. 
/ Stipa barbata (manuscr.).

Ecología: En lastonares y tomillares sobre suelos calcáreos y pedregosos. Desde 200 a 1100 m.s.m. Phlomidio-Brachypodion retusi.

Distribución general: Turquía, Italia, N de Africa y mitad oriental de la Península Ibérica (fig. 7).

Observaciones: En la Península Ibérica sólo vive la variedad típica (var. barbata), si bien para esta especie se ha reconocido, además, una variante en base a las características de la arista de la lema: var. brevipila Cosson \& Durieu, Expl. Sc. Alg. 2: 76, (1867, (Ind. loc. "In apricis ad lacum salsum Chott-el-Chergui!". Lectótipo: P-COSSON, ejemplar central (v.s.), designado en este trabajo. Et. 1.- Herb. Mus. Paris (impr.) / (Eustipa Trin.) / Stipa barbata Desf. (var.) / algerie (manuscr.). Et. 2.- Stipa barbata, Desf. / var. brevipila, Coss. et Dur. / muss. Terrains arides au bord du Chott-elChergui à Sidi-Khalifa (Algerie)/ E. Cosson / 29 Mai 1812 (manuscr.)). La var. barbata se caracteriza por presentar aristas de (10-)12$16(-20) \mathrm{cm}$, con pelos de más de $2 \mathrm{~mm}$, mientras que en la var. brevipila miden (6)7-12(-13) cm y presentan pelos de hasta $1,5 \mathrm{~mm}$.

C. Sect. Leiostipa Dumort., Obs. Gram. Belg. 134 (1823)

Stipa ser. Pseudocapillatae Roshev. in Komarov, Fl. URSS 2: 103 (1934) (Especie tipo: S.pseudocapillata Roshev.)

Stipa ser. Capillatae Roshev. in Komarov, Fl. URSS 2: 106 (1934) (Especie tipo: S.capillata L.)

Stipa sect. Leiostipa ser. Capillatae (Roshev.) Moraldo, Webbia 40(2): 212 (1986)

Stipa sect. Stipa «gr.» Leiostipa
(Dumort.) Freitag, Notes Roy. Bot. Gard. Edinburgh 42(3): 456 (1985), p.p. (Especie tipo: S.capillata L.)

Perennes, cespitosas. Lígula membranosa. Glumas subiguales. Lemas enteras, recorridas por siete líneas desiguales de pelos, con arista bigeniculada, escábrida o con pelos de menos de $0,5 \mathrm{~mm}$ en toda su longitud. Callo agudo. Páleas enteras. Lodículas 3, las dos anteriores de mayor tamaño. Cleistógamas, parcialmente cleistógamas o casmógamas. $\mathrm{x}=11$.

Especie tipo: S. capillataL. (Dumortier, 1823).

6. Stipa capillata L., Sp. Pl. ed. 2, 116 (1762)

Stipa lagascae auct. pl., non Roemer \& Schultes (1817)

Tallos de hasta $110 \mathrm{~cm}$, erectos, con nudos violáceos y escábridos. Hojas con vaina glabra u ocasionalmente escábrida; lígula de (4-)5-10 mm, aguda y escábrida; limbo convoluto, glabro en la cara abaxial y pubescente en la adaxial, el de las hojas inferiores de hasta $45 \mathrm{~cm} \times 0,5-0,9$ $\mathrm{mm}$ y el de las superiores de hasta $22 \mathrm{~cm}$ de longitud. Panícula de hasta $22 \mathrm{~cm}$, laxa, de contorno lanceolado, con ramas y pedúnculos escábridos. Glumas glabras, con 3-5 nervios escábridos; la superior de (25-)28-35(-45) mm y la inferior de (25-)30-35(-40) mm. Lemas de 8-11 mm; callo de 2,5-4 mm; arista de (12-)15$21 \mathrm{~cm}$, escábrida en los ángulos. Páleas de 7,59,5, glabras. Lodículas anteriores de 0,7-2 mm, la posterior de hasta 1,2 mm. Anteras de 3,55,5 mm. Estilos 2, plumosos. Cariópsides de 6 $8 \mathrm{~mm}$. Florece y fructifica de Julio a Septiembre.

Número cromosómico: $2 \mathrm{n}=44$ (Vázquez inéd., en plantas de Barcelona: UNEX 14601). Recuentos previos: Avdulov (1928 \& 1931, Rusia), Stebbins \& Love (1941), Tarnavschi 
(1948, Rumanía), Lorenzo-Andreu (1951 \& 1953, España), y Skalinska et al. (1968, Polonia).

Ind. loc.: «Habitat in Germania, Gallia.»

Lectótipo: UPS-BURSER, I.127(1) (Freitag, 1985; vidi microf.).

Et.1.- Nadeltwalch.

Ecologia: En albardinales subesteparios sobre suelos carbonatados arenosos. Desde 200 a 800 m.s.m. Eremopyro-Lygeion.

Distribución general: Eurasia, desde Siberia hasta el noreste de la Península Ibérica (fig. 7).

7. Stipa lagascae Roemer \& Schultes in L., Syst. Veg. ed. 15, 2: 333 (1817)
Stipa pubescens Lag., Gen. Sp. Nov. 3, (1816), non R.Br. (1810)

Stipa juncea var. lagascae (Roemer \& Schultes) Mutel, Fl. Fr. 4: 27 (1837)

Stipa gigantea fma. pubescens Hackel, Österr. Bot. Zeitschr. 27: 119 (1877)

Stipa lagascae subsp. normalis var. pubescens (Hackel) Maire, Bull. Soc. Hist. Nat. Afr. Nord 24: 266 (1936)

Tallos de hasta $140 \mathrm{~cm}$, erectos o ligeramente curvados en la fructificación, con nudos violáceos, glabros ó escábridos. Hojas con vaina glabra, escábrida o pubescente; lígula de 0,5-2,5(-3) $\mathrm{mm}$, aguda, escábrida 0 pubescente; limbo convoluto, glabro, escábrido o pubescente en la cara abaxial y escábrido o pubescente en la adaxial, el de las hojas inferiores de hasta $60 \mathrm{~cm} \times 0,3-1 \mathrm{~mm}$ y el de las superiores de hasta $20 \mathrm{~cm}$ de longitud. Panícula de hasta $65 \mathrm{~cm}$, laxa, de contorno lanceolado, con ramas y pedúnculos escábridos. Glumas glabras, con 5 nervios escábridos; la superior

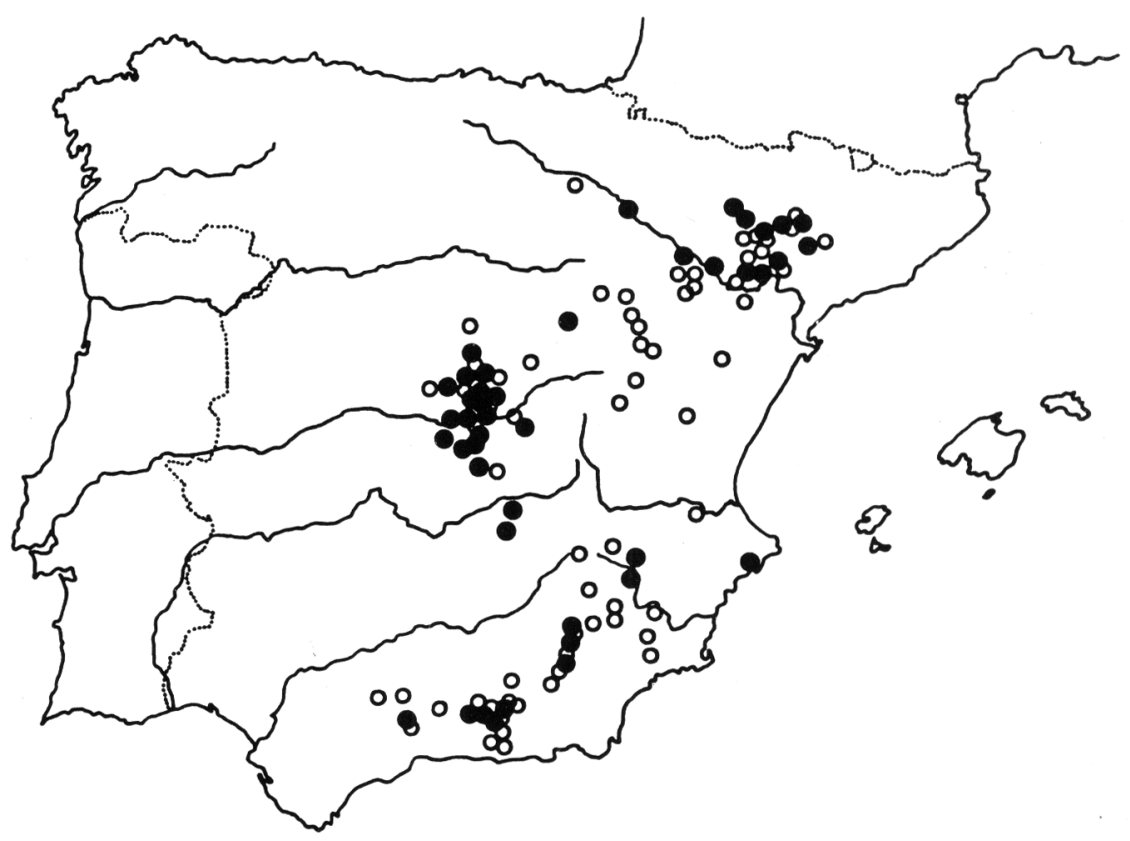

Figura 8. Distribución peninsular de Stipa lagascae: var. lagascae; 0 , var. australis. Peninsular distribution. 
de (22-)27-35(-40) mm y la inferior de (25)30-45(-50) $\mathrm{mm}$. Lemas de (7-)8-10(-10,5) $\mathrm{mm}$; callo de (1,2-)1,5-2,5(-3) mm; arista de (10-)12-16(-18) cm, pubescente en los ángulos. Páleas de (6-)7-9(-10) mm, con dorso pubescente. Lodículas anteriores de 0,9-2,5 $\mathrm{mm}$, la posterior de hasta $1,5 \mathrm{~mm}$. Anteras de (4,5-)5-8(-9) mm, a veces con pelos apicales de hasta 0,1 mm. Estilos 3, plumosos, uno más pequeño que los restantes. Cariópsides de 6 8(-9) mm. Florece de Abril a Junio.

Ind. loc:: "Venit in collibus siccis, prope Matritum en el cerro Negro, et in Murciae Regno en las Anorias, Pretola, Chinchilla et Albacete oppidis: ...».

Lectótipo: MA 185146 ejemplar único (v.s.). Designado en este trabajo.

Et.1.- Stipa pubescens Lag. / Cerro Negro (manuscr.).

Et.2.- Stipa capillata L. / Cerro Negro (Madrid) / det B. Valdés / Herbario Lagasca (impr.).

Et.3.- Stipa capillata L. (impr.).

Isolectótipo 1: MA 147289(2) ejemplar único (v.s.).

Et.1.- Stipa pubescens Lag. / Mayo-Junio / leg: Lagasca (manuscr.).

Ecologia: En lastonares subesteparios sobre suelos margosos. Desde 200 a 800 m.s.m. Stipion-Tenacissimae.

Distribución general: Región Mediterránea y SW de Asia en ambas variedades (fig. 8).

Observaciones: En esta especie se han reconocido dos variantes atendiendo a las características de la pubescencia de las hojas: var. lagascae, con superficie abaxial y vaina pubescentes, y var. australis, que las presenta glabras o escábridas. Las dos variedades presentan el mismo ámbito de distribución.

\section{Clave para las variedades}

1. Vaina y limbo de las hojas con cara abaxial pubescente

a. var.lagascae

1'. Vaina y limbo de las hojas con cara abaxial glabra o escábrida b. var. australis

a. var. lagascae

Stipa lagascae var. eriophylla Willk., Prod. Fl. Hisp. 1: 306 (1861) (Ind. loc.: «In valle fluvii Darro pr. Granada in nemorosis Staud!.». Tipo: no estudiado) Stipa lagascae subsp. normalis var. pubescens fma. breviaristata Maire, Bull. Soc. Hist. Nat. Afr. Nord 24: 266 (1936) (Ind. loc.: «Algérie: Le Kroub près Constantine (TRABUT sub S. longipes Trab. ined.)». Tipo: no estudiado)

Stipa lagascae var. pubescens fma. latifolia Maire \& Weiller, Bull. Soc. Hist. Nat. Afr. Nord 30: 307 (1939) (Ind. loc.: «Tripolitaine: Ksar Karabouli, terrains sablonneux (n. 1493)». Tipo: no estudiado)

Número cromosómico: 2n=44 (Vázquez inéd., en plantas de Granada: UNEX 14285). Recuentos previos: Gould (1970, Túnez), Freitag (1985, SW de Asia) y Moraldo (1986, Italia).

b. var. australis Maire, Bull. Soc. Hist. Nat. Afr. Nord 24: 266 (1936)

Stipa lagascae subsp. normalis var. embergeri Maire, Bull. Soc. Hist. Nat. Afr. Nord 24: 266 (1936) (Ind. loc.: «Moyen Atlas: chaine du Bou-Iblan (Emberger et Maire, 1927)». Tipo: no estudiado)

Stipa lagascae subsp. normalis var. oropediorum Maire, Bull. Soc. Hist. Nat. 
Afr. Nord 24: 266 (1936) (Ind. loc.: «Algérie occidentale: El Aricha.» Tipo: no estudiado)

Stipa lagascae subsp. normalis var. trabutii Maire, Bull. Soc. Hist. Nat. Afr. Nord 24: 266 (1936) (Ind. loc.: "Algérie: Mont Meghris.» Tipo: no estudiado)

Hojas con vaina y limbo glabro o escábrido en la cara abaxial.

Número cromosómico: $2 \mathrm{n}=44$ (Vázquez inéd., en plantas de Murcia y Teruel: UNEX $14309 \& 14322$, respectivamente).

Ind. loc.: "Algerie: Montagnes du SudOranais: Monts Mzi, Aïssa, etc. Aurès...».

Tipo: No estudiado.

\section{Stipa juncea L., Sp. Pl. 1: 78 (1753)}

Tallos de hasta $140 \mathrm{~cm}$, erectos 0 ligeramente curvados en la fructificación, con nudos violáceos, glabros o escábridos. Hojas con vaina glabra, escábrida o pubescente; lígula de 1,5-4,5 mm, aguda y escábrida; limbo convoluto, glabro, escábrido o pubescente en la cara abaxial y escábrido o pubescente en la adaxial, el de las hojas inferiores de hasta 60 $\mathrm{cm} \times 0,3-1 \mathrm{~mm}$ y el de las superiores de hasta $20 \mathrm{~cm}$ de longitud. Panícula de hasta $65 \mathrm{~cm}$, laxa, de contorno lanceolado, con ramas y pedúnculos escábridos. Glumas glabras, con 5 nervios escábridos; la superior de (30-)35-45(50) $\mathrm{mm}$, la inferior de (35-)40-50(-55) $\mathrm{mm}$. Lemas de (10-)10,5-12(-12,5) mm; callo de 2$3,5 \mathrm{~mm}$; arista de (16-)18-25(-28) cm, pubescente en los ángulos. Páleas de 10-12(13) $\mathrm{mm}$, ligeramente pubescentes en el dorso. Lodículas anteriores de 0,9-2,5 $\mathrm{mm}$, la posterior de hasta 1,5 mm. Anteras de (4,5-)5-8(-9) mm, a veces con pelos apicales de hasta $0,1 \mathrm{~mm}$. Estilos 3 , plumosos, uno más pequeño que los restantes. Cariópsides de 7-9 mm. Florece de Abril a Junio.

Ind. loc.: « Habitat in Helvetia, Gallia».

Lectótipo: LINN 94.2 (Vázquez et al., 1995).

Observaciones: Se reconocen dos variantes de acuerdo con las características foliares: var. juncea, con superficie abaxial glabra, y var. cabanasii que la presenta escábrida o pubescente.

\section{Clave para las variedades}

1. Vaina y limbo de las hojas estériles con cara abaxial glabra a. var. juncea

1'. Vaina y limbo de las hojas estériles con cara abaxial escábrida o pubescente

b. var. cabanasii

a. var. juncea

Stipa celakovskyi Martinovsky, Preslia 48: 187 (1976) (Ind. loc.: «Specimen sub nomine S.lagascae R. et S. a $M$. GANDOGER in Serrenia de Cuenca collectum in herbario Univ. Pragensis (PRC) in collectione typorum sub No. 324 conservatur». Holótipo: PRC 324. (v.s.) Et.1.- HERBARIUM UNIVERSITATIS CAROLINAE PRAHA (impr.). Et.2.- Stipa celacovskyi Martinovsky / Conf. B.Moraldo (impr.) B.Moraldo (manuscr.) / 20.I.1986 (impr.). Et.3.- HOLOTYPUS (impr.). Et.4.- Typus! / Stipa celakovskyi mihi 1975 / Dr. J.O.Martinovsky (impr.). Et.5.324. S. celakovskyi Martinovsky (manuscr.). Et.6.- Stipa lagascae R.S. I Hisp. Serrania de Cuenca / - 7.1898/ M.Gandoger (manuscr.). Et.7.- Stipa 
celakovskyi MARTINOVSKY / Preslia 48: 187-188, 1976 (impr.)

Stipa lagascae auct.hisp., non Roemer \& Schultes (1817)

Hojas estériles con vaina y limbo glabros en la cara abaxial, con lígula aguda y escábrida.

Número cromosómico: $2 \mathrm{n}=44$ (Vázquez inéd., en plantas de Cuenca y Segovia: UNEX $14377 \& 14382$, respectivamente).

Ecología: En pastizales hemicriptofíticos, claros de matorrales basófilos. Desde 400 a 1100 m.s.m. Phlomidio-Brachypodion retusi.

Distribución general: Endémica del centro de la Península Ibérica y sureste de Francia (fig. 9).

b. var. cabanasii F.M.Vázquez \& Devesa, var. nov. (Dedicada al Prof. D. Rafael Cabanás
Parejo, geólogo (1913-1989).

Hojas estériles con vaina y limbo escábrido o pubescente en la cara abaxial, con lígula aguda, escábrida o pubescente.

Foliis inferiore cum laminae et vaginae scaberulae aut pubescentis.

Número cromosómico: $2 \mathrm{n}=44$ (Devesa et al., 1991, plantas de Badajoz, sub S.lagascae).

Holótipo: ESPAÑA: Badajoz, Los Santos de Maimona, / cerro San Jorge. / 17.IV.1987 / F.M. Vázquez (UNEX 3519). Ejemplar derecho.

Ecologia: En matorrales seriales sobre sustratos arcillosos. Desde 500 a 700 m.s.m. Micromerio-Coridothymion.

Distribución general: Endémica del suroeste de la Península Ibérica (fig. 9).

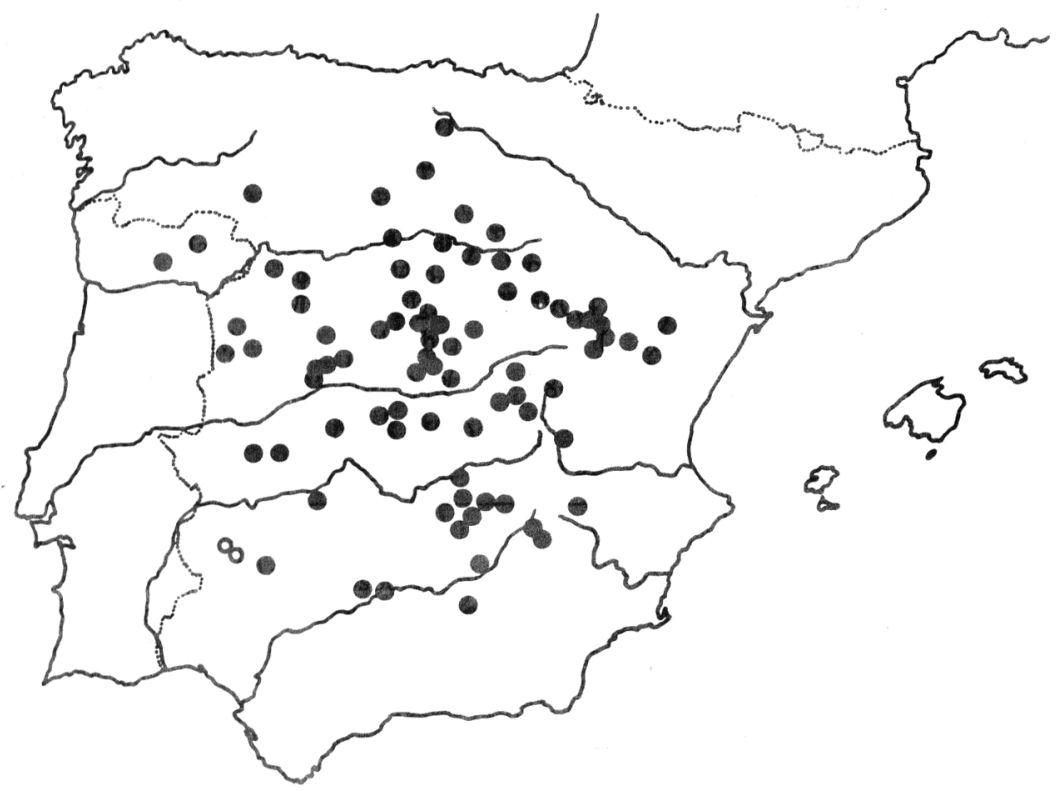

Figura 9. Distribución peninsular de Stipa juncea: distribution. 
9. Stipa clausa Trabut in Batt. \& Trabut, Fl. Algér. 366 (1902)

Tallos de hasta $160 \mathrm{~cm}$, erectos 0 ligeramente curvados en la fructificación, con nudos violáceos y pubescentes. Hojas con vaina glabra o escábrida; lígula de (0,5-) 1-2,5(-3,5) $\mathrm{mm}$, aguda u obtusa y escábrida; limbo convoluto, glabro o escábrido en la cara abaxial, y pubescente en la adaxial al menos en las hojas fértiles, el de las hojas inferiores de hasta $57 \mathrm{~cm} \times 0,6-1,2(-1,4) \mathrm{mm}$ y el de las superiores de hasta $35 \mathrm{~cm}$ de longitud. Panícula de hasta $70 \mathrm{~cm}$, laxa, de contorno lanceolado, con ramas y pedúnculos escábridos. Glumas glabras, con 3-5 nervios escábridos; la superior de (40-)45-65(-70) $\mathrm{mm}$ y la inferior de (37)40-65(-70) mm. Lemas de(11-)12-14(-15) mm; callo de (3-)3,5-4,5(-5) mm; arista de (19-)23$30(-35) \mathrm{cm}$, escábrida en los ángulos. Páleas de (11-)12-13(-14) mm, pubescentes en el dorso. Lodículas anteriores de (1,2-)1,5-2,5 $\mathrm{mm}$, la posterior de hasta $1,7 \mathrm{~mm}$. Anteras de 5,5-9 mm, con pelos apicales de hasta $0,2 \mathrm{~mm}$. Estilos 4, plumosos, dos más pequeños que el resto. Cariópsides de (8-)9-10(-12) mm. Florece de Mayo a Julio.

Ind. loc.: «Venit in incultis circa Matritum, et praesertium in Praedio Regio la Real Casa del campo dicto».

Lectótipo: MA 156116 (Vázquez \& Devesa, 1996).

Observaciones: Las poblaciones de Stipa clausa del cuadrante sudoriental de la Península Ibérica difieren del tipo en que sus individuos presentan lemas y aristas de menores dimensiones, reconociéndoseles en este trabajo categoría subespecífica.

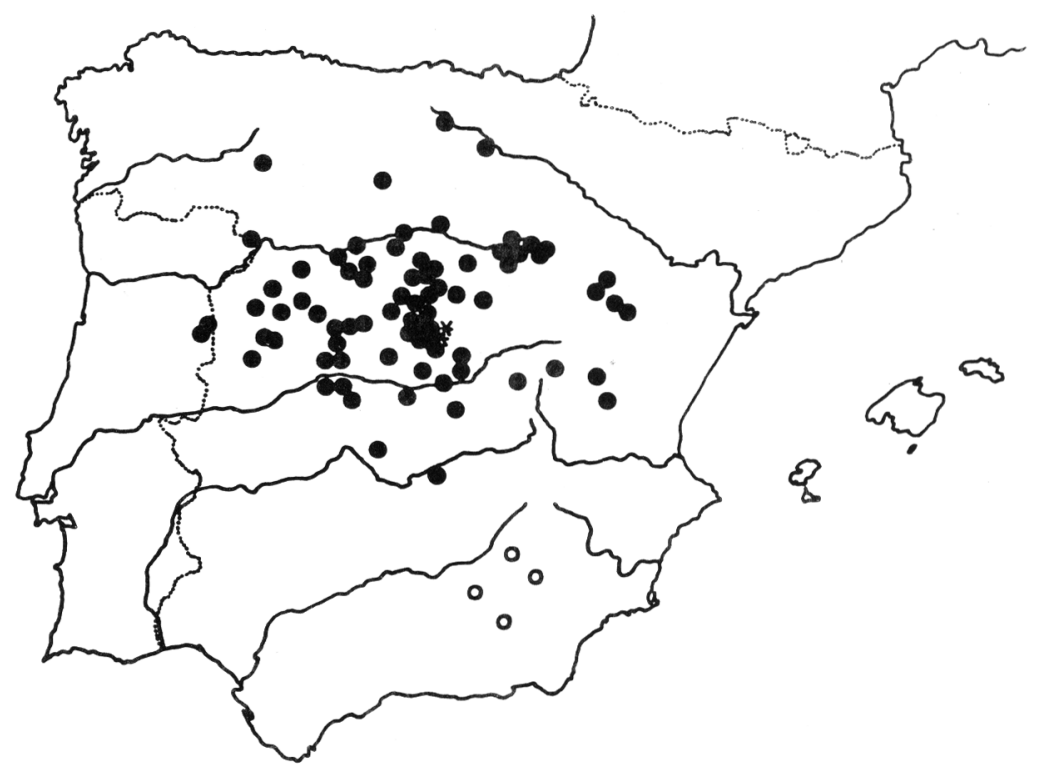

Figura 10. Distribución peninsular de Stipa clausa: subsp. clausa var. clausa; $*$, subsp. clausa var. matritensis; $\bigcirc$, subsp. cazorlensis. Peninsular distribution. 


\section{Clave para las subespecies}

1. Lemas de $12-15 \mathrm{~mm}$, con arista de (21-)23$30(-35) \mathrm{cm}$.................. 9.1. subsp. clausa

1 '. Lemas de 11-12,5 mm, con arista de 19-22 $\mathrm{cm}$ 9.2. subsp. cazorlensis

\section{1. subsp. clausa}

Stipa gigantea sensu Lag., Gen. Sp. Nov. 3 (1816), non Link (1799)

Stipa lagascae var. hackelii Fiori, Nouv. Fl. Ital. 1: 85 (1923)

Stipa lagascae subsp. clausa (Trabut)

Coutinho, Fl. Port. 70 (1913)

Stipa juncea sensu Cav., Descr. Pl. 39

(1802), non L. (1753)

Hojas con vaina y cara abaxial del limbo glabras o a veces finamente tuberculadopapilosas o claramente pubescentes y con pelos de hasta 1,5 mm. Lemas de 12-15 mm, con arista de (21-)23-30(-35) cm.

Ecología: En lastonares desarrollados sobre suelos profundos arenoso-calizos. Desde 400 a 1800 m.s.m. Agrostio-Stipion giganteae.

Observaciones: Para esta subespecie se reconocen dos variantes morfológicas en relación con la pubescencia de la cara abaxial de las hojas. Por un lado, los individuos que se corresponden con el tipo, presentan hojas con haz glabro o tuberculado-papiloso, y por otro, aquellos caracterizados por presentarlas pubescentes, y que se reconocen en este trabajo con categoría de variedad: var. matritensis.

\section{Clave para las variedades}

1. Limbo de las hojas con cara abaxial glabra o tuberculado-papilosa ....... a. var. clausa

1'. Limbo de las hojas con cara abaxial pubescente

b. var. matritensis

\section{a. var. clausa}

Hojas con vaina y cara abaxial del limbo glabras o a veces finamente tuberculadopapilosas.

Número cromosómico: $2 \mathrm{n}=44$ (Vázquez inéd.; en plantas de Ciudad Real, Palencia y Valladolid: UNEX 14419, 14420 \& 14422, respectivamente).

Distribución general: Endémica de la Península Ibérica (fig. 10).

b. var. matritensis F.M.Vázquez \& Devesa, Anales Jard. Bot. Madrid 54(1): 412 (1996)

Hojas con vaina y cara abaxial del limbo con pelos de hasta $1,5 \mathrm{~mm}$.

Holótipo: MA 29141 (Vázquez \& Devesa, 1996).

Distribución general: Endémica de la Península Ibérica (fig. 10).

9.2. subsp. cazorlensis F.M.Vázquez \& Devesa, Anal. Jard. Bot. Madrid 54(1): 413 (1996)

Hojas con vaina y cara abaxial del limbo glabra o a veces finamente tuberculadopapilosa. Lemas de 11-12,5 mm, con arista de $19-22 \mathrm{~cm}$.

Holótipo: UNEX 14864 (Vázquez \& Devesa, 1996).

Ecología: En matorrales seriales sobre suelos compactos desarrollados sobre sustratos calcáreos. Desde 800 a 1800 m.s.m. PhlomidioBrachypodion retusi. 
Distribución general: Endémica del sur de la Península Ibérica (Sierra de Cazorla y Sierra Nevada; fig. 10) y noroeste de Africa.

10. Stipa offneri Breistr., Procés-Verb. Soc. Dauph. Étud. Biól. (Grenoble) Ser. 3, 13: 2 (1950)

Stipa juncea Gouan, Hort. Monsp. 1:52 (1762), non L. (1753)

Stipa juncea auct. pl., non L. (1753)

Tallos de hasta $100 \mathrm{~cm}$, erectos, con nudos violáceos glabros u ocasionalmente pubescentes. Hojas con vaina glabra; lígula de 5-10(-12) $\mathrm{mm}$, aguda y glabra; limbo convoluto, glabro en la cara abaxial y pubescente en la adaxial, el de las hojas inferiores de hasta $62 \mathrm{~cm} \mathrm{x} \mathrm{0,3-0,9}$ $\mathrm{mm}$ y el de las superiores de hasta $25 \mathrm{~cm}$ de longitud. Panícula de hasta $41 \mathrm{~cm}$, laxa, de contorno lanceolado, con ramas y pedúnculos escábridos. Glumas trinervadas, glabras u ocasionalmente escábridas en los nervios; la superior de (10-)15-30(-35) $\mathrm{mm}$ y la inferior de (11-)16-36(-42) mm. Lemas de (7-)8-10(11) $\mathrm{mm}$; callo de 1,2-3 mm; arista de (5-)8$12(-15) \mathrm{cm}$, escábrida en los ángulos. Páleas de (7-)8-10(-11) $\mathrm{mm}$, glabras. Lodículas anteriores de 1,5-3,5 $\mathrm{mm}$, la posterior de hasta 2 $\mathrm{mm}$. Anteras de (4-)4,5-6,5 mm, con pelos apicales de hasta 0,3 mm. Estilos 2, plumosos. Cariópsides de (5-)6-8,5 mm. Florece de Abril a Junio.

Número cromosómico: 2n=44 (Vázquez inéd., en plantas de Almería, Cuenca y Valencia: UNEX 14240, 14248 \& 14246, respectivamente). Recuentos previos: Avdulov (1931, Rusia, sub S.juncea), Love (1947), Nilsson \& Lassen (1971, Islas Baleares, sub S.juncea) y Moraldo (1986, Italia, sub S.juncea).

Ind. loc.: « HABITAT Monspelii cum priori à l'Esperou \& au Puy de Saint Loup.»

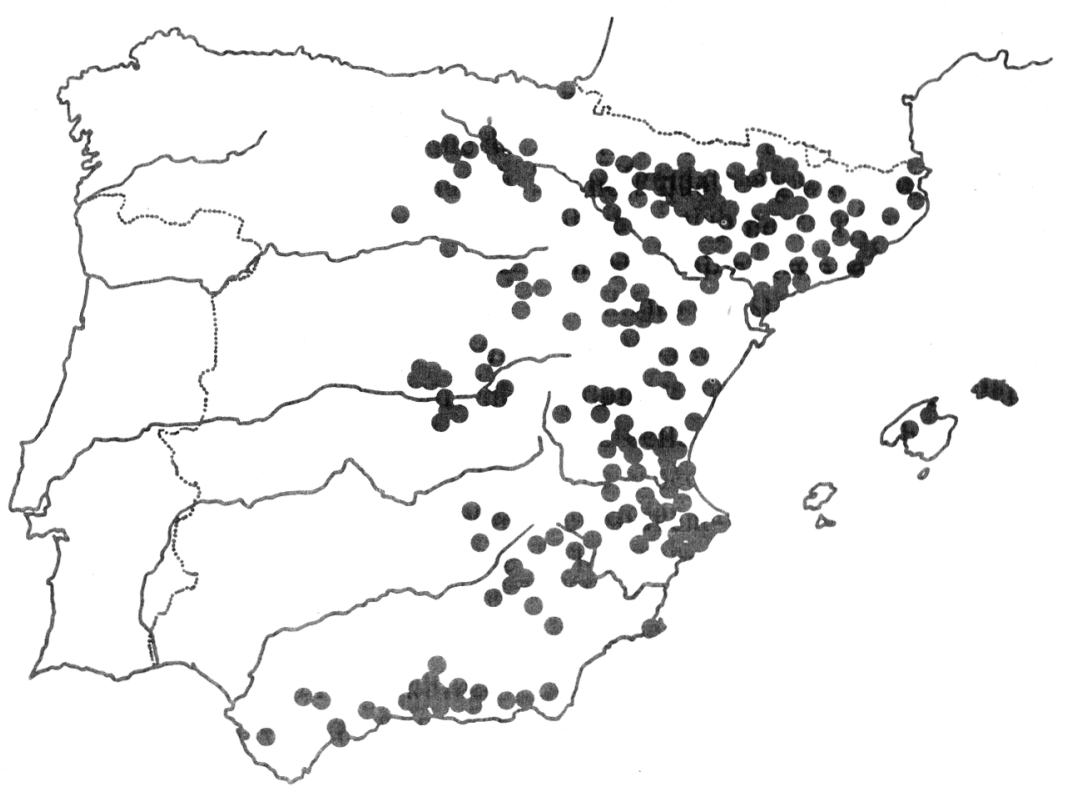

Figura 11. Distribución peninsular de Stipa offneri. Peninsular distribution of Stipa offneri. 
Tipo: No estudiado.

Ecología: En lastonares de bosques esclerófilos degradados, sobre sustratos calizos pedregosos. Desde el nivel del mar a 1800 m.s.m. Stipion tenacissimae.

Distribución general: Endémica del oeste de la Región Mediterránea: sur de Francia, oeste y sur de Italia, Sicilia, Península Ibérica, Islas Baleares y Marruecos (fig. 11).

D. Sect. Inaequiglumes (Bor) F.M.Vázquez \& Devesa, comb. in stat. nov.

Stipa ser. Inaequiglumes Bor, Fl. Ir. 70 : 387 (1970)

Stipa sect. Stipella Tzvelev, Not. Syst. Pl.

Vasc. (Leningrad) 11: 13 (1974), p.p.

Perennes, cespitosas. Lígula membranosa. Glumas desiguales. Lemas enteras, homogéneamente pubescentes, con una arista bigeniculada escábrida o provista de pelos de menos de 0,5 mm. Callo agudo. Páleas enteras. Lodículas 3, las dos anteriores de mayor tamaño. Casmógamas. $\mathrm{x}=7$.

Especie tipo: S. parviflora Desf. (Freitag, 1985).

11. Stipa parviflora Desf., Fl. Atl. 1: 98, Tab. 29 (1798)

Tallos de hasta $125 \mathrm{~cm}$, erectos 0 ligeramente curvados en la fructificación, con nudos violáceos, glabros o escábridos. Hojas con vaina glabra o escábrida; lígula de $(0,5$-) 1 $2(-2,5) \mathrm{mm}$, truncada, a veces lacerada, escábrida en el dorso y ciliada hacia la base; limbo plano o convoluto, glabro o escábrido en la cara abaxial y escábrido en la adaxial, el de las hojas inferiores de hasta $35 \mathrm{~cm} \mathrm{x}(0,2-) 0,5$ $1(-1,5) \mathrm{mm}$ y el de las superiores de hasta 30

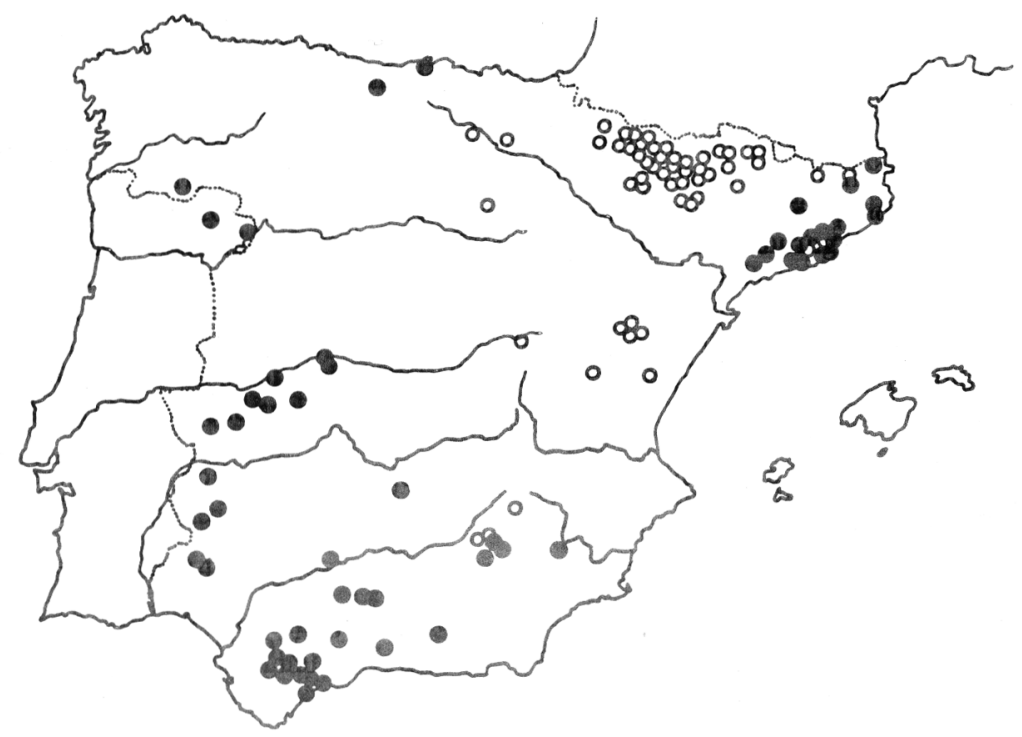

Figura 12. Distribución peninsular de Stipa parviflora: var. parviflora; 0 , var. pilosa. Peninsular distribution. 
$\mathrm{cm}$ de longitud. Panícula de hasta $52 \mathrm{~cm}$, más o menos condensada, de contorno ovado o lanceolado, con ramas y pedúnculos escábridos. Glumas glabras, con 1-3 nervios escábridos y a menudo purpúrea en el dorso; la superior de (4-)6-10(-11) mm y la inferior de (9-)12-16(18) $\mathrm{mm}$. Lemas de (3-)3,5-5,5(-6,5) $\mathrm{mm}$; callo de (0,7-)1-1,5(-2) mm; arista de (7-)9-13(-15) $\mathrm{cm}$, escábrida en los ángulos. Páleas de (1,2) 1,5-2,5(-3) mm, glabras. Lodículas anteriores de $(0,2-) 0,8-1,5(-2) \mathrm{mm}$, la posterior de hasta 1,7 mm. Anteras de 2-3 mm. Estilos 2, plumosos. Cariópsides de (2,5-)3-4,5(-5) mm. Florece de Marzo a Junio.

Ind. loc: : $\mathrm{HABITAT}$ in collibus aridis prope Mascar et in regno Tunetano.»

Lectótipo: P-DESF ejemplar único (vidi microf.). Designado en este trabajo.

Et.1.- Stipa parviflora / Herbier de la Flore Atlantique / donné au Muséum par $M$. Desfontaines / $\mathrm{N}^{\circ}$ (impr.) / S. parviflora (manusc.).

Isolectótipo 1: MA 5100 ejemplar único (v.s.).

Et.1.- Stipa parviflora Desf. / specim orig. / Berberia / Herb. Cavanilles / Desfontaines (impr.).

Et.2.- Stipa parviflora / Berberia / Desfontaines dedit (manusc.).

Isolectótipo 2: MA 8100 ejemplar único (v.s.).

Et.1.- Stipa parviflora / Desfontaines dedit / Barbarie (manusc.).

Isolectótipo 3: MAF-Pourret 375 (v.s.). Et.1.- Stipa parviflora / Barbarie (manusc. Desfontaines, conf. en MAF).

Ecología: En todo tipo de lastonares, atochares y matorrales seriales sobre sustratos calcáreos o margosos. Desde 100 a 1500 m.s.m.
Lygeo-Stipetea, Rosmarinetalia.

Distribución general: Ambas variedades en la Región Mediterránea y SW de Asia; en la Península Ibérica sólo en la mitad oriental (fig. 12).

Observaciones: Al estudiar su variabilidad se han encontrado dos grupos diferenciables atendiendo a la pubescencia de la vaina, uno de ellos integrado por los individuos que presentan vainas glabras (var. parviflora) y otro por aquellos que las presentan ligeramente escábridas o pubescentes (var. pilosa).

\section{Clave,para las variedades}

1. Hojas con vaina y limbo glabros en la cara abaxial ............................ a. var. parviflora

1'. Hojas con vaina y limbo escábridos o pubescentes en la cara abaxial

b. var. pilosa

\section{a. var. parviflora}

Stipa parviflora var. contorta Lange, Vid. Meddel. Dansk Naturh. Foren. KjØbenhavn 1: 36 (1860) (Ind. loc.: «In collibus gypsaceis ad Aranjuez cum forma «typica. Mai!»). Isolectótipo: MA 149135 ejemplar único (v.s.), designado en este trabajo. Et.1.- John Lange / plantae Europ. austral 1851-52/39. Stipa parviflora Desf. (impr.) / in collibus gypsaceis ad Aranjuez (manusc.) / Lange 20 Maí (impr.)

Stipa parviflora subsp. contorta (Lange)

Malagarriga, Subesp. Var. Geográf. 27 (1973)

Stipa ilorcitana Sennen, Bull. Inst. Catalana Hist. Nat. 32: 106 (1932) (Ind.loc.: «Murcie, sierras lorquianas». Isolectótipo. BC-SENNEN (v.s.), 
designado en este trabajo. Et.1.- Stipa ilorcitana Sennen vel S.parviflora Desf. var. contorta Lge./ Murcie Sierras argilocalcaires ou gypseuses 300-400 m/ 1929VI et VII / Leg. Sennen et Jeronimo/ Note: le S.parviflora du Tibidabo croît en touffes / celui-ci eu pieds isolés épars par le sierras lorquines (ilorcitanae) (impr.)

Stipa parviflora var. ilorcitana (Sennen)Sennen, Bull. Inst. Catalana Hist. Nat. 32: 119 (1932)

Hojas con vaina y limbo glabros en la cara abaxial.

Número cromosómico: $2 \mathrm{n}=28$ (Vázquez, inéd., en plantas de Almería, Huesca y Murcia: UNEX 14538, 14523 \& 14532, respectivamente). Recuentos previos: LorenzoAndreu (1951 \& 1953, España) y Freitag (1985, suroeste de Asia).

b. var. pilosa (Chrtek \& Martinovsky) F.M. Vázquez \& Devesa, comb. in stat. nov.

S.parviflora fma. pilosa Chrtek \& Martinovsky, Webbia 24: 398 (1969)

Hojas con vaina y limbo finamente escábridos en la cara abaxial.

Holótipo: «Porta et Rigo, Iter II Hispanicum n. 38 et 334, prov. Almeria, in collibus aridis apricis et Murcia in collibus circa Lorca, sol. schistaceo, 200-300 m, Apr.,Mai. 1899, in herb. PRC sub N. 345.» (Chrtek \& Martinovsky, 1969; no estudiado).

E. Sect. Stipella Tzvelev, Nov. Syst. Pl. Vasc. (Leningrad) 11: 15 (1974)

Stipa ser. Tortiles Roshev. in Komarov, Fl. URSS 2: 102 (1934) (Especie tipo:
S.tortilis Desf., =S.capensis Thunb.; Freitag, 1985)

Anuales, cespitosas. Lígula membranosa. Glumas subiguales. Lemas enteras, homogéneamente pubescentes, con arista bigeniculada, escábrida o con pelos de menos de $0,5 \mathrm{~mm}$. Callo agudo. Páleas enteras. Lodículas 3, las dos anteriores de mayor tamaño. Cleistógamas. $\mathrm{x}=12$.

Especie tipo: S. capensis Thunb. (Tzvelev, 1974).

12. Stipa capensis Thunb., Prodr. Fl. Cap. 19 (1794)

Tallos de hasta $105 \mathrm{~cm}$, erectos 0 ascendentes, con nudos de color violáceo y generalmente escábridos. Hojas con vaina glabra o pubescente; lígula de (0,2-)0,4-0,7(1) mm, truncada, con márgenes ciliados; limbo convoluto, glabro o pubescente en la cara abaxial y pubescente en la adaxial, el de las hojas inferiores de hasta $25 \mathrm{~cm} \mathrm{x}(0,3-) 0,4$ $0,8(-1) \mathrm{mm}$ y el de las superiores de hasta 17 $\mathrm{cm}$ de longitud. Panícula de hasta $23 \mathrm{~cm}$, densa, de contorno lanceolado, con ramas y pedúnculos escábridos. Glumas glabras, con 1-3 nervios escábridos; la superior de (12-)14$20(-25) \mathrm{mm}$ y la inferior de (14)16-26(-28) $\mathrm{mm}$. Lemas de (2,5-)3-6(-7) mm; callo de (1) 1,5-3,5(-4) mm, agudo y pubescente, con dos líneas laterales glabras; arista de (-3,5)5-15(18) cm, bigeniculada y escábrida en los ángulos, a veces densamente pelosa en la base de la columna. Páleas de (0,8-)1,5-2,5(-3) mm. Lodículas anteriores de (0,6-)1-2(-2,5) mm, la posterior de hasta $2 \mathrm{~mm}$. Anteras de (2-)2,53,5(-4) mm. Estilos 2, glabros. Cariópsides de (2-)3-5(-6) mm. Florece de Febrero a Junio.

Número cromosómico: $2 \mathrm{n}=34$ (Reese, 
1957, en Islas Canarias, sub S.tortilis) y $2 n=36$ (Vázquez inéd., en plantas de Cáceres, Granada y Sevilla: UNEX 14571, 14563 \& 14585 , respectivamente, y del Algarve y Alto Alentejo (Portugal), UNEX 14573 \& 14581). Recuentos previos: 2n=36 (Fernandes \& Queirós, 1969, Portugal; Borgen, 1970, Islas Baleares; Gould, 1970, Túnez; Dahlgren et al., 1971, Islas Baleares, y Devesa et al., 1991, España).

Ind. loc.: «Promontorio Bonae Spei Africes».

Lectótipo: UPS-THUNBERG $256^{\circ}$ (Freitag, 1985; vidi microf.).

Et.1.- Stipa capensis THUNB (1794) / (=St. retorta CAVANILLES 1795-97)/(=St. tortilis DESFONTAINES 1798) (manusc.)/ det.(impr.) H. Freitag (manusc.) / Göttingen, (impr.) 24.1.(manusc.) 19 (impr.) 72 (manusc.1).

Et.2.- Lemma: (6)6,5-7,5(7,7) mm nid callus of 2,3-2,5 mm. / Arista: 7-8 cm (basal part 2-
2,1 cm; / from 1st to 2nd hull / 1,5-1,8 cm; upper part 3,5-5 cm). / Cariópsides: 3,2 mm long (inmature) / Glummae: gl. inf $\sim 15 \mathrm{~mm} /$ gl. sup. 12-14 mm, both 3-nerved. / Ligule: 0,5 $\mathrm{mm}$, truncate, densely ciliate. / Despite the missing basal parts and the rather high / culms this specimen agrees well with the / Mediterranean and Oriental materials. / Fr. (manusc.).

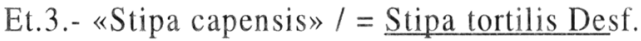
/ Scarf. (manusc.).

Et.4.- Stipa capensis (manusc.).

Ecología: En herbazales viarios y suelos esqueléticos nitrificados; indiferente edáfica. Desde el nivel del mar a 1200 m.s.m. Brometalia.

Observaciones: Algunos autores peninsulares identificaron el material de este taxón con la Stipa paleacea. Ind.loc.: No indicada. Lectótipo: P, s/n. (v.s.), designado en este trabajo. Et. 1.- Stipa paleacea / (St.

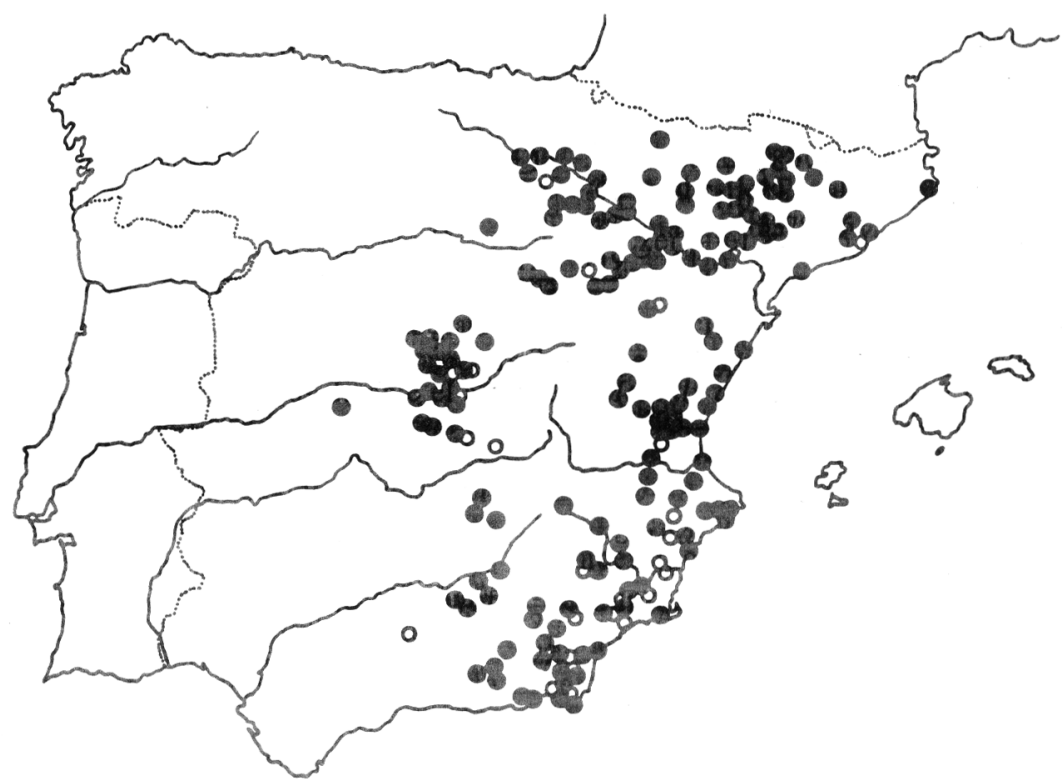

Figura 13. Distribución peninsular de Stipa capensis: var. capensis; O, Stipa capensis var. pubescens. Peninsular distribution. 
aristis contortis tomentosis, / calyce multo longioribus, / glumis subfasciculatis 3 á 6 paillutes, / cum la fl. h Poiret (manusc.). Et. 2.Her. Poiret / in Her. Moquin-Tandon (impr.). Et. 3.- Culmus ramosus, subpanicula angulosus gluma paleis pluribus / (6-8) cm uniflora ? un flosculi masculi laterales / ? medio flor. femineus (manusc.). Et. 4.- Stipa paleace (nobis) / voyag. en Barbarie ex Numidia (manusc.). Et. 5.- Antistirrhia glauca Desf. fl. alt. 2 vol. / h Poiret (manusc.). Descrita por Poiret en 1789 (Cavanilles, 1802; Lagasca, 1816). Sin embargo, estudiado el tipo que se conserva en París, se ha podido comprobar que los ejemplares allí conservados pertenecen a un género diferente, Themeda Forskål, concretamente a $T$. triandra Forskål, por lo que el primer nombre disponible para la denominación del taxón es el de Thunberg: Stipa capensis.

Se trata de un taxón que en la Península Ibérica presenta dos pautas de variación en base a la pelosidad de las hojas fértiles en su cara abaxial, lo que permite segregar dos grupos distintos que se reconocen aquí con categoría de variedad: var. pubescens, con cara abaxial pubescente, y var. capensis con cara abaxial glabra o escábrida, ambas con una distribución peninsular muy similar, si bien esta última suele vivir en general en áreas de menor xericidad.

\section{Clave para las variedades}

1. Hojas con vaina y limbo glabros o escábridos en la cara abaxial ............. a. var. capensis

1'. Hojas fértiles con vaina y limbo pubescentes en la cara abaxial b. var. pubescens

a. var. capensis

Stipa retorta Cav., Obs. Valenc. 1: 119, 2: 325 (1795-97) (Ind. loc.: No indicada.
Lectótipo: MA 476394, ejemplar central (v.s.), designado en este trabajo. Et.1.N.30. Stipa. Species ut nobis videtur á lin. nom descripta. / Crescit locis aridis en el castillo de Sagunto. / flor. Junio. / Arista pilis brevibus ut gentibus imperta (manusc.) Et.2. - Stipa contorta / este nombre le puse quando la encontré en 1791. / Sagunti Maio. (manusc.) Et.3.JARDÍN BOTÁNICO DE MADRID (impr.) / Stipa capensis Thunb (manusc.) / Revisado (impr.) E. Paunero, 1964 (manusc.) Et.4.- CAVANILLESII TYPI / Stipa retorta Cav. / Sagunto (Valencia) / V-1791 (impr.). Isolectótipo: MA 476393, ejemplar superior derecho (v.s.). Et.1.- Stipa contorta / Sagunti Maio (manusc.) Et.2.- CAVANILLESII TYPI / Stipa retorta Cav. / Sagunto (Valencia) / V-1791)

Stipa tortilis Desf., Fl. Atl. 1: 99, Tab 31, fig. 1 (1798) (Ind. loc.: «Habitat in arvis». Lectótipo: P-DESF ejemplar único (vidi microf.), designado en este trabajo. Et.1.Stipa tortilis, / Herbier de la Flore Atlantique / donné au Museum par M. Desfontaines (impr.) / Stipa tortilis (manusc.)

Stipa capensis var. tortilis (Desf.) Breistr., Procès-Verb. Soc. Dauph. Étud. Biol. (Grenoble), ser. 3, 17: 2 (1950)

Stipa humilis Brot., Fl. Lusit. 1: 86 (1804) (Ind. loc.:»Hab. in solo macro, sabuloso ad Conimbricam, Olisipon., et alibi in Beira et Extremadura.». Tipo: No estudiado).

Hojas fértiles con vaina y cara abaxial del limbo glabras, las basales a veces pubescentes.

Distribución general: Región Mediterránea (fig. 13). Naturalizada en la Región Macaronésica y sur de Africa (Freitag, 1985). 
b. var. pubescens (Ball) Breistr., Procès-Verb. Soc. Dauph. Étud. Biol. (Grenoble), ser. 3, 17: 2 (1950)

Stipa tortilis var. pubescens Ball, Jour. Linn. Soc. London 16: 711 (1878)

Stipa tortilis var. pilosa Trabut, Bull. Soc. Bot. Fr. sér. 2, 7: 395 (1885) (Ind. loc.: «Sables à Boucaada.». Tipo: no estudiado)

Hojas fértiles con vaina y cara abaxial pubescente, con pelos de más de $1 \mathrm{~mm}$.

Ind. loc.: «Mar. merid.- Legimus prope Sektana!».

Tipo: No estudiado.

Isolectótipo: COI (v.s.), designado en este trabajo. Et.1.- Iter Maroccanum 1871 (impr.) / S. tortilis var. pubescens / Ex regione inferiori / Atlantis Majoris prope Sektana / alt 1300 1400 met. / Mayo 18-19 / J.BALL (manusc.).

Distribución general: Como la variedad típica, aunque más abundante en la mitad Sur de la cuenca Mediterránea (fig. 13).

F. Sect. Jarava (Ruiz y Pavón)F.M.Vázquez \& Devesa, comb. et stat. nov.

Jarava Ruiz \& Pavón, Prodr. Fl. Perú 2 (1794), p.p.

Stipa subgen. Jarava (Ruiz y Pavón)Trin. \& Rupr., Acta Acad. Petrop. sér. 6, 5: 42 (1842)

Perennes, cespitosas. Lígula membranosa. Glumas subiguales. Lemas enteras, parcialmente escábridas, con arista bigeniculada escábrida 0 pubescente y con pelos de menos de $0,5 \mathrm{~mm}$. Callo agudo. Pálea entera. Lodículas 3, las dos anteriores de menor tamaño. $x=11$.
Especie tipo: Stipa ichu (Ruiz \& Pavón)Kunth (=Jarava ichu Ruiz \& Pavón; Swallen, 1979).

13. Stipa papposa Nees, Agrost. Brasil. 377 (1829)

Achnatherum papposum (Nees)

Barkworth, Phytologia 74(1):11 (1993)

Calamagrostis plumosa Sprengel in L., Syst. Veg. ed. 16, 1: 253 (1825) (Ind.loc.: «Monte Video. Sello». Tipo: no estudiado), non Stipa plumosa Trinius (1836)

Stipa delilei Steudel, Syn. Pl. Glum. 1: 126 (1854) (Ind. loc.: «Monspelii ex seminibus peregrinis.». Tipo: no estudiado)

Stipa tenuiflora Phil., Linnaea 33: 281 (1864) (Ind. loc.: «Prope $>>$ Llico $<<$ in prov. Colchagua invenit orn. Landbeck.». Lectótipo: SGO 37390 (vidi microf.), Designado en este trabajo. Et.1.S.tenuiflora Ph. (manusc.). Et.2.- Stipa tenuiflora Ph. / Llico. Decemb. 1861 / Landbeck. (manusc.). Et.3.- HERBARIO DEL MUSEO NACIONAL DE HISTORIA NATURAL, CHILE. EX HERBARIO F.PHILIPPI ... Et.4.ETIQUETA DE CORRECCIÓN (impr.) / Typus, Stipa tenuiflora Ph. (manusc.) / det. C. Muñoz P. (impr.) / XI-1943 (manusc.)

Tallos de hasta $45 \mathrm{~cm}$, erectos, con nudos glabros y violáceos. Hojas con vaina glabra; lígula de hasta $1,5 \mathrm{~mm}$, truncada y escábrida; limbo convoluto, glabro en la cara abaxial y pubescente en la adaxial, el de las hojas inferiores de hasta $9 \mathrm{~cm} \times 0,2 \mathrm{~mm}$ y el de las superiores de hasta $4 \mathrm{~cm}$ de longitud. Panícula de hasta $20 \mathrm{~cm}$, laxa, de contorno lanceolado y con ramas y pedúnculos escábridos. Glumas uninervadas, glabras; la superior de 6-8 $\mathrm{mm}$ y 
la inferior de 5-7 mm. Lemas de 6-7,5 mm, con dorso escábrido y pelos patentes de hasta $6 \mathrm{~mm}$ en el ápice; callo de 1,5-2 mm, obtuso y pubescente; arista de $2-3 \mathrm{~cm}$, geniculada y escábrida. Páleas de hasta $3 \mathrm{~mm}$, glabras. Lodículas anteriores de hasta $1 \mathrm{~mm}$, la posterior de hasta 0,2 mm. Estambres con anteras de 2,53,2 mm. Estilos 2, plumosos. Cariópsides de hasta $5 \mathrm{~mm}$. Florece de Septiembre a Noviembre.

Número cromosómico: $2 \mathrm{n}=40,42$ y 44 . Recuentos previos: $2 \mathrm{n}=40$, Bowden \& Senn (1962, Argentina) y Matthei (1965, Chile); 2n=42, 44 (Avdulov, 1928); 2n=44 (LorenzoAndreu, 1953).

Ind.loc: «Ad Monte - Video. 4. (Sellow.)».

Tipo: No estudiado.

Isolectótipo: US 993503 (Hitchcock, 1925; no estudiado).

Distribución general: Originaria de América del Sur (Argentina, Brasil, Chile y Uruguay). En Europa sólo se ha indicado su presencia -probablemente introducida- en la Península Ibérica, concretamente en herbazales de zonas viarias de las inmediaciones de Sabadell, Barcelona (Casasayas \& Farras, 1985).

G. Sect. Lasiagrostis (Link)Hackel in Engl. \& Prantl, Nat. Pflanzenfam. 2, 2: 46 (1887)

Lasiagrostis Link, Hort. Berol. 1: 99 (1827) Stipa subgen. Lasiagrostis (Link)Steud., Syn. Pl. Glum. 1: 132 (1854)

Achnatherum Beauv., Agrost. 146 (1812), p.p.
Perennes, estoloníferas. Glumas subiguales. Lemas con ápice emarginado, pubescentes en toda su longitud, con pelos patentes; arista articulada, con pelos de menos de $0,5 \mathrm{~mm}$ en toda su longitud. Callo agudo. Páleas enteras. Lodículas 3, las dos anteriores de menor tamaño. Casmógamas. $\mathrm{x}=12$.

Especie tipo: Stipa calamagrostis (L.)Beauv.) (=Agrostis calamagrostis L.; Freitag, 1985).

14. Stipa calamagrostis (L.)Wahlenb., Vegt. Helv. Tent. 23 (1813)

Agrostis calamagrostis L., Syst. Nat. ed. 10, 2: 872 (1759)

Achnatherum calamagrostis (L.)Beauv., Agrost. 146 (1812)

Lasiagrostis calamagrostis (L.) Link, Hort. Berol. 1: 99 (1827)

Tallos de hasta $140 \mathrm{~cm}$, erectos o ligeramente curvados en la fructificación, con nudos violáceos, glabros o escábridos. Hojas con vaina glabra o escábrida, de márgenes ciliados; lígula de $(0,2-) 0,4-1(-1,2)$, ciliada hacia la base; limbo plano o convoluto, glabro o escábrido en la cara abaxial y siempre escábrido en la adaxial, el de las hojas inferiores de hasta $55 \mathrm{~cm} \times(0,4-) 0,6-1,5(-2) \mathrm{mm}$ y el de las superiores de hasta $28 \mathrm{~cm}$ de longitud. Panícula de hasta $35 \mathrm{~cm}$, de contorno lanceolado. Glumas glabras, con nervios escábridos; la superior de (4,5-)5,5-7(-8) mm y la inferior de $(5,5-) 6,5-8(-8,5) \mathrm{mm}$. Lemas de (2,8-)3-4,5(-5) mm, con dientes de 0,2-0,7 $\mathrm{mm}$; callo de 0,3-0,8(-1) $\mathrm{mm}$, agudo; arista de (0,5-)0,8-1,5(-2) cm, escábrida en los ángulos. Páleas de 3-4 mm. Lodículas anteriores de 0,5$1,9 \mathrm{~mm}$, la posterior de hasta 2,2 $\mathrm{mm}$. Anteras de (2-)2,5-3(-3,5) mm. Estilos 2, plumosos. Cariópsides de (2-)2,5-3,5(-4) mm. Florece de Mayo a Septiembre. 
Número cromosómico: $2 \mathrm{n}=24$. Recuentos previos: Gervais (1966, Francia) y Löve \& Löve (1974, Yugoslavia, sub A.calamagrostis).

Ind. loc.: No indicada.

Lectótipo: Icon. TABLA III; fig. 11A y 11B; Scheuchzer, 1719 (Vázquez et al., 1995).

Ecología: En gleras, gelifractos y pedregales calizos móviles de alta montaña, o en guijarrales fluviales. Desde 400 a 1800 m.s.m. Stipion-Calamagrostis.

Distribución general: S y CS de Europa, extendiéndose desde Alemania hasta el norte de la Península Ibérica (fig. 14).

H. Sect. Aristella (Trin.)Hackel in Engl. \& Prantl., Nat. Pflanzenfam. 2, 2: 46 (1887)

Stipa a. aristella Trin., Fund. Agrost. $110(1820)$

Aristella (Trin.)Bertol., Fl. Ital. 1: 690 (1834)

Stipa subgen. Aristella (Trin.)Rouy, Fl. Fr. 14: 98 (1913)

Achnatherum sect. Aristella (Trin.)Tzvelev, Nov. Syst. Pl. Vasc. (Leningrad) 9: 55 (1971)

Stipa ser. Bromoides Martinovsky, Preslia 48: 186 (1976) (Especie tipo: Stipa bromoides (L.)Dörfler)

Stipa sect. Leiostipa ser. Bromoides (Martinovsky) Moraldo, Webbia 40(2): 211 (1986)

Perennes, estoloníferas. Lígula membranosa. Glumas desiguales. Lemas con ápice emarginado y pelos adpresos en toda su longitud; arista recta o geniculada, pubescente, con pelos de menos de $0,5 \mathrm{~mm}$. Callo obtuso. Páleas enteras. Lodículas 3, las dos anteriores de aproximadamente el mismo tamaño que la posterior. Cleistógamas. $\mathrm{x}=7$.

Especie tipo: Stipa bromoides (L.)Dörfler (=Agrostis bromoides L.).

15. Stipa bromoides (L.)Dörfler, Herb. Norm. 34: 129 (1897)

Agrostis bromoides L., Mantissa 30 (1767)

Achnatherum bromoides (L.)Beauv., Agrost. 146 (1812)

Aristella bromoides (L.)Bertol., Fl. Ital. 1: 690 (1834)

Lasiagrostis bromoides (L.) Nevski \& Roshev. in Komarov, Fl. URSS 2: 72 (1934)

Stipa aristella L., Syst. Nat. ed. 12, 3: 229 (1768) (Ind.loc.: «Habitat Monspelii. Gouan». Lectótipo: LINN 94.6 (Vázquez et al., 1995)

Tallos de hasta $150 \mathrm{~cm}$, con nudos violáceos, glabros o escábridos. Hojas con vaina glabra y márgenes ciliados; lígula de 0,1-0,5 mm, escábrida; limbo de las hojas inferiores de hasta $72 \mathrm{~cm} \times 0,5-1,5 \mathrm{~mm}$, el de las superiores de hasta $35 \mathrm{~cm}$ de longitud. Panícula de hasta $35 \mathrm{~cm}$, fusiforme. Glumas glabras, escábridas en los nervios; la superior de (8-)9-11(-13) mm y la inferior de (8-)9-16(19) $\mathrm{mm}$. Lemas de (5-)6-8(-9) mm, con dientes apicales de 0,3-0,9 $\mathrm{mm}$; callo de 0,3-0,8 mm, obtuso; arista de (1-)1,5-2(-2,5) cm, escábrida en los ángulos. Páleas de (3-)3,5-5(-5,5) mm, con dorso pubescente. Anteras de 2,5-5,5 mm. Lodículas anteriores de 1-2(-3,5) mm, la posterior de hasta $2,5 \mathrm{~mm}$. Estilos 2, plumosos. Cariópsides de (3-)4-6(-7,5) mm. Florece entre Mayo y Agosto.

Número cromosómico: $2 \mathrm{n}=28$ (Vázquez inéd., en plantas de Badajoz: UNEX 12689). Recuentos previos: Lorenzo-Andreu \& García 
(1950, España), Ujhelyi (1961, Hungría), Löve \& Löve (1961, Ga; 1974, Yugoslavia), Freitag (1985, SW de Asia), Strid \& Andersson (1985, Grecia) y Moraldo (1986, Italia).

Ind. loc.: « Habitat Monspelii D. Gouan».

Lectótipo:LINN 84-4 (Vázquez et al., 1995).

Ecología: En fenalares sobre suelos calcáreos relativamente profundos y frescos. Desde 200 a 800 m.s.m. Brachypodion phoenicoidis.

Distribución general: Eurasia (desde Rusia al sur de la Península Ibérica; ausente en el norte y centro-norte de Europa) y noroeste de Africa (fig. 14).
J. Sect. Macrochloa (Kunth) F.M.Vázquez \& Devesa, comb. et stat.nov.

Macrochloa Kunth, Révis. Gram. 1: 58 (1829)

Stipa subgen. Macrochloa (Kunth)Steud., Syn. Pl. Glum. 1: 132 (1854)

Perennes, cespitosas. Lígula reemplazada por pelos. Glumas subiguales. Lemas con ápice dentado, pubescentes en toda su longitud, con arista geniculada, diferenciada en una columa plumosa con pelos patentes y el resto pubescente. Callo agudo. Páleas enteras. Lodículas 3, las dos anteriores de mayor tamaño, ocasionalmente la posterior de mayor tamaño. Casmógamas. $\mathrm{x}=12$.

Especie tipo: Stipa tenacissima Loefl. ex L.

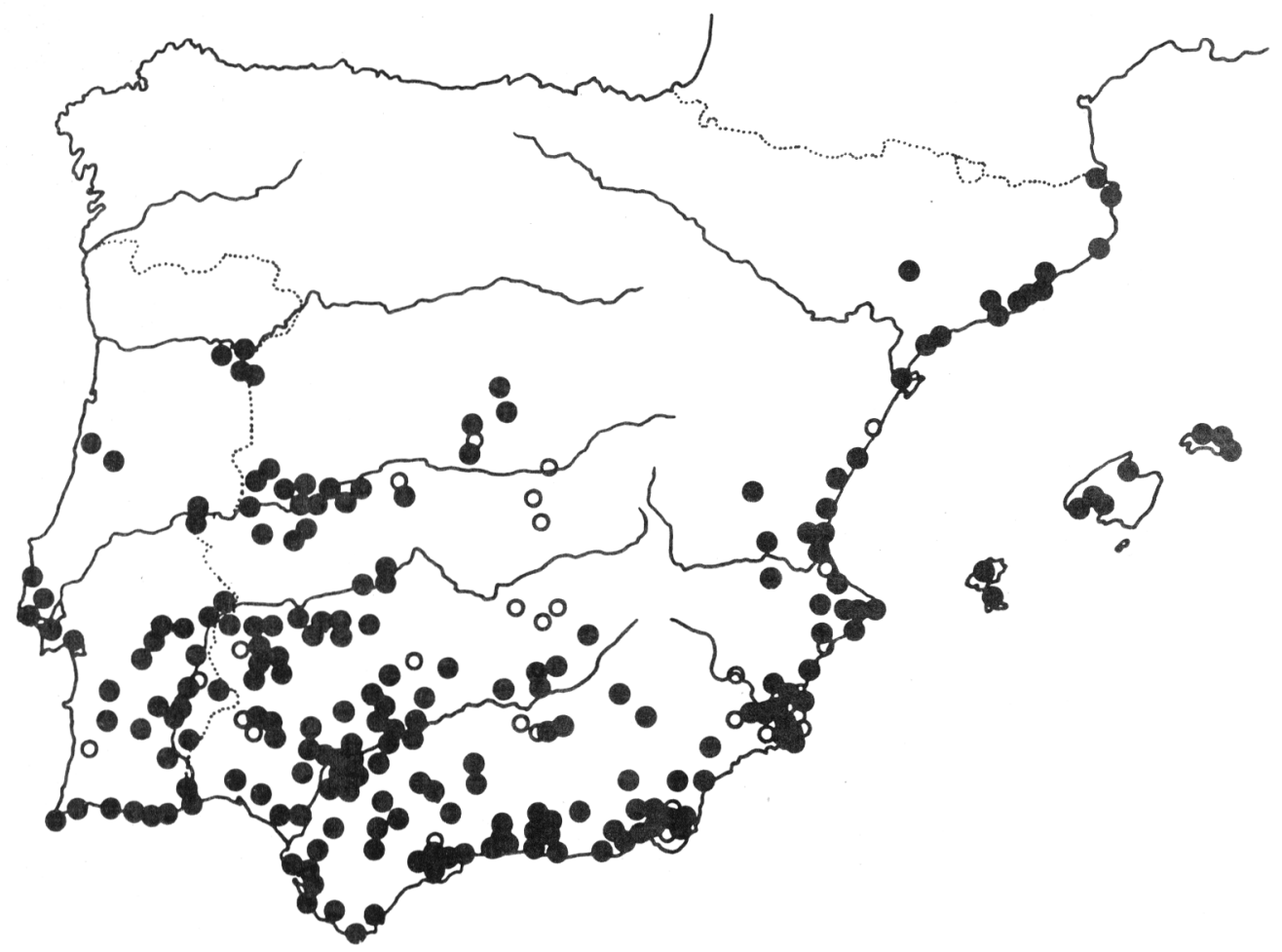

Figura 14. Distribución peninsular de: O, Stipa calamagrostis, - S.bromoides. Peninsular distribution. 
16. Stipa tenacissima Loefl. ex L., Cent. Pl. 1: $6(1755)$

Macrochloa tenacissima (L.) Kunth, Révis. Gram. 1: 59 (1829)

Lasiagrostis tenacissima (L.) Trin. \&

Rupr., Spec. Gram. Stirp. 1: 94 (1842) Stipa gabesensis Moraldo, Raffaelli \& Ricceri, Candollea 44: 78 (1989) (Holótipo: FI 3016/1 (v.s.). Et.1.- Nome (impr.) Stipa gabesensis Moraldo, Raffaelli et Ricceri / Candollea 44(1): 78. 1989 (manuscr.1) / Localitá TUNISIA Pseudosteppe aux environs de Gabes / HOLOTYPUS/ coll.: M.Raffaelli, C.Ricceri N. / Data 16.IV.1986 / Det. (impr.) M.Raffaelli, C.Ricceri (manuscr.2)

Stipa kelibiae Moraldo, Raffaelli \& Ricceri, Candollea 44: 80 (1989) (Holótipo: FI 3016/2 (v.s.) Et.1.- Nome (impr.) / Stipa kelibiae Moraldo, Raffaelli et Ricceri / Candollea 44(1): 80.1989 (manuscr.1)/
Localitá HOLOTYPUS TUNISIA Tunisi: / Fra kelibia e EL-Haouaria $30 \mathrm{~m} /$ coll. M.Raffaelli, C.Ricceri (manuscr.2) Antera sessil $8,5 \mathrm{~mm}$ barbate / all apice Palea $9 \mathrm{~mm}$ pelosa nel $1 / 4$ superiore / Lemma $10 \mathrm{~mm}$ densamente barbata Resta I attaccata a 1,5 mm dell apice della columna (manuscr.1)

Stipa kralifii Moraldo, Raffaelli \& Ricceri, Candollea 44: 80 (1989) (Holótipo: FI 3016/3 (v.s.) Et.1.- Nome (impr.) Stipa kralifii Moraldo, Raffaelli et Ricceri / Candollea 44(1): 80.1989 (manuscr.1)/ Localitá HOLOTYPUS TUNISIA Strada n.13 fra SFAX e FAID: / pendici di D.J.Sidi-Kralif m. 300-350 / Coll.: M. Raffaelli, C. Ricceri / Date 15/04/86 / Det. (impr.) M. Raffaelli, C. Ricceri (manuscr.2)

Tallos de hasta $170 \mathrm{~cm}$, con nudos violáceos y escábridos. Hojas con vaina glabra o escábrida; lígula de 0,2-1 mm, truncada, con

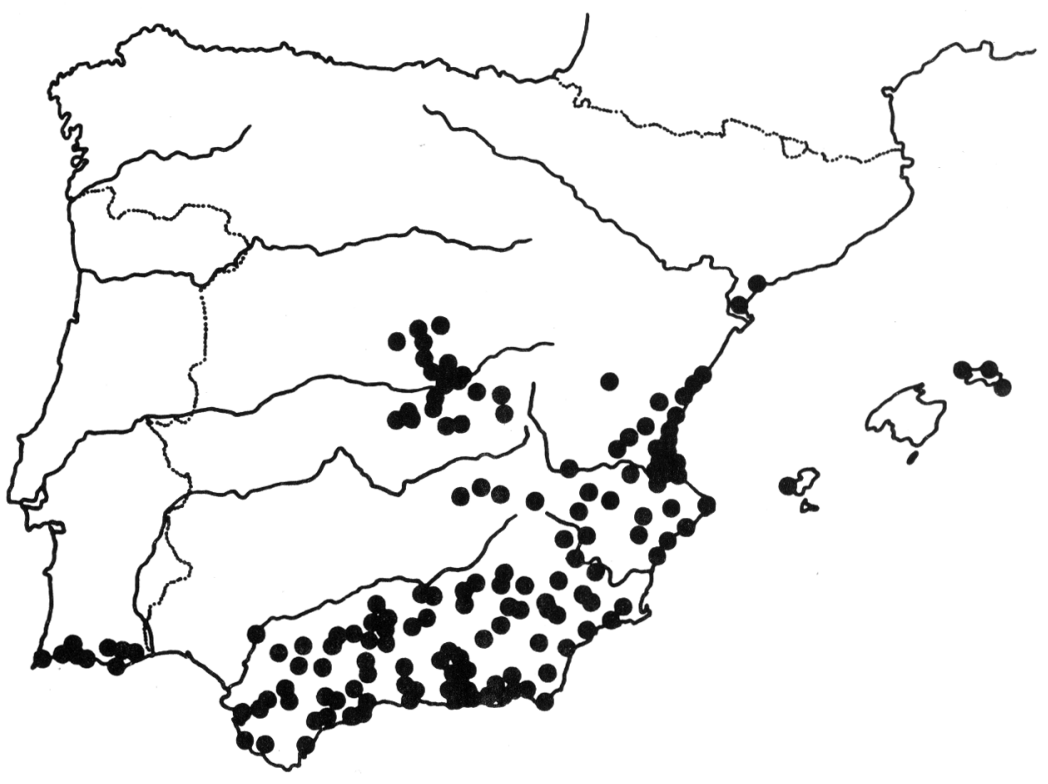

Figura 15:- Distribución peninsular de Stipa tenacissima. Peninsular distribution of Stipa tenacissima 
lóbulos de hasta $4 \mathrm{~cm}$; limbo convoluto, glabro en la cara abaxial y escábrido en la adaxial; el de las hojas inferiores de hasta $70 \mathrm{~cm} \mathrm{x}(0,5$ $0,8-1,8(-2) \mathrm{mm}$ y el de las superiores de hasta $40 \mathrm{~cm}$ de longitud. Panícula de hasta $40 \mathrm{~cm}$, fusiforme o de contorno sublanceolado, con ramas y pedúnculos escábridos. Glumas subiguales, glabras, con nervios escábridos; la superior de (15-)20-30(-35) mm y la inferior de (18-)22-35(-40) mm. Lemas de (7-)9-12(14) $\mathrm{mm}$, pubescentes, con dientes de 1-2(-3) $\mathrm{mm}$; callo de $(0,1-) 0,5-2(-3) \mathrm{mm}$; arista de (3,5-)4,5-8,5(-10) cm, escábrida en los ángulos y vilosa en la columna. Páleas de (6-)7-10(-12) $\mathrm{mm}$, glabras. Lodículas anteriores de 1,5-3 $\mathrm{mm}$, la posterior de hasta $4 \mathrm{~mm}$. Anteras de (7)8,5-12(-15) $\mathrm{mm}$, con pelos de 0,1-0,5 mm. Estilos 2, plumosos. Cariópsides de (4,5-)5,58(-9) mm. Florece de Febrero a Junio.

Número cromosómico: 2n=24 (Labadie, 1979, Argelia; Fernandes \& Queirós, 1969, Portugal) y $2 n=66$ (Lungeanu, 1980, Marruecos).

Ind. loc.: «Habitat in Hispaniae collibus sabulosis».

Lectótipo: LINN 94-7 (Vázquez et al., 1995).

Ecología: En etapas de degradación de bosques mediterráneos sobre suelos calcáreos: lastonares, espartales y atochares. Desde el nivel del mar a 1500 m.s.m. Lygeo-Stipetalia.

Distribución general: Oeste de la Región Mediterránea (fig. 15) y norte de Africa, habiéndose indicado también -aunque rara- para Turquía (Scholz, 1985).

K. Sect. Giganteae (Martinovsky) F.M. Vázquez \& Devesa, comb. in stat. nov.

Stipa ser. Giganteae Martinovsky,
Preslia 48: 186 (1976)

Macrochloa Kunth, Révis. Gram. 1: 178 (1829), p.p.

Perennes, cespitosas. Lígula membranosa. Glumas subiguales. Lemas bidentadas, pubescentes, con arista bigeniculada y con pelos de menos de 0,5 mm. Callo agudo. Páleas bífidas. Lodículas 3, la posterior de mayor tamaño. Casmógamas. $\mathrm{x}=12$.

Especie tipo: Stipa gigantea Link. (Martinovsky, 1976).

17. Stipa gigantea Link in Schrader, Jour. Bot., 2: 313 (1799)

Lasiagrostis gigantea (Link) Trin. \& Rupr., Spec. Gram. Stirp. 1: 96 (1.842)

Macrochloa gigantea (Link) Hackel, Cat. Rais. Gram. Port. 16 (1880)

Tallos de hasta $245 \mathrm{~cm}$, erectos 0 ligeramente curvados en la fructificación, con nudos violáceos glabros. Hojas con vaina glabra o escábrida; lígula de (0,4-)0,5-7(10) mm, aguda o truncada, escábrida; limbo convoluto, a veces flexuoso en las hojas estériles, con cara abaxial glabra o escábrida y cara adaxial pubescente, el de las hojas inferiores de hasta $130 \mathrm{~cm} \times(0,5-) 0,7-1,3(-1,6) \mathrm{mm}$ y el de las superiores de hasta $35 \mathrm{~cm}$ de longitud. Panícula de hasta $65 \mathrm{~cm}$, laxa, de contorno oval o lanceolado, con ramas y pedúnculos escábridos. Glumas glabras, con 3 nervios escábridos; la superior de (22-)26-35(-40) $\mathrm{mm}$ y la inferior de (21-)25-34(-38) mm. Lemas de (14-)1621(-24) mm, con dientes apicales de (4-)5-7(8) $\mathrm{mm}$; callo de $(2,2-) 2,8-4,2(-5,5) \mathrm{mm}$, pubescente; arista de (6-)8-11(-13) cm, bigeniculada y escábrida en los ángulos. Páleas de (13-)15-21(-25) mm, bífidas, con dorso pubescente y dientes apicales de (0,3-)0,5-3(4) $\mathrm{mm}$. Lodículas anteriores de (1-)1,3-2,5(- 
$2,9) \mathrm{mm}$, la posterior de hasta $3,5 \mathrm{~mm}$. Anteras de (9-)10-16(-18) mm, con pelos apicales de $(0,2-) 0,5-0,7(-0,8) \mathrm{mm}$. Estilos 2, plumosos. Cariópsides de (7-)9-12(-14) mm. Florece de Marzo a Junio.

Ind. loc.: "An den Sandhügeln bei Setuval, Bellas, und am südlichen Abhange der Estrella fanden wir es nicht, selien».

Tipo: No estudiado.

Observaciones: Al estudiar la morfología de las anteras se reconocen en la especie dos grupos de individuos claramente diferenciables. Uno, que comprende la mayoría de las poblaciones peninsulares, lo integran individuos en los que los pelos apicales de las anteras superan los $0,5 \mathrm{~mm}$, y otro, restringido a las marismas del SW de España, en cuyos individuos los pelos de las anteras nunca sobrepasan los 0,45 mm de longitud. Además, a esta diferencia hay que añadir la relativa a la morfología de la panicula (laxa y más o menos condensada, respectivamente), el número de flores (menos de 80 en el primer grupo y más de 100 en el segundo) así como la fenología de la floración, caracteres que se han utilizado para reconocer sendas subespecies: subsp. gigantea y subsp. donyanae, esta última restringida al litoral onubense.

\section{Clave para las subespecies}

1. Anteras con pelos de más de $0,45-0,7(-0,9)$ $\mathrm{mm}$. 17. 1. subsp. gigantea

1'. Anteras con pelos de hasta $0,2-0,35(-0,4)$ $\mathrm{mm}$

17. 2. subsp. donyanae

\section{1. subsp. gigantea}

Stipa arenaria Brot., Fl. Lusit. 1:86 (1804) (Ind. loc.: «Hab. in aridis et arenosis Lusitaniae meridionalis: occurrit passim

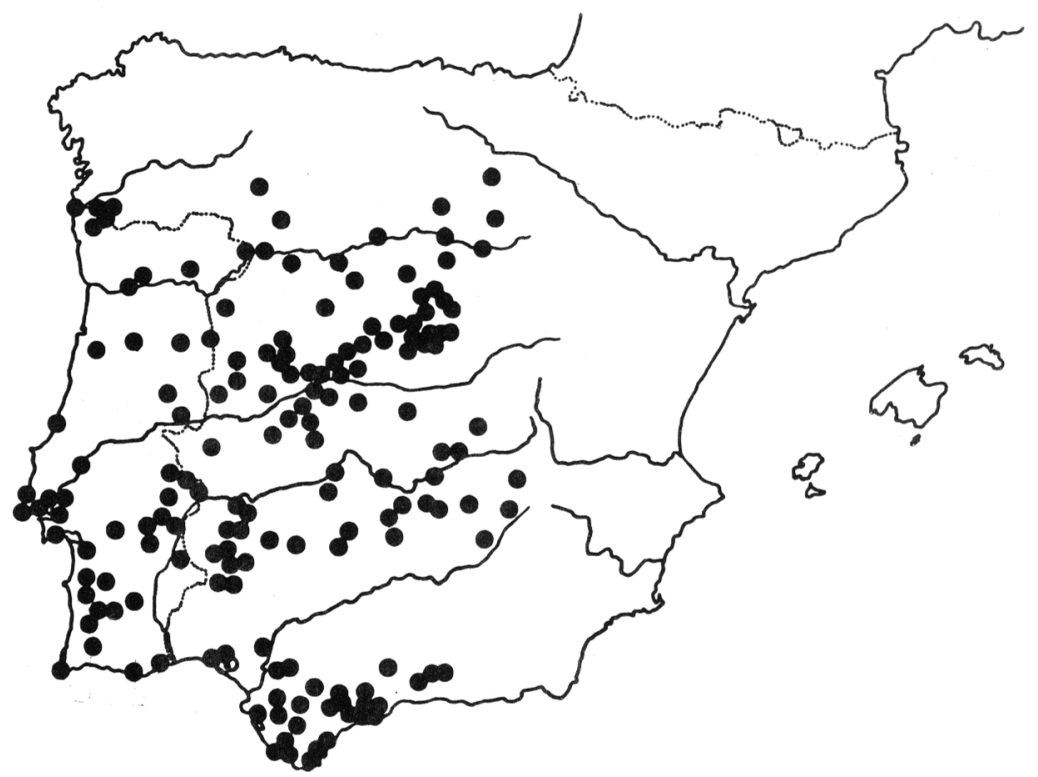

Figura 16.- Distribución peninsular de Stipa gigantea: subsp. gigantea; 0 , subsp. donyanae. Peninsular distribution. 
in pinetis et dumetis ab Almada ad Promontorium barbaricum, vulgo Cabo de Espichel.»; Tipo: No estudiado)

Macrochloa arenaria (Brot.)Kunth, Révis. Gram. 1: 59 (1829)

Avena cavanillesii Lag., Gen. Sp. Nov. 4, (1816) (Ind. loc.: «H. locis arenosis siccis veteris Castellae, Baeticae, Murciae Regni, et circa Matritum. Floret Junio». Lectótipo: MA 5240 ejemplar único (v.s.), designado en este trabajo. Et.1.- Avena cavanillesii Lag. / Valdelatas (Madrid) / Herb. Lagasca (manusc.) Et.2.- Avena cavanillesii Lag. / Stipa arenaria Brot. Fl. Lus. Pers. Eneh. / bot. vol. 4. Venit locis arenosis aridis, / in meseti castella circa Matritum en Valde / latas prope Fuencarral oppidum...., / colitur in R.M.H., / Floret Junio et autumno 4. (manusc.)

Gluma superior de (20-)25-37(-42) mm, la inferior de (22-)25-40(-44) mm. Lemas de (13-)15-20(-24) mm, con dientes de (2-)4-7,5(8) $\mathrm{mm}$; callo de $(2,2-) 2,5-4,5(-5,5) \mathrm{mm}$ y arista de (6-)7-12(-14) cm. Páleas de (14-)16-22($25) \mathrm{mm}$, con dientes de $(0,2-) 1-3,5(-4,5) \mathrm{mm}$. Anteras de (9-)10-16(-18) mm, con pelos de 0,45-0,7(-0,9) mm. Florece de Marzo a Mayo.

Número cromosómico: 2n=96 (Vázquez, inéd., en plantas de Ciudad Real, Huelva y Salamanca: UNEX 14342, 14327 y 14367 , respectivamente). Recuentos previos: Fernandes \& Queirós (1969, Portugal), Queirós (1973 \& 1974, Portugal) y Devesa et al. (1991, España).

Ecología: En matorrales seriales y bosques mediterráneos degradados sobre sustratos preferentemente ácidos y de textura gruesa. Desde el nivel del mar a 2400 m.s.m. AgrostioStipion giganteae.

Distribución general: Endémica de la mitad occidental de la Península Ibérica (fig. 16) y noroeste de Africa (Marruecos, Argelia y Túnez).

\section{2. subsp. donyanae F.M.Vázquez \& Devesa, subsp. nova}

Gluma superior de (20-)23-27(-30) mm, la inferior de (20-)23-28(-32) mm. Lemas de (11-)14-18 mm, con dientes de 3-9 mm, callo de $(1,5-) 2-3(-3,5) \mathrm{mm}$ y arista de 5-8,5(-10) cm. Páleas de (13-)15-19 mm, con dientes de 0,5-3,5 mm. Anteras de (8-)9-11,5(-12,5) mm, con pelos de 0,2-0,35 $(-0,4) \mathrm{mm}$. Florece de Mayo a Junio.

Glumae superiore (20-)23-27(-30) mm, inferiore (20-)23-28(-32) mm. Lemma fertile (11-)14-18 mm, cum dentis 3-9 mm; callus $(1,5-) 2-3(-3,5) \mathrm{mm}$ et aristae $5-8,5(-10) \mathrm{cm}$. Palea (13-)15-19 mm, cum dentis 0,5-3,5 mm. Antherae (8-)9-11,5(-12,5) mm, cum pileus 0,2$0,35(-0,45) \mathrm{mm}$. Florescentia Maius-Iunius.

Número cromosómico: 2n=96 (Vázquez inéd., en plantas de Huelva: UNEX 14352).

Holótipo: ESPAÑA: Almonte, Reserva Biológica de Doñana, laguna de Santa Olalla, 2-V-1990, S.García \& F.M.Vázquez (UNEX 14352). Ejemplar único.

Ecología: En brezales higrófilos sobre suelos arenosos. Genistion micrantho-anglicae.

Distribución general: Endémica del suroeste de la Península Ibérica: Parque Nacional de Doñana, Huelva (fig. 16), y NW de Africa.

\section{TAXONES DUDOSOS}

\section{Sect. Stipa}

18. Stipa tirsa Steven, Bull. Soc. Nat. Moscou 30(2): 115 (1857). 
Stipa pennata subsp. tirsa (Steven)Kneucker, Allgem. Bot. Zeitschr. 8: 182 (1902)

Stipa stenophylla Czern., Consp. Fl. Charc. 75 (1859) (Ind. loc.:»Charcov.». Lectótipo: LE-TRINIT, ejemplar central (1) (v.s.), designado en este trabajo. Et.1.Herbarium Academiae Scientarium Petropoli. (impr.). Et.2.- MUSEUM BOTANICUM ACADEMIAE SCIENTIARUM / PETROPOLITANAE (impr.) / Stipa stenophylla Czern. (manuscr.) / XapbkoBCkaR ry6 (impr.) Gmenb npn p. / Voranu (manuscr.) / 1853.VI.29 (manuscr.) B.M. YephReBb. Et.3.- Stipa stenophylla Czern. (manuscr.) / 192 (impr.) 4 (manuscr.) / det (manuscr.) P.Smirnov (impr.)

Perenne, cespitosa. Tallos de hasta 50 $\mathrm{cm}$, erectos, con nudos violáceos pubescentes. Hojas con vaina escábrida; lígula de hasta 0,3 mm, truncada, ciliada en el margen; limbo convoluto, con márgenes escábridos, cara abaxial esparcidamente pelosa y cara adaxial pubescente, el de las hojas inferiores de hasta $45 \mathrm{~cm} \times 0,7 \mathrm{~mm}$ y el de las superiores de hasta $20 \mathrm{~cm}$. Panícula de hasta $18 \mathrm{~cm}$, laxa y de contorno lanceolado, con ramas y pedúnculos escábridos. Glumas subiguales, glabras, con 3-5 nervios escábridos; la superior de 35-47 $\mathrm{mm}$ y la inferior de 37-52 mm. Lemas de 13-15 $\mathrm{mm}$, con dorso recorrido por 7 filas de pelos; callo de hasta $4,5 \mathrm{~mm}$; arista de $26-40 \mathrm{~cm}$, con columna glabra y pelos de hasta $6 \mathrm{~mm}$ en el resto. Páleas de 13-14 mm, glabras. Lodículas anteriores de hasta $2,8 \mathrm{~mm}$, la posterior de hasta $2 \mathrm{~mm}$. Anteras de hasta $7 \mathrm{~mm}$. Estilos 2, plumosos. Cariópsides de 12-15 mm. Florece de Junio a Septiembre. La descripción de este taxón se ha efectuado no sólo con material español sino también de otras procedencias (véase Anexo 1).

Número cromosómico: $2 \mathrm{n}=44$ (sub Stipa stenophylla Czern): Avdulov (1931, Rusia) y Tischler $(1950, \mathrm{n}=22)$.

Ind. loc: «Per totam Tauriam vulgatissima......Eandem ex Ucrania et campis maeoticis habeo».

Lectótipo: H, 1065655 (Martinovsky \& Skalicky, 1969; v.s.)

Et.1.- Lectotypus! / Stipa tirsa Steven / Elegunt (impr.) Dr Jan Martinovsky / et Vladimir Skalicky (manuscr.).

Et.2.- R.Roshevitz Notae criticae (impr.) / Stipa stenophylla Czern / IV. 1934 (manuscr.).

Et.3.- Stipa (manuscr.) ? pennata (manuscr.) / Kaltfgik camp. Maeotic. (manuscr.) / Graff (manuscr.).

Et.4.- Ad 3 1/2' altum. Semen cum arista 1'4' ipsum 7-8" ' longum basi totum sericeum dein / stria unica usque ad apicem et duabus ad dimidium dense ciliatis, caespitibus / haud ita magnis crescens nec solitariis ut St (Thyrsa quam) Graffiana (manuscr.).

Et.5.- HERB. STEVEN.

El área de distribución de esta especie se centra fundamentalmente en el este de Europa y el centro-suroeste de Asia (Freitag, 1985; Roshevits, 1934) si bien se conocen poblaciones puntuales en el sureste y centro de Francia (Kerguélen, 1975; Martinovsky, 1980), norte de Italia (Pignatti, 1982; Moraldo, 1986) y España (Paunero, 1960). En la Península Ibérica sólo se tiene constancia de su existencia a través de un pliego de M.Lagasca conservado en el Jardín Botánico de Madrid (MA 146661; vide Paunero, 1.c.), en cuya etiqueta original se indica «Se cría en montes y colinas áridas cerca de Madrid, Aranjuez, Mancha y Reino de Murcia», información vaga y dudosa, sobre todo si se tiene en cuenta que el taxon no ha vuelto a ser recolectado.

II. NASSELLA Desv. in C.Gay, Hist. Chile Bot. 6: 263 (1854) 
Urachne subgen. Nassella Trin., Mém. Acad. Imp. Sc. St. Petersbourg, Sér. 5, 11:77 (1830)

Plantas perennes y cespitosas. Hojas con vaina glabra, escábrida o vilosa; lígula membranosa, truncada o aguda, glabra escábrida o ciliada; limbo con márgenes involutos, glabro, escábrido o pubescente. Panícula laxa, de contorno lanceolado u oval, con ramas y pedúnculos escábridos. Glumas 2 , subiguales, con 3-5 nervios, glabras 0 escábridas. Lemas fusiformes, pubescentes, con una corona apical ciliada. Páleas bicarenadas. Callo agudo y pubescente. Anteras 3. Lodículas 3 , enteras y agudas, con sección plana, las dos anteriores de mayor tamaño. Estilos 2, plumosos. Cariópsides fusiformes. $\mathrm{x}=10,11$.

Especie tipo: Nassella pungens Desv. (Parodi, 1947).

1. Nassella mucronata (Humb., Bonpl. \& Kunth)Pohl in Barkworth, Taxon 39(4): 611 (1990).

Stipa mucronata Humb., Bonpl. \& Kunth, Nov. Gen. \& Sp. 1: 125 (1816)

Stipa setigera C.Presl, Reliq. Haenk. 1: 226 (1830) (Ind.loc.: «Hab...». Lectótipo: PR 198060, ejemplar izquierdo (v.s.), designado en este trabajo. Et.1.Herbarium / Musei / Nationalis / Pragae. / Evid. / cisio 198060. / Invent. / cisio 1241 (impr.). Et.2.- Stipa setigera / Hackel / 8 (manuscr.). Et.3.- NB... Presl. / Impositium ... / Hackel (manuscr.). Et.4.- Typus (impr.). Et.5.- 198060 (impr.) / Stipa setigera Presl. (manuscr.) / HERBARIUM MUSEI NATIONALIS PRAGAE (impr.)

Stipa trochlearis Nees \& Mey., Acta Acad. Caes. Leop. Carol. 19, Suppl. 1: 151 (1843) (Ind.loc.: «Ad Arequipam urbem
Peruviae in campis siccis pedum 1200 altitud., et ad lacum Titicacam». Tipo: no estudiado)

Tallos de hasta $120 \mathrm{~cm}$, erectos o ligeramente curvados en la fructificación, con nudos violáceos, glabros o pubescentes. Hojas con vaina glabra o escábrida; lígula de 0,1-0,4 mm, truncada, ciliada en los márgenes; limbo plano o convoluto, glabro o ligeramente pubescente en la cara abaxial y escábrido o pubescente en la adaxial, el de las hojas inferiores de hasta $18 \mathrm{~cm}$ x 0,8-2,5 mm, y el de las superiores de hasta $12 \mathrm{~cm}$. Panícula de hasta $18 \mathrm{~cm}$, laxa, de contorno lanceolado, con ramas y pedúnculos escábridos. Glumas glabras, con 3-5 nervios escábridos; la superior de 13-17 mm y la inferior de 11-15 mm. Lemas de 5-8 mm, papilosas en el dorso, con dientes apicales de hasta $1 \mathrm{~mm}$; callo de $2-3 \mathrm{~mm}$, agudo y pubescente; arista de $5-8 \mathrm{~cm}$, escábrida en los ángulos. Páleas de 1-1,7 mm, bicarenadas, glabras. Lodículas 3, desiguales; las anteriores de hasta $1 \mathrm{~mm}$ y la posterior de hasta 0,3 mm. Estambres con anteras de 3-5,5 mm. Estilos 2, plumosos. Cariópsides de 3-5 mm. Florece de Mayo a Julio. La descripción de este taxón se ha efectuado no sólo con material español sino también de otras procedencias (véase Anexo I).

Número cromosómico: $2 \mathrm{n}=36$ (Love, 1947, Méjico), 2n=64 (Bowden \& Senn, 1962, Argentina) y $2 \mathrm{n}=66$ (Covas \& Bocklet, 1945 , Argentina).

Ind.loc.: «Crescit in montanis regni Mexicani, prope Actopan et vicum Magdalenae, altit. 1040 hexap.».

Lectótipo: P-HUMBOLDT \& BONPLAND (vidi microf.), designado en este trabajo.

Et.1.- Herb. Mus. Paris, / Herbier Humboldt \& Bonpland (impr.). 


\section{Et.2.- TYPE (impr.).}

Et.3.- Stipa mucronata (manusc.).

Et.4.- Stipa trochlearis Nees \& Mey. (manusc.) / Determinavit (impr.) Octavio Velarde / Mayo 1961 (manusc.).

Distribución general: Originaria de América del Sur (Argentina, Bolivia, Colombia, Ecuador, Perú y Venezuela), desde donde se ha extendido al resto del continente y naturalizado ocasionalmente en el suroeste de Europa: Francia (Kerguélen, 1975; Martinovsky, 1980), Italia (Martinovsky, 1980; Pignatti, 1982; Moraldo, 1986), Portugal y España. En la Península Ibérica sólo se conoce de herbazales viarios de los alrededores de Coimbra (García, 1946, sub Stipa setigera C.Presl) y Madrid.

Observaciones: Esta especie puede confundirse con N.neesiana (Trin. \& Rupr.)Barkworth. Ind.loc.: «Ins Juan Fernandez (Prescott!) Huc?». Lectótipo: Le-Trin., ejemplar derecho (vidi microf.), designado en este trabajo. Et. 1.- Stipa (Perianth 4 lineale) / det Prescott 1829 (manuscr.1). Et. 2.- Herb. trint. (impr.). Et. 3- Herbarium / Academiae/ Scientiarum / Petropol. (impr.). Et. 4- Stipa neesiana f. Fernandeziana (manuscr. 2). Taxón afín ausente en la flora peninsular pero conocido de Francia (Kerguélen, 1975; Martinovsky, 1980) e Italia (Martinovsky, 1980; Pignatti, 1982; Moraldo, 1986). Sus principales diferencias radican en la longitud del callo (mayor de $4 \mathrm{~mm}$ en N.neesiana, y de hasta 3,5 mm en N.mucronata); las dimensiones de las lemas (7-11 y 5-8 mm, respectivamente) y la arista (6-12 cm y $5-8 \mathrm{~cm}$, respectivamente), así como en el tamaño de los pelos de la corona, menores de 0,6 mm en N.neesiana y de más de 1,2 mm en N.mucronata (Spegazzini, 1901; Hitchcock, 1925).

\section{ANEXO 1}

Selección de parte del material estudiado.

Stipa eriocaulis: ESPAÑA PENINSULAR. HUESCA: Ibón de Armeña, 21-VIII-1983, G. Montserrat, JACA 219483. Arensa, 17-VIII1980, G. Montserrat, JACA-G 2901. Barbaraens, 3-VIII-1980, G. Montserrat, JACA-G 2631. Bielsa, 4-VII-1976, P. Montserrat, JACA 133176. Bisauri, 4-VII-1987, J.A. Sesó, G. Montserrat et al., JACA 663587. Plan de Cotiella, 3-VII-1980, G. Montserrat, JACA-G 1693. Jaca, Oroel, 5-VII-1966, S. Silvestre, SEV 25599. San Juan de la Peña, 9-VIII-1991, S. García \& F.M. Vázquez, UNEX 14591. Seira, 17-V-1982, G. Montserrat, JACA-G 16. Saravillo, 29-VIII1984, G. Montserrat, JACA 56184. LÉRIDA: Bormort, 11 -VI-1987, A.M. Romo, MA 464561. Collado de Montalbán, 11-VII-1990, F.M. Vázquez, UNEX 14477. Montrech de Rubiés, sobre Roig, 6-VI-1980, A.M. Romo, BC 688159. Pont de Suert, 21-VI-1987, P.\& G. Montserrat et al., JACA 595587. Urgel, coll de Boixols, 22VII-1959, A. \& O de Bolòs, BC 149363.

Stipa apertifolia var. apertifolia: ESPAÑA PENINSULAR. ALBACETE: Sierra de Alcaraz, 24-VI-1979, P.F. Cannon, P.R. Crane, et al., SEV 52227. Sierra de Taibilla, 17-VII-1923, A. Charpin \& F. Fdez. Casas, MA 227044. ALMERíA: Sierra de María, 18-V-1987, F. Gómez, BC 800664. CASTELLÓN DE LA PLANA: Morella, 30-VI-1962, A. \& O. de Bolòs, BC 140148. San Juan de Penyagolosa, 15-VII1961, J. Vigo, BC 261254. CUENCA: Cuenca, VI-1898, M. Gandoger, PRC 388 (Holótipo). Estrecho de Paredes, 25-VI-1968, S. Rivas Goday \& J. Borja, SALAF 3323. GRANADA: Sierra de Alfacar, 25-VI-1977, F. Valle, GDAC 11956. Sierra de Baza, 10-VII-1984, J. Torres, G. Blanca et al., GDAC 26147. Cerro Trevenque, 1990, $R$. Wagenitz, FREITAG s/n. Dornajo, 24-VIII-1989, S. García \& F.M. Vázquez, UNEX 14479. Padul, 26-VI-1984, F. Pérez \& J. Molero, GDA 17855. JAÉN: Barón de la Tejada, 19-VI-1926,J. Cuatrecasas, BC 67618. Plan de Serrezuela, Bedmar, 7-VI-1926, J. Cuatrecasas, MAF 29013. Cazorla, Fuente de Acevo, 18-VI-1975, J.L. 
González, F. Muñoz et al., MA 480634. Sierra de Mágina, 19-VI-1979, J. Díez, J. Ubera et al., SEV 106965. MADRID: Cerro Negro, sin fecha, J. Cavanilles, MA 4954. MÁLAGA: Sierra Almijara, 7-VII-1935, M. Laza, MAF 29011 Fuente de Espina, 24-VII-1980, J.M. Nieto, MGC 7959. TERUEL: Puerto Escandón, 31-VI-1987, L. Villar, JACA 66787.

Stipa apertifolia var. nevadensis: ESPAÑA PENINSULAR. GRANADA: Sierra de Baza, 10VII-1984, J. Torres, G. Blanca et al., GDAC 26143 (Holótipo).

Stipa iberica var. iberica: ESPAÑA PENINSULAR. ALBACETE: Alpera, 27-V1987, E. Villanueva et al., MA 428056. ALMERÍA: La Alcarria, VIII-1962, E.F. Galiano, SEV 53994. BARCELONA: Castelgali, 19-III-1899, J. Cadevall, BC-Cadevall. Manlleu, 14-VII-1990, F.M. Vázquez, UNEX 14449. La Mola, VI-1896, E. Vayreda, BC-Vayreda. BURGOS: Aranda de Duero, VI-1942, A. Caballero, MA 4966. Treviño, 25-VI-1983, J.A. Alejandre, MA 400708. CASTELLÓN DE LA PLANA: San Juan de Penyagolosa, VII-1954, M. Calduch, BC 141835. CUENCA: Aliaguilla, VI-1978, G. Mateo, VAB 781346. Monte Beteta, 17-VI-1990, S. García \& F.M. Vázquez, UNEX 14447. Carrascosa del Campo, 17-VI-1990, S. García \& F.M. Vázquez, UNEX 14438. Estrecho de Paredes, 25-VI-1968, S. Rivas Goday \& J. Borja, MAF 102572. Herdam, V.1875, R. Agelet, FI s/n (Holótipo). Tragacete, 17-VI-1990, $S$. García \& F.M. Vázquez, UNEX 14451. GRANADA: Dehesa de Alfacar, sin fecha, $R$. Tortosa, GDA s/n. Sierra de Cázulas, 8-VI-1991, D. \& F.M. Vázquez, UNEX 14429. Huéscar, 11 VII-1978, A.M. Romero, GDA 12425. GUADALAJARA: Alcolea del Pinar, 16-VI1990, S. García \& F.M. Vázquez, UNEX 14434. Molina de Aragón, 16-VI-1990, S. García \& F.M. Vázquez, UNEX 14448. Tergaza, 13-VII1965, E. Paunero \& M.A. Rivas, MA s/n. Valderrebollo, 6-VI-1970, F. Bellot et al., MA 198079. HUESCA: Abizanda, 11-VI-1983, G. Montserrat et al., JACA 685583. Barbastro, 3VI-1984, P. Montserrat, JACA 16484. Ronda de Isabena, 11-IX-1984, G. Montserrat, JACA G683/84. Peñalba, 31-V-1981, J.A. Devesa et al., SEV 106966. Siétamo, 12-VII-1990, F.M. Vázquez, UNEX 14443. LÉRIDA: Ager, 5-VI1987, P. \& G. Montserrat, JACA 505387. Collado de Colmians, 11-VII-1990, F.M. Vázquez, UNEX 14457. Guines, 17-VI-1917, E. Gros, BC 67626. Montsech d'Estall, 1-VII-1982, A.M. Romo, BC 801098. Llano de Urgel, VII-1858, A.C. Costa, COI-Willk. MADRID: Aranjuez, 9-VI-1990, F.M. Vázquez, UNEX 14435. Carabaña, VI-1919, C. Vicioso, MA 4960. Ontígola, V-1960, J. Borja, MAF 71161 . Vaciamadrid, 2-VI-1914, E. Huguet del Villar, MA 156383. PALENCIA: Alar del Rey, VI-1936, M. Losa, GDA s/n. Villafría de la Peña, 13-VII-1980, J.A. Devesa et al., SEV 106967. SALAMANCA: La Orbada, 8-VII-1980, F.J. Fernández Diéz, Exsicc. Fl. Esp. Cent. III Univ. Salamanca n. 296, SEV 92755. SEGOVIA: San Cristóbal de Cuéllar, 16-VI-1990, S. García \& F.M. Vázquez, UNEX 14456. Garbayosa, 16VI-1990, S. García \& F.M. Vázquez, UNEX 14450. Cerca de Segovia, sin fecha, E. Huguet del Villar, MA 156382. SORIA: Cerro de Santa Ana 28-IX-1983, A. Segura, MA 357342. Monteagudo, 8-VIII-1935, C. Vicioso, MA 4968. Torralba del Moral, 6-VI.1983, A. Segura, MA 357427. TARRAGONA: Sierra Llarga de Borjas Blancas, 14-V-1949, S. Rivas Goday \& J. Benet, MAF 94174. TERUEL: Aguilar de Alfambra, 19-VI-1982, P. Montserrat et al., JACA 43782. Alcañiz, 17-VI-1990, S. García \& F.M. Vázquez, UNEX 14444. Sierra de Gúdar, 30-VII-1960, J. Borja, MAF 65750. Tornos, 6-VII-1972, P. Montserrat, JACA 446372. TOLEDO: Tembleque, 18-V-1982, S. Laorga, MAF 112236. VALENCIA: Bujaraloz, 23-V-1972, P. Montserrat, JACA 178682. Mas de Jacinto, 17VI-1990, S. García \& F.M. Vázquez, UNEX 14436. Villargordo, sin fecha, A.J. Cavanillles, MA 4964. VALLADOLID: Canillas de Esgueva, 12-VIII-1983, J.L. Fernández, MA 349168. Quintanilla de Trigueros, VI-1963, G. Cruz, MA 181276. VIZCAYA: Gordoa, 17-VI-1984, P.M. Uribe, MGC 17813. ZARAGOZA: Calatayud, 3-VI-1914, C. Vicioso, Exsicc. Pl. d'Espagne F. Sennen s.n., LISU 9666. Ejea de los Caballeros, 16-V-1988, D. Gómez, JACA 56888. Sástago, 12-III-1959, P. Montserrat, JACA 2355.

Stipa iberica var. pseudodasyphylla: ESPAÑA PENINSULAR. LÉRIDA: Conques, 11-VII- 
1990, F.M. Vázquez, UNEX 14463. La Noguera, 14-V-1987, 14-V-1987, A.M. Romo, MA 464563. Rocallaura, 2-VI-1932, P. Font Quer, BC 90020.

Stipa iberica var, austro-iberica: ESPAÑA PENINSULAR. ALBACETE: Peñascosa, 25-VI1984, sin recolector, MA 330621. GRANADA: Dehesa de Alfacar, 25-VII-1975, A.T. Romero \& C. Morales, GDAC 24327. Jayena, 8-VI-1991, D. \& F.M. Vázquez, UNEX 14426. JAÉN: Sierra de Mágina, Huelma, 8-VII-1979, H. Ern, B s/n (Holótipo). VALENCIA: Sierra de Mariola, $G$. Mateo \& $R$. Fuiguerola, VAB 85/155. Dos Santos, 17-VI-1990, S. García \& F.M. Vázquez, UNEX 14461. Los Yesos, VI-1980, J. Mansanet et al., MA 462702.

Stipa pauneroana: ESPAÑA PENINSULAR. ALICANTE: Alcoy, 14-VI-1987, J.R. Nebot, VAB 870224. CUENCA: Beteta, 13-VII-1932, A. Caballero, MA 4970. GRANADA: Sierra de Alfacar, 25-VII-1975, A.T. Romero \& C. Morales, GDAC 24327. Castilleja, con dirección a Huéscar, 12-VII-1971, J. Fernández Casas, MA 412716. Sierra de Cázulas, 8-VI-1991, D. \& F.M. Vázquez, UNEX 14465. GUADALAJARA: Alcolea del Pinar, 9-VII-1965, E. Paunero, MA 182534. Aranzueque, 28-V-1965, F. Buendía, MA 184491(Holótipo). Guadalajara, 16-VI1990, S. García \& F.M. Vázquez, UNEX 14460. LÉRIDA: La Guardia de Tremp, 31-V-1953, F. Masclans, BC 598793. Pobla de Seguer, 6-VI1918, P. Font Quer, BC 67628. MADRID: Aranjuez, 9-VI-1990, F.M. Vázquez, UNEX 14468. Rivas del Jarama, 20-V-1919, C. Vicioso, MA 4955. TERUEL: Pozondón, 11-VII-1965, E. Paunero, MA 182539. TOLEDO: Dos Barrios, 13-V-1990, S. García \& F.M. Vázquez, UNEX 14471. Toledo, 13-V-1990, S. García \& F.M. Vázquez, UNEX 14467. Villatobas, 1-VI-1982, S. Laorga, MAF 112235. VALENCIA: Requena, 20-VI-1985, E. Sanchís \& C. Roig, VAB 890294. VALLADOLID: Casas Nuevas, VII-1963, G. Cruz, MA 181273.

Stipa barbata: ESPAÑA PENINSULAR. ALBACETE: Almansa, 3-VI-1919, P. Font Quer, BC 90043. El Carrascal, 24-V-1933, J. González Albo, MA 143240. CIUDAD REAL: Sierra de Almorchón, 25-V-1933, J. González Albo, MAF
29003. La Solana, 12-V-1990, S. García \& F.M. Vázquez, UNEX 14505. CUENCA: Tarancón, 17-VI-1990, S. García \& F.M. Vázquez, UNEX 14507. GERONA: Samaría, 29-V-1932, P. Font Quer, BC 90007. GRANADA: Cuéllar, 27-IV1990, F.M. Vázquez, UNEX 14512. Granada, sin fecha, V. López Seoane, n. 452, MA 4997. Padul, 25-IV-1990, F.M. Vázquez, UNEX 14510. HUESCA: Fraga, 18-V-1972, G. \& P. Montserrat, JACA 142472. Peraltilla, 12-VII1990, F.M. Vázquez, UNEX 14518. Sariñena, 11-V-1980, G. Montserrat, JACA 533480. LÉRIDA: Almacellas, 9-V-1926, P. Font Quer, BC 90008. Saroca de Segre, 11-V-1960, F. Masclans, BC 597096. Urgel, 6-VI-1895, A.C. Costa, BC-Costa. LOGROÑO: Alcanadre, 3-VI1983, P. Uribe \& J.A. Alejandre, MA 400658. MADRID: Alcalá de Henares, VI-1897, E. Vayreda, BC- Vayreda. Aranjuez, 12-VI-1962, A. Rodríguez, SEV 6667. La Marañosa, 28-IV1960, A. Segura, MA 357446. Vaciamadrid, $27-$ V-1924, E. Huguet del Villar, MA 156372. Cerro Negro, V-1802, C.G. Neés, MA 146664. MURCIA: El Moral, 27-IV-1990, F.M. Vázquez, UNEX 14514. NAVARRA: Andosilla, 11-VI1987, P.M. Uribe, MA 477834. Mendavia, 18V-1985, J.A. Alejandre, MA 365891. SORIA: Cihuela, 20-V-1964, A. Segura, MA 357336. TERUEL: Barrachina, 13-VI-1985, J. Ferrer, JACA 336685. Monreal del Campo, sin fecha, $J$. Benedicto, MA 4990. TOLEDO: Dos Barrios, 13-V-1990, S. García \& F.M. Vázquez, UNEX 14519. La Guardia, 17-V-1982, S. Laorga, MAF 110893. Pedro Muñoz, 12-V-1990, S. García \& F.M. Vázquez, UNEX 14506. Villacañas, 13-V1990, S. García \& F.M. Vázquez, UNEX 14516. Yepes, 7-VI-1961, S. Rivas Goday \& D. Jiménez, MAF 91300. VALLADOLID: Cisterniga, V1944, M. Laza, GDA s/n. Encinillas de Esgueva, 7-VII-1983, J.L. Fernández, MA 349017. ZARAGOZA: Bujaraloz, 15-V-1951, O. Bolòs, BC 116333. Castelserás, in collibus comm. ad collem Sactae Barbatae, 18-V-1875, Loscos Exsicc. Fl. Aragonensis Cent. Prima n. 95, BC 97595. Zuera, 12-V-1951, O de Bolòs \& J. Braun Blanquet, BC 116318.

Stipa capillata: ESPAÑA PENINSULAR. BARCELONA: Manlleu, 8-X-1925, Hno. Gonzalo, Exsicc. Pl. d'Espagne F. Sennen, n. 
5553, MA 5133. CASTELLÓN DE LA PLANA: San Juan de Penyagolosa, 12-VII-1957, O. de Bolòs \& J. Vigo, BC 139992. GERONA: Cabanas, 25-VI-1905, F. Sennen, Exsicc. Pl. d'Espagne F. Sennen s.n., BC-Sennen. LÉRIDA: Prat de Montosa, Urgell, 2-XI-1943, P. Font Quer, BC 103016. SORIA: Cadosa, 28-IX-1983, A. Segura, MA 358973. TERUEL: Sierra de Albarracín, 1886, B. Zapater, 5135. Orihuela, VIII-1895, E. Reverchón, Exsicc. Pl. d'Espagne E. Reverchón, n. 1029, MA 5134. VALLADOLID: Quintanilla de Trigueros, VI-1963, G. Cruz, MA 181270. ZARAGOZA: Gallocanta, 17-IX-1981, D. Gómez, JACA 563781. Used, 8-IX-1981, A. Segura, MA 357430.

Stipa lagascae var. lagascae: ESPAÑA PENINSULAR. ALICANTE: Villajoyosa, sin fecha, M. Martínez, MA 205480. ALBACETE: Balazote, 27-IV-1990, F.M. Vázquez, UNEX 14282. Hellín, 25-IV-1990, F.M. Vázquez, UNEX 14290. CIUDAD REAL: La Solana, 12-V-1990, S. García \& F.M. Vázquez, UNEX 14296. Tomelloso, 12-V-1990, S. García \& F.M. Vázquez, UNEX 14298. CUENCA: Tarancón, 17-VI-1990, S. García \& F.M. Vázquez, UNEX 14292. GRANADA: Cuéllar, 27-IV-1990, F.M. Vázquez, UNEX 14285. Puebla de Don Fadrique, 27-IV-1990, F.M. Vázquez, UNEX 14286. Sierra Nevada, acceso al Trevenque, 21-V-1980, A.T. Romero \& C. Morales, GDAC 24562. GUADALAJARA: Aguilar de Anguita, 9-VIII1965, E. Paunero \& M.A. Rivas, MA 185232. HUESCA: Albero Alto, 3-VI-1988, P. Montserrat, JACA 128888. Castilloroy, 6-VI1987, P. \& G. Montserrat, JACA 518787. Peñalba, 31-V-1981, J.A. Devesa et al., SEV 102568. LÉRIDA: Balaguer, 3-VI-1987, P. \& G. Montserrat, JACA G107387. MADRID: Aranjuez, 21-III-1852, J. Lange, MA 149144. Cerro Negro, sin fecha, M. Lagasca, MA 185146 (Lectótipo). Chinchón, 9-VI-1990, F.M. Vázquez, UNEX 14281. Manzanares el Real, 27-V-1965, P. Montserrat, JACA 27365. Valdemoro, 24-IV1966, S. Silvestre, SEV 24799. Villaverde, 1VI-1950, A. Rodríguez, MA 169121. MÁLAGA: Antequera, 4-VI-1969, J. Borja, MA 291053. NAVARRA: Bárdenas Reales, 17-V-1988, D. Gómez, JACA 65188. TOLEDO: Dos Barrios, 13-V-1990, S. García \& F.M. Vázquez, UNEX
14299. El Romeral, 17-V-1982, S. Laorga, MAF 112240. Villacañas, 13-V-1990, S. García \& F.M. Vázquez, UNEX 14598. ZARAGOZA: Caspe, 28-V-1988, J. \& G. Montserrat, JACA 103088. Zaragoza, 19-V-1875, F. Loscos, Exsicc. Fl. Aragonensis, Cent. Prima n. 96, MAF 28974.

Stipa lagascae var. australis: ESPAÑA PENINSULAR. ALBACETE: Elche de la Sierra, 27-IV-1990, F.M. Vázquez, UNEX 14305. La Pulgosa, 23-V-1986, J.M. Herranz, MA 352156. CIUDAD REAL: Santa Cruz de Mudela, V-1958, J. Borja, MA 200038. CÓRDOBA: Entre Concepción y Fuente Tójar, 13-VI-1984, J. Arroyo, et al., UNEX 14867. CUENCA: Pinares de Tobar, 6-VII-1932, A. Caballero, MA 5148. Villaconejos, 17-VI-1990, S. García \& F.M. Vázquez, UNEX 14323. GRANADA: Sierra de Baza, sin fecha, J. Torres et al., MGC 23236. Sierra de Cázulas, 8-VI-1991, D. \& F.M. Vázquez, UNEX 14326. Sierra de Lújar, sin fecha, S. Clemente, MA 5151. Puebla de Don Fadrique, 27-IV-1990, F.M. Vázquez, UNEX 14320. GUADALAJARA: Taracena, 4-VI-1970, F. Bellot et al., MA 198080. HUESCA: Albeda, 9IX-1986, P. Montserrat, JACA 598486. Fraga, Vedat de Fraga, 4-VI-1978, J.M. Montserrat \& A.M. Romo, SALAF 360. Purroy de la Solana, 10-VII-1990, F.M. Vázquez, UNEX 14319. Sesa, 19-V-1972, P. Montserrat, JACA 159672. JAÉN: Las Hermanas, 4-VI-1926, J. Cuatrecasas, MA 5150. El Pozo, VI-1905, E. Reverchón, Esxicc. Pl. d'Espagne Elise Reverchón, n. 616, MA 5152. LÉRIDA: Vilanova de Aguda, 11-VI-1985, J. Pedrol, MA 419703. LOGROÑO: Alcanadre, 3VI-1983, P.M. Uribe \& J.A. Alejandre, MA 400683. MADRID: Alcalá de Henares, 6-VI1964, P. Montserrat, JACA 111464. Dehesa de Arganda, V-1964, J. Borja, MAF67680. El Prado, 1-XI-1931, E. Huguet del Villar, MA 156367. Vaciamadrid, 30-V-1965, E.F. Galiano \& N. Gutiérrez, SEV 13109. MÁLAGA: Antequera, 5-VI-1969, J. Borja, MAF 74110. MURCIA: Alhama de Murcia, 26-IV-1990, F.M. Vázquez, UNEX 14303. El Moral, 27-IV-1990, F.M. Vázquez, UNEX 14317. Parroquia, 27-IV-1990, F.M. Vázquez, UNEX 14314. SEVILLA: Estepa, 24-IV-1990, F.M. Vázquez, UNEX 14301. TERUEL: Brochales, hacia Podondón, 11-VII1965, E. Paunero \& M.A. Rivas, MA 185226. 
Pozuel del Campo, 16-VI-1990, S. García \& F.M. Vázquez, UNEX 14322. Tortajada, 12-VI1988, G. Mateo, VAB 882040. VALENCIA: Cofrentes, 26-IV-1990, F.M. Vázquez, UNEX 14302. ZARAGOZA: Aviñón, 2-VII-1955, P. Montserrat, JACA 43755. Caspe, 28-VI-1979, P. Montserrat \& L. Villar, JACA 120479. Gallocanta, 12-VII-1981, D. Gómez \& G. Montserrat, JACA 562881. Moneguillo, 1-VII1956, P. Montserrat, JACA 2327. Gallocanta, 6VIII-1981, D. Gómez et al., JACA 563481.

Stipa juncea var. juncea: ESPAÑA PENINSULAR. ALBACETE: Pico Almenara, 4-VII-1983, J.M. Herranz, MA 330634. Viatos, Sierra de Alcaraz, 26-IV-1990, F.M. Vázquez, UNEX 14373. ÁVILA: Aldeavieja, 27-V-1990, F.M. Vázquez, UNEX 14391. Armavira, 27-V-1990, F.M. Vázquez, UNEX 14401. San Miguel de Corneja, 27-V-1990, F.M. Vázquez, UNEX 14397. BADAJOZ: Castuera, 2-V-1964, P. Montserrat, JACA 61864. Llerena, 27-V-1988, J.P. Carrasco \& T. Ruiz, UNEX 12691. Zafra, 1-V-1969, S. Rivas Goday \& M. Ladero, MAF 82438. BURGOS: Montes de la Abadesa, 24-VI-1914, P. Font Quer, GDA 22. Montería del Pinar, 24VI-1959, P. Montserrat, JACA 83454. La Vid, 28-VI-1974, P. Montserrat, JACA 335974. CÁCERES: Trujillo, 13-V-1990, S. García \& F.M. Vázquez, UNEX 14388. CÓRDOBA: Arroyo Galapagar, 13-VI-1989, J. Arroyo et al., UNEX 14865. Cardeña, 30-V-1976, J.A. Devesa, SEV 35102. Villanueva de Córdoba, 14-V-1984, J.A. Devesa \& B. Valdés, UNEX 1430. CIUDAD REAL: Sierra de Alhambra, 25-V-1932, J. González, MA 29140. Almagro, 12-V-1990, S. García \& F.M. Vázquez, UNEX 14384. Tomelloso, 12-V-1990, F.M. Vázquez, UNEX 14399. Valdepeñas, 30-V-1980, T. Luque et al., SEV 109011. CUENCA: Buciegos, 17-VI-1990, S. Garcia \& F.M. Vázquez, UNEX 14394. Ciudad Encantada, 28-VII-1977, G. López, MAF 100353. Salinas del Manzano, 17-VI-1990, S. García \& F.M. Vázquez, UNEX 14390. Torre del Palancar, 16-VII-1966, S. Rivas Goday \& J. Borja, MAF 76024. GUADALAJARA: Alcolea del Pinar, 16VI-1990, S. García \& F.M. Vázquez, UNEX 14378. Molina de Aragón, 16-VI-1990, S. García \& F.M. Vázquez, UNEX 14376. Pobo de Dueñas,
10-VIII-1981, D. Gómez et al., JACA 563981. JAÉN: Nava de San Pedro, 23-VI-1980, J.A. Devesa et al., SEV 98377. Palomares, 19-VI1979, M.J. Díez et al., SEV 102570. LEÓN: Herreros de Jamuz, 28-V-1977, A. Carbón, MAF 88399. MADRID: Cerro de los Angeles, sin fecha, E. Huguet del Villar, MA 156378. Casa de Campo, sin fecha, P. Isern, MA 5177. Chamartín de la Mora, V-1897, C. Pau, Caroli Pau Herb. Hisp. s/n, MA 5166. Valdelatas, sin fecha, V. Cutanda, MA 5159. PALENCIA: Quintanar del Puerto, 9-VII-1990, F.M. Vázquez, UNEX 14379. SALAMANCA: Madrigal de las Altas Torres, 16-VI-1990, S. García \& F.M. Vázquez, UNEX 14395. Sierra de Peña de Francia, 16-VI-1961, S. Rivas Goday, MAF 100434. Sieteiglesias de Torres, 4-VII-1971, B. Redondo, JACA s/n. SEGOVIA: Fuente de Cuéllar, 16-VI-1990, S. García \& F.M. Vázquez, UNEX 14382. Retamares de Cuéllar, 30-VI-1978, S. Rivas Goday, MAF 101409. Garbayosa, 16VI-1990, S. García \& F.M. Vázquez, UNEX 14392. Perales de Pedraza, 16-VI-1990, S. García \& F.M. Vázquez, UNEX 14393. SORIA: Adrades, 16-VI-1964, P. Montserrat, JACA 166564. Almazán, 21 -VII-1976, E.F. Galiano et al., SEV 102092. Las Fraguas, Puerto de Villaciervos, 28-VI-1974, P. Montserrat, JACA 339774. TERUEL: Sierra de Albarracín, sin fecha, $B$. Zapater, MA 5147. Puerto Escandón, 28-VI1955, P. Montserrat, JACA 26555. Royuela, 18 VII-1965, E. Paunero \& M.A. Rivas, MA 185229. TOLEDO: Argés, río Guajaraz, 20-V-1981, D. Belmonte \& S. Laorga, MAF 112243. Dos Barrios, 13-V-1990, S. García \& F.M. Vázquez, UNEX 14375. La Estrella de la Jara, 25-V-1966, M. Ladero, MAF 88054. Pedro Muñoz, 12-V1990, S. García \& F.M. Vázquez, UNEX 14371. VALLADOLID: Casas Nuevas, VI-1963, G. Cruz, MA 5142. Encinas de Esgueva, 7-VII1983, J.L. Fernández, MA 349015. ZAMORA: Cañizal, 16-VI-1990, S. García \& F.M. Vázquez, UNEX 14398. Villafalifa, VI-1964, J. Borja, MAF 100839.

Stipa juncea var. cabanasii: ESPAÑA PENINSULAR. BADAJOZ: La Parra, V-1992, F.M. Vázquez, UNEX s/n. Los Santos de Maimona, 17-IV-1987, F.M. Vázquez, UNEX 3519 (Holótipo). 
Stipa clausa subsp. clausa var. clausa: ESPAÑA PENINSULAR. ÁVILA: Valle de Amblés, 12VII-1979, M. Ladero, MA 292601. Sierra de Gredos, 12-VII-1958, A. Rodríguez, MA 189005. San Lorenzo, El Barco de Ávila, 27-V-1990, F.M. Vázquez, UNEX 14407. BURGOS: Montes de la Abadesa, 24-VII-1914, P. Font Quer, n. 130, BC 67646. Río Linares, 9-VI-1983, A. Segura, MA 357377. CÁCERES: Plasencia, 21 V-1863, E. Bourgeau, Exsicc. Pl. d'Espagne E. Bourgeau n. 2563, MA 5168. CIUDAD REAL: Arenas de San Juan, 25-VI-1935, J. González, MA 29145. Cabañeros, 5-VI-1990, J.A. Devesa $\&$ R. Tormo, UNEX 14419. CUENCA: Boniches, 15-VII-1966, J. Borja \& S. Rivas Goday, MAF 76466. Tejadillos, 17-VI-1990, S. García \& F.M. Vázquez, UNEX 14411. GUADALAJARA: Tamajón, 4-VII-1978, M.A. Rivas \& C. Soriano, MA 366365. LEÓN: Herreros de Jamuz, 28-V1973, A. Carbó, JACA 971. MADRID: Aranjuez, 9-VI-1991, F.M. Vázquez, UNEX 14421. Casa de Campo, sin fecha, M. Lagasca, MA 185145 (Lectótipo). Chamartín, 29-V-1924, M. Rivas Mateos, MAF 28980. Escorial, 16-VI-1852, J. Lange, Herb. John Lange s/n, MA 149143. La Mata, 27-V-1990, F.M. Vázquez, UNEX 14405. Torrelodones, VI-1924, sin recolector, MAF 28978. PALENCIA: Quintanar del Puerto, 9VII-1990, F.M. Vázquez, UNEX 14420. SALAMANCA: Aldealengua, 16-VI-1987, A. Amor, SALAF 16011. Madrigal de las Altas Torres, 16-VI-1990, S. García \& F.M. Vázquez, UNEX 14427. Nuevos Naharros, 4-VI-1982, J. Sánchez, Exsicc. Fl. Esp. Univ. Salamanca, Cent. III n. 297, SEV 92754. SEGOVIA: Fuentes de Cuéllar, 16-VI-1990, S. García \& F.M. Vázquez, UNEX 14414. Segovia, sin fecha, E. Huguet del Villar, MA 157856. Villacastín, 27-V-1990, F.M. Vázquez, UNEX 14408. Villar de Sobrepeña, 3VI-1982, C. Cebolla et al., GDA 20266. SORIA: Almansa, VII-1964, J. Borja, MAF 102569. Berlanga, 14-VI-1980, A. Segura, n. 19691, SEV 69390. Carbonera, 5-VII-1955, P. Montserrat, JACA 45655. Quintana Redonda, 13-VI-1957, A. Segura, MA 14447. Ribarroya, 5-VI-1982, A. Segura, MA 357402. TERUEL: Orihuela, VII1895, E. Revechón, Exsicc. Gramineae A. Kneucker, 1900, n. 4, COI s/n. Pozuelo del Campo, 16-VI-1990, S. García \& F.M. Vázquez, UNEX 14417. TOLEDO: Puebla de Don
Fadrique, 13-V-1990, S. García \& F.M. Vázquez, UNEX 14416. Gamonal, 23-VI-1984, T. Ruiz, SALAF 10626. Proximidades de Talavera de la Reina, 13-V-1990, S. García \& F.M. Vázquez, UNEX 14412. VALLADOLID: Encinas de Esgueva, 21-VII-1978, J.L. Fernández, MA 349015. Medina del Campo, 16-VI-1990, S. García \& F.M. Vázquez, UNEX 14424. Olmedo, sin fecha, M. Gutiérrez, MA 5175. Tordesillas, 9-VII-1990, F.M. Vázquez, UNEX 14406. ZAMORA: Fuentesaúco, 16-VI-1990, S. García \& F.M. Vázquez, UNEX 14426. ZARAGOZA: Las Cuerlas, 9-VII-1981, G. Montserrat, JACA 363081. Gallocanta, 6-VIII-1981, D. Gómez et al., JACA 563381.

PORTUGAL PENINSULAR. BEIRA ALTA: Almeida, margen do río Coa, VII-1884, A.R. da Cunha, LISU 3652. Castelo Medo, margen del río Coa, VII-1884, A.R. da Cunha, LISU 3653. TRAS-OS-MONTES E ALTO DOURO: Entre Vila Cha da Barciosa y Miranda do Douro, 7-VII-1952, J.M. Miranda, Exsicc. Pl. Lusit. n. 1124, COI s/n.

Stipa clausa subsp. clausa var. matritensis: ESPAÑA PENINSULAR. MADRID: Vaciamadrid, 14-V-1911, C. Pau, MA 29141 (Holótipo).

Stipa clausa subsp. cazorlensis: ESPAÑA PENINSULAR. GRANADA: Sierra de Baza, 28VI-1984, J. Torres et al., MA 459667. Puebla de Don Fadrique, 5-VII-1979, P.F. Cannon et al., SEV 53236. JAÉN: Los Arenales, Cazorla, 19VIII-1976, J.L. González et al., MA 480635. Cambil, 28-IV-1990, F.M. Vázquez, UNEX 14864 (Holótipo).

Stipa offneri: ESPAÑA PENINSULAR. ALICANTE: Alcoy, 3-VIII-1958, A. Rigual, MA 372930. Altea, Sierra de Baña, 26-V-1952, A. Rigual, MA 372928. Benidorm, 1-V-1955, A. Rigual, MA 372900. Crevillente, 22-V-1959, A. Rigual, MA 372933. ALBACETE: Alcaraz, $27-$ IV-1990, F.M. Vázquez, UNEX 14245. Casas de Lázaro, 25-VI-1984, J.M. Herranz, MA 330633. Hellín, 26-IV-1990, F.M. Vázquez, UNEX 14232. ALMERÍA: Enix, 26-IV-1919, E. Gros, BC 9009. Sierra de Gádor, 6-VI-1963, S. Rivas Goday, MAF 79863. Vélez Rubio, 26-IV-1990, F.M. 
Vázquez, UNEX 14240. BARCELONA: Bagá, 27-IV-1952, O. de Bolòs, BC 12304. Manlleu, 14-VII-1990, F.M. Vázquez, UNEX 14251. San Miguel de Fray, sin fecha, E. Vayreda, BCVayreda. Penedés, 7-IV-1980, I. Soriano, SALAF 10014. Tarrasa, sin fecha, J. Cadevall, BCCadevall. BURGOS: Encinillas, 16-VII-1980, J. Devesa, M.J. Gallego, T. Luque \& S. Talavera, SEV 107171. San Felices, 3-VI-1930, C. Pau, MA 28133. Valle de Tobalina, 14-VI-1986, J.A. Alejandre, MA 365867. La Vid, 28-VI-1974, $P$. Montserrat, JACA 336074. CÁDIZ: Alcalá, Sierra de las Cabras, 2-VI-1925, P. Font Quer, BC 90036. Algodonales, 19-V-1978, B. Cabezudo, J. Rivera \& S. Silvestre, SEV 87350. Grazalema, VI-1916, J. Borja, MAF 71235. CASTELLÓN DE LA PLANA: Ares, 12-VI1980, A.M. Romo, BC 801642. Peñíscola, 16-IV1909, F. Sennen, MA 5121. Vistabella del Maestrazgo, 14-VII-1962, J. Vigo, BC 261236. CIUDAD REAL: Almagro, sin fecha, $J$. Benedicto, BC 67647. Laguna de Ruidera, 6-V1933, J. González Albo, MAF 28992. CUENCA: Buciegos, 17-VI-1990, S. García \& F.M. Vázquez, UNEX 14236. Salinas del Manzano, 17-VI-1990, S. García \& F.M. Vázquez, UNEX 14249. Solán de Cabras, 17-VII-1941, A. Caballero, MA 5124. Valdemeca, 17-VI-1990, S. García \& F.M. Vázquez, UNEX 14241. GERONA: Armetera, 16-V-1948, A. Batalla \& F. Masclans, BC 163586. Llemana, 1-VI-1923, P. Font Quer, BC 90012. Puig, 7-V-1912, P. Font Quer, BC 67667. GRANADA: Albuñela, 20-VI-1988, S. López, GDAC 31952. Sierra Elvira, V-1968, J. Varo, GDAC 3599. Huéscar, 27-IV-1990, F.M. Vázquez, UNEX 14234. Las Mimbres, 1907, J. Díez, GDA s/n. Sierra de la Yedra, 15-IV-1980, A.T. Romero \& C. Morales, GDAC 24567. GUADALAJARA: Almadrones, 16-VI-1990, S. García \& F.M. Vázquez, UNEX 14253. Molina de Aragón, 16-VI-1990, S. García \& F.M. Vázquez, UNEX 14247. Zorita de los Canes, 26-V-1968, P. Montserrat, JACA 193168. HUESCA: La Afortunada, 12-V-1981, G. Montserrat, JACA-G 160. Barbastro, 26-V-1987, G. Montserrat, JACA 403487. Santa Eulalia de la Peña, Belsué, 8-V-1967, P. Montserrat, JACA 254967. Peña Montañesa, 2-VII-1983, D. Gómez, JACA-DG 662. Riglos, 7-IV-1973, P. Montserrat \& L. Villar, JACA 122. Viacamp, 17-V-1986, P.
Montserrat et al., JACA 383586. JAÉN: Cazorla, Fuente Acero, 18-VI-1982, C. Soriano, MA 458104. Segura de la Sierra, 27-VI-1982, C. Soriano, MA 458106. LÉRIDA: Alós de Balaguer, 13-V-1981, J. Pedrol, MA 419368. Borges Blanques, 2-IV-1972, A. Boldú, BC 631632. Conques, 11-VI-1990, F.M. Vázquez, UNEX 14250. Salas de Pallars, 19-VI-1987, $P$. \& G. Montserrat, JACA 558187. Vilanova de Meya, 4-VI-1987, P. \& G. Montserrat, JACA 490787. LOGROÑO: Leza de río Leza, 19-V1985, R. Fernández de Betoño \& J.A. Alejandre, MA 365846. San Vicente de la Somosierra, 11 VI-1983, J.A. Alejandre, MA 400665. MADRID: Aranjuez, sin fecha, G.F. Reuter, MA 5163. Morata, 30-V-1965, E.F. Galiano, SEV 13105. Perales de Tajuña, sin fecha, J. Izco, MAF 72495. MÁlAGA: Alcaucín, 19-V-1982, J.M. Nieto, MGC 20443. Sierra de Almijara, 10-V-1982, B. Cabezudo et al., MGC 20444. Sierra de Mijas, 12-VI-1888, E. Hackel, Exsicc. Pl. d'Espagne E. Reverchón, n. 256, MA 5107. Ojén, 19-V-1990, J.C. Puertas \& M.D. Ramírez, MGC s/n. MURCIA: Cartagena, 21-IV-1901, F. de Paula, MA 5120. El Moral, 27-IV-1990, F.M. Vázquez, UNEX 14239. Moratalla, 27-IV-1990, F.M. Vázquez, UNEX 14257. NAVARRA: Fitero, 28IV-1987, J. Fernández de Betoño \& J.A. Alejandre, MA 423000. Foz de Lumbier, 3-VI1970, P. Montserrat, JACA 175070. Bárdenas Reales, 15-V-1988, G. Montserrat, JACA 52488. PALENCIA: Quintanar del Puerto, 9-VII-1990, F.M. Vázquez, UNEX 14252. SORIA: Castañares, 1-VII-1952, sin recolector, JACA 18458. Ribas de Escalote, 2-VII-1964, A. Segura, MA 357445. Somaén, 30-V-1981, J.A. Devesa et al., SEV 107490. TARRAGONA: Aleixar, 6-VI1954, E. Batalla, BC 598798. Atmetla, 26-IV1928, Hno. Teodoro, Exsicc. Pl. d'Espagne, F. Sennen n. 6776, BC 67671. Pratdip, 2-V-1972, R. Folch, BC 626925. TERUEL: Baños de Segura, 20-VI-1982, P. Montserrat et al., JACA 58782. Sierra de Gúdar, 30-VI-1960, J. Borja, MA 178173. Muniesa, 19-IV-1960, P. Montserrat, JACA 760. Rubielos de Mora, VI-1959, J. Borja, MAF 67673. TOLEDO: Dos Barrios, 29-V-1981, J.A. Devesa et al., SEV 107170. Ocaña, 13-V1990, S. García \& F.M. Vázquez, UNEX 14255. Villatoba, 1-1! 1982, S. Laorga, MAF 112237. VALENCIA: Ademuz, 18-IV-1973, L. Villar, 
JACA 24773. Betera, 9-III-1985, G. Mateo \& M.B. Crespo, VAB 853164. Olleira, 2-VIII-1982, M. Palasí, MA 331670. Dos Santos, 17-VI-1990, S. García \& F.M. Vázquez, UNEX 14256. Solana de la Parra, 16-VI-1986, S. Piera, VAB 861898. Pobla de Vallbona, 23-III-1986, M.B. Crespo, VAB 86624. VIZCAYA: Arrieta, 24-VI-1983, sin recolector, JACA 227683. Labastida, 19-V1984, J.A. Alejandre, MA 400659. Leza, 22-VI1985, J.A. Alejandre, MA 365906. Puebla de Cavarca, 9-VI-1984, J.A. Alejandre, MA 400707. Sobrón, 18-VI-1984, J.A. Alejandre, MA 400691. ZARAGOZA: Alfajarín, 25-V-1983, G. Montserrat \& D. Gómez, JACA 78183. Bujaraloz, 7-V-1954, O. de Bolòs \& J. Braun-Blanquet, BC 116309. Puerto Charola, 13-VI-1973, L. Villar, JACA 178963. Horta, 14-VI-1915, P. Font Quer, BC 67663. Montes de Rueda, 3-V-1957, P. Montserrat, JACA 2314. Sigües, 7-VI-1972, L. Villar, JACA 378.

ISLAS BALEARES. MALLORCA: Bellver, 12-IV-1873, H. Willkomm, COI-Willk. Palma, V-1899, M. Gandorger, Exsicc. Fl. Hisp. M. Gandorger n. 499, MA 5125. Can Picafort, 1V-1971, F. Masclans, BC 607454. MENORCA: Binignardo, 4-V-1877, A. Rodríguez, BC 67665. Ferreires, 30-IV-1952, P. Montserrat, JACA 46851. Mahón, 2-V-1900, A. Pons \& P. Guerau, MA 5115 .

Stipa parviflora var. parviflora: ESPAÑA PENINSULAR. ALBACETE: Almansa, 3-VI1919, P. Font Quer, MAF 69041. Tobarra, 7-V1928, J. Cuatrecasas, n. 2051, MAF 29002. ALICANTE: Alcoy, 20-V-1988, C. Nebot, VAB 886711. Benidorm, 2-V-1954, A. Rigual, MA 372908. Sierra de San Julián, 1-V-1933, M. Martínez, MA 5094. ALMERÍA: Alba, 30-V1971, J. Fernández Casas, MA 412569. El Alquián, 7-IV-1988, F.M. Vázquez, UNEX 14538. Sierra de los Filabres, Benizalón, 15-IV1988, A.B. Robles \& C. Morales, GDAC 28326. Tabernas, 25-IV-1990, F.M. Vázquez, UNEX 14537. Vera, 22-III-1978, J. Fernández Díez, MA 210889. BARCELONA: Cardona, V-1909, P. Font Quer, BC 67718. Tarrasa, sin fecha, J. Cadevall, BC-Cadevall. CIUDAD REAL: Sierra Peraco, 22-V-1933, J. González, MA 29150. Valdepeñas, 12-V-1990, S. García \& F.M. Vázquez, UNEX 14540. CASTELLÓN DE LA
PLANA: Almenara, 17-IV-1946, E. Sierra, Fl. Hisp. Cent IV n. 305, S 19.209.2, BC 104636. Zorita del Maestrazgo, 20-IX-1977, P. Montserrat, JACA 240177. CUENCA: Santa Cruz de Moya, V-1979, G. Mateo, VAB 79/596. GERONA: Gerona, sin fecha, J.A. Devesa et al., UNEX 1058. GRANADA: Baza, 25-IV-1977, B. Molesworth, SEV 107167. La Calahorra, Puerto de la Ragua, 12-VII-1980; A. Romero \& C. Morales, GDAC 24326. Guadix, 27-IV-1990, F.M. Vázquez, UNEX 14526. Huéscar, 27-VI1971, J. Fernández Casas, MA 414555. GUADALAJARA: Guadalajara, 1-VI-1878, F. Fernández, LISU 9651. Pontón de la Oliva, 1VI-1985, E. Monasterio \& A. Galán, MAF 125424. HUESCA: Albelda, 15-V-1971, P. Montserrat, JACA 02281. Candasnos, 5-V-1971, P. Montserrat, JACA 92871. Castilloroy, 28-V1987, G. Monserrat, JACA 438987. Purroy de la Solana, 10-VII-1990, F.M. Vázquez, UNEX 14543. Sesa, 2-VI-1979, P. Montserrat, JACA 48979. JAÉN: Cabra de Santo Cristo, 4-VI-1925, J. Cuatrecasas, BC 67712. Cambil, 28-IV-1990, F.M. Vázquez, UNEX 14535. Jódar, sierra de Mágina, 17-IV-1926, E. Gros, MAF 29012. LÉRIDA: Almacellas, 2-V-1958, F. Masclans, BC 597087. Cervera, 31-V-1981, J.A. Devesa, T. Luque \& C. Romero, Fl. Selecta, Cent. I. n.97, SEV 77979. Terrades, 29-VI-1948, P. Font Quer \& A. Bolòs, BC 595966. Urgel, 10-VI-1962, F. Masclans, BC 596984. Vilanova, 10-VI-1962, F. Masclans, BC 597084. LOGROÑO: Alto de Cantabria, sin fecha, I. Zubía, MA 5078. Pantano de Cervera, 16-IV-1960, A. Segura, MA 357432. MADRID: San Agustín de Guadalix, 12-V-1985, A. Galán \& E. Moreno, MAF 124748. Aranjuez, 17-V-1924, P. Font Quer, BC 81688. Ciempozuelos, sin fecha, V. Cutanda, n. 299, MA 5071. Seseña, Cuesta de la Reina, 30-V1965, B. Valdés, SEV 106964. Villaverde, Cueva de la Bruja, 1-VI-1950, A. Rodríguez, MA 169115. MURCIA: Alhama de Murcia, 26-IV1990, F.M. Vázquez, UNEX 14532. Cartagena, 27-I-1901, F. de Paula, MA 5089. Jumilla, 15III-1985, G. \& I. Mateo, VAB 85/3169. Totana, 22-VI-1962, P. Montserrat, JACA 2294. NAVARRA: Arguedas, Bárdenas Reales, 18-V1988, D. Gómez, MA 478492. El Salvador, 11 VI-1987, P.M. Uribe, MAF 132504. Tudela, 23VI-1935, A. Pérez, MA 5080. SORIA: San 
Felices, 23-V-1962, A. Segura, MA 357345. Somaén, 31-III-1973, P. Montserrat, JACA 5473. TARRAGONA: Ares, 25-V-1979, A.M. Romo, BC 687497. TERUEL: Calonda, 18-V-1981, A. Aguilella, VAB 81/754. Montalbán, 3-V-1957, P. Montserrat, JACA 2290. TOLEDO: Borox, 8V-1980, S. Laorga \& S. Valenzuela, MAF 110889. Ontígola, 12-V-1968, P. Montserrat, JACA 2293. Toledo, 28-IV-1976, A. Oelas, MAF 99969. VALENCIA: Ademuz, 1-V-1988, G. Mateo, MA 440284. Benisanó, camp de Turia, 10-VI-1985, A. Aguilella, VAB 861288. Játiva, 16-V-1896, C. Pau, Caroli Pau Herb. Hisp., MA 5095. Sagunto, V-1791, A.J. Cavanilles, MA 5092. Villena, 30-V-1919, P. Font Quer, BC 81372. VIZCAYA: Oyón, 29-VI-1982, sin recolector, JACA PV1879. ZARAGOZA: Almunia de Doña Godina, 12-VI-1974, $P$. Montseriat \& L. Villar, JACA 258374. Caspe, 28-VI-1979, P. Montserrat \& L. Villar, JACA 120579. Embid de la Ribera, 1-VI-1972, A. Segura, MA 357363. Monegrillo, 29-V-1988, J. \& G. Montserrat, JACA 121888. Tauster, 12VI-1973, L. Villar, JACA 137070. Zuera, 16-V1981, A. Segura, MA 357388.

Stipa parviflora var. pilosa. ESPAÑA PENINSULAR. ALICANTE: Novelda, castillo de la Magdalena, 14-V-1953, A. Rigual, MA 372917. Santa Pola, 17-IV-1987, A. Charpin n. 20826, MA 392649. Villena, 23-V-1981, A. Pastor, VAB 81/755. ALMERÍA: Sierra de los Filabres, Olula del Río, 21-V-1971, E.F. Galiano et al., SEV 8032. Sartenilla, 25-IV-1990, F.M. Vázquez, UNEX 14521. Vélez Rubio, 8-V-1975, E. F. Galiano et al., SEV 106963. BARCELONA: Barcelona, Tibidabo, 19-III-1921, F. Sennen, Pl. d'Espagne n. 1041, MA 5087. CÓRDOBA: Priego de Córdoba, 28-III-1980, J. Muñoz et al., SEV 124295. GRANADA: Cuéllar, 27-IV-1990, F.M. Vázquez, UNEX 14534. HUESCA: Barbastro, 12-VII-1990, F.M. Vázquez, UNEX 14523. LOGROÑO: Alcanadre, 3-VI-1983, P.M. Uribe, MA 400685. MADRID: Aranjuez, sin fecha, P. Pourret, MAF-Pourret 376. Dehesa de Arganda, V-1914, C. Vicioso, MA 5067. Vaciamadrid, 27-V-1924, E. Huguet de Villar, MA 156390. MURCIA: Llano del Real, 5-IV1979, F. García et al., SEV 120841. Lorca, 13VI-1923, Hno. Jerónimo, Pl., d'Espagne F.
Sennen, n. 4969, COI. Moratalla, 27-IV-1990, F.M. Vázquez, UNEX 14533. TOLEDO: Proximidades de Quintanar de la Orden, 12-V 1990, S. García \& F.M. Vázquez, UNEX. Villacañas, 13-V-1990, S. García \& F.M. Vázquez, UNEX 14525. VALENCIA: Civa, 20V-1844, H.M. Willkomm, Esxicc. Iter Hisp. H.M. Willkommnii, n. 64, COI-Willk. ZARAGOZA: Bujaraloz, 22-V-1983, A. Segura, MA 357387. Calatayud, sin fecha, B. Vicioso, n. 601, MA 5084.

Stipa capensis var. capensis: ESPAÑA PENINSULAR. ALBACETE: Sierra de Aguas, 7-V-1973, G. López \& E. Valdés, MAF 89423. ALICANTE: Alcoy, 20-V-1988, O. de Bolòs \& F. Masclans, BC 142256. Novelda, 28-V-1933, P. Michel, MA 5042. Villajoyosa, 2-IV-1966, S. Rivas Goday et al., MAF 68841. ALMERÍA: Adra, 25-IV-1990, F.M. Vázquez, UNEX 14560. Venta de los Yesos, 13-V-1982, J. Lázaro, MGC 13201. Mojacár, 1-III-1970, J. Fernández Casas, MA 412717. Viator, 27-II-1955, P. Montserrat, JACA 2276. BARCELONA: Castelldefels, 20V-1917, P. Font Quer, MA 5021. Garraf, 9-XI1947, A. \& O. de Bolòs, BC 108516. Taró, VI1942, A. Bolòs, BC 99585. Tortosa, 24-VI-1917, P. Font Quer, BC 67684. BADAJOZ: Alconera, 18-VI-1953, J. Borja, MAF 86899. Badajoz, $25-$ IV-1966, A. Segura, MA 357448. Castuera, 1-V1964, P. Montserrat, JACA 42264. Fuente del Maestre, 22-IV-1989, F.M. Vázquez, UNEX 13104. Valdecaballeros, 19-V-1977, J. MalatoBeliz, MA 291085. CÁDIZ: Algodonales, 31-V1980, A. Aparicio, SEV 59097. Espera, 10-V1974, S. Silvestre, SEV 24865. Alrededores de Grazalema, 1-V-1969, E.F. Galiano, P. Gibbs \& B. Valdés, SEV 108477. Tarifa, 20-III-1975, E.F. Galiano et al., SEV 108483. CÁCERES: Alcollarín, 9-IV-1988, A. Ortega \& M.C. Viera, UNEX 12904. El Gordo, 12-VI-1964, M. Ladero, C. Valle \& T. Ruiz, SALAF 10363. Monfragüe, 15-IV-1983, M. Luceño, MA 446697. Trujillo, 13-V-1990, S. García \& F.M. Vázquez, UNEX 14571. CÓRDOBA: Adamuz, 12-VI-1982, A. Aparicio, F. García \& S. Silvestre, SEV 99589. Peñas del Aguila, 11-V-1978, E. Domínguez \& J. Muñoz, SEV 99580. El Cabril, 16-V-1981, L. Corral \& P. Fernández, SEV 99907. Rute, 26VI-1978, J.M. Muñoz, SEV 108485. Comarca de 
los Pedroches, 16-V-1976, J.A. Devesa, SEV 35113. CIUDAD REAL: Santa Cruz de Mudela, V-1958, J. Borja, MA 205514. CASTELLÓN DE LA PLANA: Benicasim, 1-IV-1975, J. Izco, MAF 128476. Villavieja, 20-V-1984, G. Mateo \& A. Aguilella, VAB 84/3327. GERONA: Cadaquéz, VI-1885, D. F. Tremols, MA 5020. Lloret, sin fecha, M. Rivas Mateos, MAF 29115. Port Bou, 1-VI-1890, E.J. Neyraut, LISU 9683. GRANADA: Alhedín, 11-V-1978, F. Pérez Raya, MA 447581. Granada, V-1950, F. Muñoz Medina, GDA s/n. Padul, 25-IV-1990, F.M. Vázquez, UNEX 14563. Sierra de Mandrial, 7-VI-1983, A. Montes et al., GDA 15657. HUELVA: Belmonte, 4-V-1931, E. Gros, Caroli Pau Herb. Hisp. s.n. MA 5019. Corteconcepción, 2-V-1975, B. Cabezudo et al., SEV 99594. El Rocío, 16-III1990, F.M. Vázquez, UNEX 14578. JAÉN: Andujar, 30-IV-1954, A. Rodríguez, MA 169118. Despeñaperros, 24-IV-1970, P. Montserrat, JACA 55070. Sierra de Mágina, 3-VI-1925, J. Cuatrecasas, MAF 29120. LÉRIDA: Els Cubells, 18-V-1918, E. Gros, MA 5031. MADRID: San Agustín de Guadalix, 1-VI-1982, J.C. Moreno Sainz, MA 451112. Navalagamella, 18-V-1976, A. Crespo et al., BC 657033. Villa del Prado, 3V-1982, P. Cantó \& D. Sánchez-Mata,. MAF 114818. MÁLAGA: Algarrobo, 24-IV-1987, S. Castroviejo, MA 376311. Benagolbosa, VI-1944, Laza, GDA s/n. Frigiliana, 19-IV-1974, S. Talaverı \& B. Valdés, SEV 99598. Ronda, 27V-1981, M.J. Díezetal., SEV 113427. MURCIA: Los Alcázares, 6-VI-1932, E. Huguet del Villar, MA 156402. Cartagena, 4-VI-1932, E. Huguet del Villar, MA 156405. Parroquia, 27-IV-1990, F.M. Vázquez, UNEX 14575. Los Urrutias, 27III-1975, G. Mateo, VAB 75/372. SALAMANCA: La Fregeneda, 9-V-1987, A. Amor, SALAF 15982. SEVILLA: Alcalá de Guadaira, 11-IV-1970, E.F. Galiano et al., BC 116607. Aznalcóllar, 16-III-1990, F.M. Vázquez, UNEX 14579. Ecija, 5-IV-1977, B. Cabezudo et al., MGC 21948. Estepa, 24-IV-1990, F.M. Vázquez, UNEX 14565. Lora del Río, 2-IV-1982, M. Barrera et al., SEV 85248. El Ronquillo, 16III-1990, F.M. Vázquez, UNEX 14585. Villaverde del Río, 21-V-1982, J. Morales et al., SEV 99606. TARRAGONA: Marina, 1-V-1972, F. Masclans, BC 610170. Tarragona, VII-1860, Costa n.103, BC-Costa. TOLEDO: Alcaudete,
17-V-1967, P. Montserrat, JACA 40967. VALENCIA: Almassora, 1954, M. Calduch, BC 142087. Benisanó, 10-VI-1985, A. Aguilella, VAB 861290. Cofrentes, 26-IV-1990, F.M. Vázquez, UNEX 14564. Sagunto, 28-V-1946, E. Sierra, Fl. Hisp. Cent. IV n. 303, MA 382141. Sierra de la Murta, sin fecha, J. Borja, MAF 29112. ZARAGOZA: Ametla, V-1917, P. Font Quer, BC 67683.

ISLAS BALEARES. CABRERA: Garigas, 2-V-1933, A. Marcos, BC 87581. Sierra de Ruta, 23-IV-1948, P. Palau-Ferrer, MA 5036. CONEJERA: Isla Conejera, 12-IV-1950, $P$. Palau-Ferrer, MA 149137. IBIZA: Ibiza, IV. 1899, C. Pau, MA 5030. FORMENTERA: Espalmador, 30-III-1918, P. Font Quer, BC 67678. MALLORCA: Alcudia, IV-1899, M. Gandoger, Exsicc. Gandoger n. 501, MA 5033. San Gual Vell, Palma, 7-V-1987, P. Montserrat \& L. Villar, JACA 30887. Palina, 5-VIII-1952, P. Palau-Ferrer, BC 118515. Port d'Inca, Torrent, 5-V-1987, L. Villar \& C. Chocarro, JACA 28087. MENORCA: Camino de la Ciudadela, 16-IV-1957, P. Montserrat, JACA 2277. Moncarella, 14-IV-1988, G. Montserrat, JACA 10888. Pon sa de Alayor, 20-V-1913, $P$. Font Quer, BC 67691.

PORTUGAL PENINSULAR. ALGARVE: Albufeira, 23-IV-1968, J. Malato-Béliz et al., COI 10475. Lagos, 13-IV-1990, S. García \& F.M. Vázquez, UNEX 14573. Sagres, 14-IV1990, S. García \& F.M. Vázquez, UNEX 14574. Silves, 14-IV-1990, S. García \& F.M. Vázquez, UNEX 14566. ALTO ALENTEJO: Aljustrel, $13-$ IV-1990, S. García \& F.M. Vázquez, UNEX 14572. Elvas, 5-VI-1956, J. Malato-Béliz \& A. Guerra, MA 291072. Evora, V-1891, A. Moller, COI s/n. Vila Viçosa, 4-V-1947, A. Fernandes \& F. Sousa, COI s/n. Mértola, IV-1888, A. Moller, COI s/n. Sendas, 15-IV-1990, S. García \& F.M. Vázquez, UNEX 14569. Torrao, 24-VI-1968, E. Paunero, MA 187906. BEIRA ALTA: Figueira de Castelo Rodrigo, 27-IV-1943, S. Castro et al., MA 183903. BEIRA BAIXA: Castelo Branco, 21-V-1959, J. Matos \& A. Marques, Exsicc. Fl. Lusit. n. 6652, COI 6652. Malpica, 19-VI-1956, A. Fernandes et al., COI 5901. BEIRA LITORAL: Coimbra, V.1882, A. Moller, COI s/ n. Souselas, 7-VI-1966, sin recolector, COI 86. ESTREMADURA: Ajuda, VI-1846, F. 
Welwitsch, LISU-W 3676. Sierra d'Arrabida, IV-1880, A. Moller, COI 253. Serra de Monsanto, VI-1880, J. Daveau, Exsicc. Fl. Lusit. n. 606, COI s/n. Setubal, IV-1887, A. Moller, COI s/n. TRAS-OS-MONTES E ALTO DOURO: Barca d'Alba, VI-1902, G. Sampaio, COI s/n. Moncorvo, 26-VI-1955, A. Fernandes et al., COI 5626.

Stipa capensis var. pubescens: ESPAÑA PENINSULAR. ALICANTE: Alicante, 1797, A.J. Cavanilles, MA 5044. ALMERÍA: Cabo de Gata, con dirección al Alquián, 25-III-1977, M.J. Gallego et al., SEV 99335. Los Nietos, 9-IV1979, J.A. Devesa et al., SEV 99581. Tabernas, 3-VI-1967, P.W. Ball et al., MA 187075. Torrevieja, 10-VI-1932, E. Huguet del Villar, MA 156398. Vera, 25-IV-1990, F.M. Vázquez, UNEX 14557. BADAJOZ: Jerez de los Caballeros, 15-III-1990, F.M. Vázquez, UNEX 14547. CIUDAD REAL: Almagro, 12-V-1990, S. García \& F.M. Vázquez, UNEX 14552. Valdepeñas, 12-V-1990, S. García \& F.M. Vázquez, UNEX 14558. CÓRDOBA: Luque, 19-V-1982, I. Fernández et al., SEV 99592. HUELVA: Almonaster, 29-III-1980, J. Rivera \& S. Talavera, SEV 53982. La Nava, 15-III-1990, F.M. Vázquez, UNEX 14546. JAÉN: Mengíbar, 30-IV-1969, E.F. Galiano, SEV 108481. Cambil, 28-IV-1990, F.M. Vázquez, UNEX 14548. MADRID: Aldea del Fresno, 8-V-1983, D. Sánchez-Mata \& P. Cantó, MAF 114808. Aranjuez, 14-V-1966, F. Bellot, SEV 6683. MÁlAGA: Antequera, 17-V-1970,E.F. Galiano et al., SEV 108480. MURCIA: Alhama de Murcia, 26-IV-1990, F.M. Vázquez, UNEX 14559. Escombreras, 5-VI-1932, E. Huguet del Villar, MA 156403. Mazarrón, V-1965, J. Borja, MA 200041. SEVILLA: Constantina, 5-V-1984, I. López et al., SEV 105844. TOLEDO: Cabañas de Yepes, 4-VI-1981, S. Laorga, MAF 110883. Talavera de la Reina, 13-V-1990, S. García \& F.M. Vázquez, UNEX 14550. VALENCIA: Peñíscola, 9-V-1909, F. Sennen, Exsicc. Pl. d'Espagne F. Sennen n. 393, BC-Sennen. Simat de Valldigna, V-1977, J. Mansanet \& G. Mateo, VAB $77 / 628$.

PORTUGAL PENINSULAR. BAIXO ALENTEJO: Odemira, 13-IV-1990, S. García \& F.M. Vázquez, UNEX 14554. Povoa, 13-IV-1990, S. García \& F.M. Vázquez, UNEX 14553.
Stipa papposa: ESPAÑA PENINSULAR. BARCELONA: Sabadell, 30-XI-1983, T. Casasayas i Fornel, BC 647992.

Material estudiado no cartografiado: CHILE. COLCHAGUA: Llico, XII-186I, Landbeck, SGO 37390.

Stipa calamagrostis: ESPAÑA PENINSULAR. ALBACETE: Riópar, Chorros del río Mundo, 12-VII-1976, J. Borja, MAF 94831. BARCELONA: Vallé du Llobregat, VII-1911, F. Sennen, Pl. d'Espagne Exsicc. F. Sennen n. 1237, BC 67605. Massif du Tibidabo, VII-1911, F. Sennen, pl. d'Espagne Exsicc. F. Sennen n. 1239, BC 67727. CASTELLÓN DE LA PLANA: Vertiente Norte del Plá de Vistabella, 5-IX-1987, C. Fabregat, VAB 890478. CUENCA: Hoz de Beteta, 6-VII-1979, B. Cabezudo et al., SEV 990208. GERONA: Ripoll, 16-VIII-1913, F. Sennen, Pl. d'Espagne, Exsicc. F. Sennen, s/n, COI s/n. GUADALAJARA: Somolinos de Atienza, VI-1962, S. Rivas Goday \& M. Mayor, GDA 7810. HUESCA: Pueyo de Aragués, 16VII-1956, P. Montserrat, JACA 2378. Font Blanca, valle de Añisclo, 2-VIII-1975, $P$. Montserrat, JACA 4501. Biescas, 7-X-1969, P. Montserrat, JACA 7436. Roda de Isabena, 31VII-1987, G. Montserrat, JACA 729987. Plan, con dirección a Chia, 17-VIII-1983, G. Montserrat, JACA s/n. Torla, 9-X-1988, L. Villar, JACA 314188. JAÉN: Prueres, VII-1896, F. Beltrán, COI 209. Rasos, 2-VIII-1981, A. Hernández, BC 652328. LÉRIDA: Areo, 18-VII1972, P. Font Quer, BC 67592. Bajada del Puerto de Bonaigua, 10-VIII-1985, J.A. Mejías et al., SEV 126065. Tremp, 11 -VII-1990, F.M. Vázquez, UNEX 14475. NAVARRA: Isaba, 22VIII-1971, L. Villar, JACA V1914. Usún, 23VII-1987, J. \& G. Montserrat, JACA 808787. TERUEL: Alcalá de la Selva, X-1964, S. Rivas Martínez \& J. Borja, MAF 68575. Sierra de Javalambre, 4-VIII-1892, C. Pau, Caroli Pau Herb. Hisp., COI s/n. Sierra de Gúdar, VII-1958, J. Borja, MAF 65747. VALENCIA: San Nicolau, 27-VII-1944, P. Font Quer, BC 94887. Puebla de San Miguel, 20-VII-1988, G. Mateo, VAB 882503. VIZCAYA: Berguenda, 2-X-1971, $O$. de Bolòs, BC 607283. Maeztu, 1-IX-1983, G. Montserrat, JACA V3435. 
Stipa bromoides: ESPAÑA PENINSULAR. ALBACETE: Sierra de Alcaraz, VII-1962, $J$. Borja, MA 205489. AVILA: Romacastañas, 7 VII-1982, D. Sánchez-Mata et al., MAF 114805. Cuevas del Valle, 24-VIII-1982, A. Segura, MA 357425. BADAJOZ: La Albuera, 1-VII-1990, F.M. Vázquez, UNEX 12689. La Parra, 6-VII1992, F.M. Vázquez, UNEX s/n. Valle de Santa Ana, 9-X-1990, F.M. Vázquez, UNEX 14602. BARCELONA: Alella, primavera de 1944, $P$. Montserrat, BC 610991. Santa María de Gorello, 26-VII-1953, A. \& O. de Bolòs, BC 124201. Planes de Vallvidriera, 20-VI-1918, P. Font Quer, BC 67730. Rubí, 25-VI-1944, A. Bolòs, BC 100560. Tiana, VII-1910, F. Sennen, Pl. d'Espagne Exsicc. F. Sennen s/n, MA 5292. Vilasar, can de Boquet, 20-VIII-1945, P. Montserrat, BC 610989. CÁCERES: Cáceres, finca «La Alberca», 26-VI-1986, M. Ladero \& M.T. Santos, SALAF 15608. Losar de La Vera, 19-VII-1988, A. Amor, SALAF 16643. Serrejón, 5-XII-1982, D. Belmonte, MAF 117175. Aliseda, 30-VI-1973, S. Rivas Goday et al., MAF 87328. CÁDIZ: Algodonales, 17-VI-1983, A. Aparicio \& J. Blázquez, MA 467272. Grazalema, Sierra de San Cristóbal, sin fecha, S. Clemente, MA 5288. CIUDAD REAL: Ciudad Real, 13-V-1934, J. González, MA 5285. CÓRDOBA: Cabra, 1 VII-1963, E.F. Galiano, SEV 6669. Finca de «La Victoria», Córdoba, 16-VI-1940, Hno. Mauricio, GDA. GERONA: Blanes, 10-VII1945, sin recolector, Fl. Hisp. Cent. II Exsicc. n.103, S.19.209.11, BC 100097. Vall de Viany, 1-VII-1951, F. Masclans, BC 598791. GRANADA: Puerto de Alazores, 20-VI-1980, C. Curras \& A. Romero, MGC 20146. JAÉN: Sierra de Cazorla, 25-VIII-1966, E. Paunero, MA 181026. Pontones, 22-VII-1975, F. Muñoz Garmendia \& C. Soriano, MA 480638. Sierra de Segura, 12-IX-1954, E.F. Galiano, MAF 19229. MÁLAGA: Sierra de Antequera, VII-1969, S. Rivas Goday, MAF 93186. Sierra de Mijas, 19VII-1888, E. Reverchón, Pl. d'Andalusie Exsicc. n. 296, MA 5289. MURCIA: Sierra de Segura, $3-$ VI-1887, J. Vélez, MA 5284. ORENSE: Cobas, 14-VI-1987, sin recolector, MA 435830. SANTANDER: Potes, 6-VIII-1971, S. Talavera \& B. Valdés, SEV 106956. SEVILLA: Algámitas, 9-VI-1970, E. F. Galiano \& B. Valdés, SEV 109012. TARRAGONA: Sierra de Marina, 6-
VII-1941, A. Bolòs, BC 98710. TOLEDO: Santa Quiteria, 27-VIII-1945, P. Montserrat, BC 610988.

PORTUGAL PENINSULAR. TRAS-OSMONTES E ALTO DOURO: Bragança, 23-VII1959, A. Telles \& B. Rainha, COI 640118. Miranda do Douro, 29-VI-1940, F. Sousa \& T. de Morais, COI s/n.

Stipa tenacissima: ESPAÑA PENINSULAR. ALBACETE: Fuente de Alamo, 26-IV-1990, F.M. Vázquez, UNEX 14504. Almansa, 3-VI1919, P. Font Quer, BC 90027. Balazote, 27-IV1990, F.M. Vázquez, UNEX 14276. Casas de Ibáñez, 26-IV-1990, F.M. Vázquez, UNEX 14262. Hellín, 26-IV-1990, F.M. Vázquez, UNEX 14268. ALICANTE: Alcoy, sin fecha, A.J. Cavanilles, n. 48, MA 5216. Benidorm, Sierra Helada, 24-IV-1952, A. Rigual, MA 372899. Hifac, 12-V-1923, P. Font Quer, BC 90025. Santa Pola, 8-III-1987, G. Mateo et al., VAB. Villena, Peña Rubia, 1-IV-1961, A. Rigual, MA 372858. ALMERÍA: El Alquián, 25-IV-1990, F.M. Vázquez, UNEX 14269. Almería, 10-IV1944, H. Jerónimo, MA 382715. Sierra de los Filabres, 28-IV-1972, B. Molesworth, MGC 7623. Cabo de Gata, 23-IV-1932, E. Huguet del Villar, MA 158282. Barranco de Huetín, 10-VII1981, R. Lázaro, MGC 8113. Lomas del Panadero, 27-II-1988, A. Asensi \& B. Díez, MGC 23103. Tabernas, 25-IV-1990, F.M. Vázquez, UNEX 14483. Vélez Rubio, 26-IV-1990, F.M. Vázquez, UNEX 14278. Vera, 25-IV-1990, F.M. Vázquez, UNEX 14492. CÁDIZ: Arcos de la Frontera, 23-IV-1979, B. Cabezudo et al., SEV 53869. Algodonales, sierra de Líjar, 31-V-1979, A. Aparicio et al., MGC 11335. Barbate, 23-IV1982, J. Arroyo, SEV 120840. Caños de Meca, 1-IV-1980, F. Amor \& A. Barroso, SEV 107383. Grazalema, puente del Horno, 3-VI-1983, A. Aparicio, MA 467237. Zahara, 9-VI-1980, A. Martínez, SEV 107530. CASTELLÓN DE LA PLANA: Benicasim, 1-VIII-1954, F. Masclans, BC 141834. Calig, 27-IV-1987, G. Mateo, VAB 871837. Oropesa del Mar, 1-V-1989, S. López et al., VAB 892790. CIUDAD REAL: Entrepeñas, 10-VI-1973, P. Montserrat, JACA 158673. Loranca de Tajuña, 4-IV-1970, F. Bellot et al., MA 198084. Lagunas de Ruidera, 3-V-1933, J. 
González, MAF 27992. La Solana, 12-V-1990, S. García \& F.M. Vázquez, UNEX 14262. Valdepeñas, 12-V-1990, S. García \& F.M. Vázquez UNEX 716/90. CÓRDOBA: Benamejí, 13-V-1980, M.L. Díaz \& J.M. Muñoz, SEV 107382. Luque, 16-IV-1980, J. Muñoz, SEV 107526. Priego de Córdoba, VI-1960, J. Borja, MAF 71164. Rute, 8-III-1980, J.M. Muñoz, SEV 107380. CUENCA: Carrascosa del Campo, 17VI-1990, S. García \& F.M. Vázquez, UNEX 14498. Tarancón, 17-VI-1990, S. García \& F.M. Vázquez, UNEX 14482. GRANADA: Solana de Alfacar, 10-VI-1977, F. Valle \& C. Morales, GDAC 11962. Baza, regni granatensis copiosa, 9-VII-1845, sin recolector, COI-Willk. Benandilla, 27-III-1989, J. Hodar, GDAC 31020. Benalzade, 25-IV-1990, F.M. Vázquez, UNEX 14488. Sierra Elvira, V-1968, J. Varo, GDAC 536. Galera, 27-IV-1990, F.M. Vázquez, UNEX 14267. Guadix, 27-IV-1990, F.M. Vázquez, UNEX 14271. Huéscar, 26-V-1978, A.M. Negrillo, GDA 10262. Sierra del Manar, 28-X1978, B. Camus et al., GDAC 24546. Silla del Moro, 15-IV-1990, F. Moreno \& C. Morales, GDAC 24548. Padul, 25-IV-1990, F.M. Vázquez, UNEX 14497. Vélez de Benaudalla, 8-IV-1979, J.A. Devesa et al., SEV 104312. JAÉN: Alcaudete, 28-IV-1990, F.M. Vázquez, UNEX 14277. Cambil, 28-IV-1990, F.M. Vázquez, UNEX 14273. La Guardia, 26-IV-1989, D. Gómez \& R. García, JACA 51589. Jaén, 28-IV-1990, F.M. Vázquez, UNEX 14264. Jódar, 27-IV-1941, E. Guinea, MA 439542. Sierra de Mágina, 12VI-1925, J. Cuatrecasas, MAF 27997. Pegalajar, 19-VI-1979, M.J. Diez et al., SEV 104547. MADRID: Aranjuez, sin fecha, G.F. Reuter, MA 5205. Arganda, 16-IV-1933, J. Cuatrecasas, MAF 28003. Carabaña, VI-1919, C. Vicioso, MA 5210. Chinchón, 9-VI-1990, F.M. Vázquez, UNEX 14272. Madrid, Atocha, 19-V-1907, M. Rodríguez, MA 382711. Piul, VI-1892, J. Mas Guindal, MAF 62724. Rivas, V-1852, P. Irsen, MA 5208. Torrelaguna, 16-VI-1990, S. García \& F.M. Vázquez, UNEX 14487. Valdemoro, 24IV-1966, S. Silvestre, SEV 102572. Villarejo de Salvanes, 22-V-1986, H. Aranz, MA 401772. MÁLAGA: Alhaurín el Grande, 26-V-1989, B. Cabezudo \& J.M. Nieto, MGC. Alhaurín de la Torre, 18-IV-1974, S. Talavera \& B. Valdés, SEV 101995. Antequera, Sierra de Archidona,
24-IV-1990, F.M. Vázquez, UNEX 14501. Cuevas del Becerro, 24-III-1987, B. Díez \& A. Asensi, MGC 22017. Coín, 22-III-1987, S. Herville et al., MGC 23541. Fuente Concepción, 1-VI-1990, C. Molina et al., MGC s/n. Marbella, 12-V-1985, G. Michel, MGC 20089. Sierra de Mijas, Benalmádena, 12-IV-1984, B. Cabezudo et al., MGC 16290. Nerja, 29-IV-1919, E. Gros, BC 67587. Sierra Tejeda, 29-IV-1982, B. Cabezudo \& J.M. Nieto, MGC 20432. Tolox, 31 III-1990, M. Hernández \& D. Navas, MGC s/n. Sierra de las Yeguas, 13-VI-1973, S. Talavera \& B. Valdés, SEV 100128. MURCIA: Águilas, 25III-1975, F.J. Fernández, MA 291083. Alhama de Murcia, 26-IV-1990, F.M. Vázquez, UNEX 14280. Cartagena, 16-V-1905, F.J. Jiménez, MA 5213. Cieza, 26-IV-1990, F.M. Vázquez, UNEX 14500. Sierra de Espuña, 18-IV-1927, F. Sennen, P1. d'Espagne Exsicc. n. 6449, BC-Sennen. El Moral, 27-IV-1990, F.M. Vázquez, UNEX 14265. Moratalla, 27-IV-1990, F.M. Vázquez, UNEX 14266. SEVILLA: Algámitas, 9-VI-1970, E.F. Galiano \& B. Valdés, SEV 30547. Badalatosa, 5 IV-1977, B. Cabezudo et al., GDAC 6494. Coripe, 12-III-1977, M.J. Gallego et al., SEV 32060. Morón, Sierra de Esparteros, 24-IV-1933, C. Vicioso, MA 5197. Estepa, 24-IV-1990, F.M. Vázquez, UNEX 14279. El Saucejo, 14-IV-1978, B. Cabezudo \& E. Ruíz del Clavijo, SEV 32018. Sevilla, sin fecha, M. Colmeiro, MA 5196. TARRAGONA: Hospitalet et Atmetla, 10-IV1917, P. Font Quer, Pl. d'Espagne F. Sennen Exsicc. n. 6777, LISU 9673. TOLEDO: Dos Barrios, 29-V-1981. J.A. Devesa et al., SEV 104548. Mora, 23-IV-1980, S. Laorga, MAF 110886. Ocaña, 13-V-1990, S. García \& F.M. Vázquez UNEX 14503. VALENCIA: Dehesa de Albufera, 1-V-1955, L. Ceballos \& A. Rodríguez, MA 167318. Ayora, 26-IV-1990, F.M. Vázquez, UNEX 14499. Ramblas de Estenas, Utiel, 15 VII-1986, G. García, VAB 885960. Sagunto, VII-1903, R. Prosper, MA 5217. Valencia, sin fecha, M. Lagasca, MA 158281. Valldigna, sin fecha, A.J. Cavanilles, MA 5218.

ISLAS BALEARES. IBIZA: Ibiza, cabo Martinet, 10-V-1980, S. Rivas Martinez et al., MA 422483. Isla Esparto, 19-V-1950, F. Palau Ferrer, MA 158280. MENORCA: Ciudadela, 31-III-1958, P. Montserrat, JACA 105858. Mahón, 8-IV-1952, P. Montserrat, JACA 21552. 
GIBRALTAR: Ladera Oeste del Peñón, 17-V-1985, J. Besusasan et al., SEV 124949.

PORTUGAL PENINSULAR. ALGARVE: Albufeira, 23-IV-1968, E.F. Galiano et al., SEV 8918. Lagos, 14-IV-1990, S. García \& F.M. Vázquez, UNEX 14480. Portimao, sin fecha, $F$. Welwitsch, LISU-W s/n. SILVES, 14-IV-1990, S. García \& F.M. Vázquez, UNEX 14489. Tavira, sin fecha, A.G. Guimaraes, COI s/n. Cabo de San Vicente, II-1880, G.F. Guimaraes, COI s/n.

Stipa gigantea subsp. gigantea: ESPAÑA PENINSULAR. ALBACETE: Sierra Relumbras, 21-VI-1986, J.M. Herranz, MA 352155. ÁVILA: Amavira, 27-V-1990, F.M. Vázquez, UNEX 14356. Aldeavieja, 27-V-1990, F.M. Vázquez, UNEX 14348. Ávila, 14-VII-1893, A.E. Lomax, MA 5226. Barco de Ávila, 27-V-1990, F.M. Vázquez, UNEX 14595. San Miguel de Corneja, 27-V-1990, F.M. Vázquez, UNEX 14366. Puerto de Navalmoral, 12-VII-1984, D. Sánchez-Mata, SEV 114046. BADAJOZ: Alconera, 2-V-1989, F.M. Vázquez, UNEX 9967. Cabeza la Vaca, 5V-1989, T. Ruíz \& M.C. Viera, UNEX 13089. Cornalvo, 17-III-1988, T. Ruíz \& R. Tormo, UNEX 13091. Esparragosa de Lares, 17-III-1988, T. Ruiz \& R. Tormo, UNEX 13097. Jerez de los Caballeros, 3-V-1987, F.M. Vázquez, UNEX 14341. Mérida, 22-IV-1976, E.F. Galiano et al., SEV 108879. Zafra, 18-VI-1953, J. Borja \& A. Rodríguez, MA 160914. BURGOS: Aranda del Duero, VI-1942, A. Caballero, MA 5271. Lerma, 12-VI-1986, J.A. Alejandre, MA 365908. CÁDIZ: Algeciras, 4-V-1974, B. Molesworth, SEV 108188. Algodonales, 19-V-1978, B. Cabezudo et al., SEV 124297. Bornos, 30-IV1969, D.M.C. Brinton-Lee, SEV 83104. Conil, 1-IV-1980, F. Amor \& A. Barroso, SEV 108189. Grazalema, 14-VII-1925, P. Font Quer, BC 81340. San Roque, 10-V-1922, E. Gros, BC 81343. Tarifa, 14-IV-1981, J. Arroyo \& J.M. Gil, SEV 76289. Vejer de la Frontera, 13-IV1978, T. Luque \& B. Valdés, SEV 55408. CÁCERES: Aliseda, 30-VIII-1990, F.M. Vázquez, UNEX 14354. Baños de Montemayor, 15-V-1944, A. Caballero, MA 5266. Pico Calvitero, 26-VI-1990, F.M. Vázquez, UNEX 14343. Deleitosa, 28-III-1945, S. Rivas Goday, MAF 86463. Guadalupe, 21-VI-1948, A. Caballero, MA 5263. Navalvillar de Ibor, 8-IV-
1988, J.P. Carrasco \& R. Tormo, UNEX 12898. Perales del Puerto, 18-IV.1982, sin recolector, SALAF 20906. Talayuela, 8-V-1983, T. Ruíz, SALAF 7781. Trujillo, 16-IV-1983, $P$. Montserrat, JACA 11983. CIUDAD REAL: Sierra de la Alhambra, 30-V-1933, J. González, BC 84777. Almagro, 12-V-1990, S. García \& F.M. Vázquez, UNEX 14349. Luciana, 12-V1990, S. García \& F.M. Vázquez, UNEX 14369. Puebla de Don Rodrigo, 12-V-1990, S. García \& F.M. Vázquez, UNEX 14350. Urda, 19-VII-1959, P. Montserrat, JACA 69159. Valdepeñas, 12-V1990, S. García \& F.M. Vázquez, UNEX 14342. CÓRDOBA: Sierra Morena, V-1920, C. Pau, BC 67641. Villaviciosa, 15-V-1920, C. Pau, MA 5252. GRANADA: Contraviesa, 15-V-1980, A.T. Romero \& C. Morales, GDAC 24545. HUELVA: Almonte, Reserva Biológica de Doñana, 20-IV1972, B. Cabezudo, SEV 1771.16. Mazagón, 17V-1979, S. Silvestre et al., SEV 108192. La Nava, 15-III-1990, F.M. Vázquez, UNEX 14339. Palos de la Frontera, 6-IV-1979, M.J. Diez et al., SEV 102564. JAÉN: Despeñaperros, 5-V-1977, P. Montserrat, JACA 37877. LEÓN: Vallecillo, 3-XII-1978, P. Montserrat, JACA 468278. LOGROÑO: Berceo, 27-VII-1872, P. de Avila, BC 67568. MADRID: Altos de Bernardino, $17-$ VI-1854, E. Bourgeau, Pl. d'Espagne Exsicc. s.n., COI-Willk. Cercedilla, 9-VII-1909, M. Rivas Mateos, MAF 65001. El Escorial, sin fecha, V. Cutanda, MA 5234. Guadalix de la Sierra, 23-V1968, P. Montserrat, JACA 144368. Las Matas, 27-V-1990, F.M. Vázquez, UNEX 14364. Rascafría, 16-VI-1990, S. García \& F.M. Vázquez, UNEX 14341. Villalba, VII-1893, J. Mas Guindal, MAF 62723. MÁLAGA: Sierra de Aguas, 24-V-1977, J. Varo et al., GDA 15316. Sierra de Almijara, 23-VI-1935, M. Laza, MAF 27975. Antequera, 24-IV-1990, F.M. Vázquez, UNEX 14328. Sierra Bermeja, 18-IV-1845, $M$. Willkomm Iter Hisp. Exsicc. n.735, COI-Willk. Cómpeta, 14-VI-1919, C. Pau, BC 67642. Sierra de Mijas, 8-V-1919, E. Gros, MA 5255. Torremolinos, 8-V-1919, E. Gros, BC 67640 PONTEVEDRA: Bayona, 22-IV-1945, F. Bellot, MAF 72635. SALAMANCA: La Alberca, $27-$ VI-1946, E. Paunero, MA 5262. Sierra de Béjar, 15-VI-1990, S. García \& F.M. Vázquez, UNEX 14367. Cantagallo, 15-VI-1990, S. García \& F.M. Vázquez, UNEX 14333. Guijuelo, 27-VI- 
1928, C. Pau, MAF 27976. SEVILLA: Aznalcóllar, 16-III-1990, F.M. Vázquez, UNEX 14334. Morón de la Frontera, 24-V-1925, P. Font Quer, BC 81341. SEGOVIA: El Espinar, VII-1943, S. Rivas Goday, MAF 78476. Pajares de Pedraza, 16-VI-1990, S. García \& F.M. Vázquez, UNEX 14331. San Idelfonso, 30-VI1935, J. González Albo, MA 5141. Villacastín, 27-V-1990, F.M. Vázquez, UNEX s/n. SORIA: Quintana de Gormaz, 8-VIII-1984, G. Mateo, VAB 84/3329. La Rasa, 8-VI-1980, A. Segura, JACA 594580. TOLEDO: Calderina, 29-V-1924, P. Font Quer, BC 67636. La Estrella, sin fecha, M. Ladero, MAF 84474. Puebla de Don Fadrique, 13-V-1990, S. García \& F.M. Vázquez, UNEX 14359. Veleda, 6-IV-1983, T. Ruiz, SALAF 4335. VALLADOLID: Olmedo, sin fecha, D. Gutiérrez, MA 5270. Tordesillas, 9-VII-1990, F.M. Vázquez, UNEX 14329. ZAMORA: Río Esla, 29-VI-1934, E. Sierra, BC 91873. Villalcampo, 6-IV-1982, F. Navarro \& C.J. Valle, SALAF 3676.

PORTUGAL PENINSULAR. ALGARVE: Balasa, 1-IV-1853, E. Bourgeau, Pl. d'Espagne Exsicc. s/n, COI-Willk. Sagres, plataforma del Cabo de San Vicente, sin fecha, F. Welwistch, LISU-W 6848. Monte Clérigo, 19-IV-1968, F. Bellot et al., COI 10319. Tavira, 21-IV-1956, J. Malato-Béliz et al., MA 291042. ALTO ALENTEJO: Alcacer do Sal, V-1921, A. Fernandes, LISU 1470. Sierra de San Mamede, 3-IV-1950, J. Malato-Béliz, MA 291041. Redondo, V-1909, R. Palhinha \& E. Mendes, LISU 3623. Vendas Novas, 24-III-1990, S. García \& F.M. Vázquez, UNEX 14360. Vimeiro, 24-III-1990, S. García \& F.M. Vázquez, UNEX 14338. BAIXO ALENTEJO: Aljustrel, 13-IV1990, S. García \& F.M. Vázquez, UNEX 14363. Grándola, IV-1848, E. Welwistch, LISU-W 139017. Santana, 17-IV-1968, F. Bellot \& B. Casaseca, MA 187919. Santiago do Cacém, 3IV-1880, J. Daveau, LISU 3641. BEIRA ALTA: Almeida, VI-1890, M. Ferreira, COI s/n. Celorico de Beira, VII-1885, M. Ferreira, COI s/n. Viseu, 7-VII-1980, A. Marques, COI 2090. BEIRA BAIXA: Castelo Branco, VI-1891, A.R. da Cunha, LISU 3639. Covilha, 6-VII-1893, A. $R$. da Cunha, LISU 3640. BEIRA LITORAL: Bussaco, V-1893, M. Ferreira, Fl. Lusit. Exsicc. n. 1251, COI 310. Serra de Louza, sin fecha, $L$.
Moller, COI 262. DOURO, Frazao, VII-1890, M. Ferreira, COI s/n. Matosinhos, VI-1899, G. Sampaio, COI s/n. ESTREMADURA: Alfeite, V-1879, J. Daveau, LISU 3643. Cascais, IV1882, P. Coutinho, LISU 3631. Monte Leira, 22V-1946, C. Fontez et al., GDA s/n. Setubal, sin fecha, E. Luisier, COI s/n. MINHO: Sierra do Gêres, VIII-1871, J. Henriques, LISU 3632. Ponte do Mouro, VI-1885, J. de Mariz, LISU 3628. RIBATEJO: Alpiarca, 23-IV-1966, M. Ruiz, COI 625. TRAS-OS-MONTES E ALTO DOURO: Miranda do Douro, VI-1888, J. de Mariz, LISU 3628. Villareal, VI-1877, $J$. Henriques, COI 262.

Stipa gigantea subsp. donyanae: ESPAÑA. HUELVA: Almonte, Laguna del Ojillo, 2-V1990, S. García \& F.M. Vázquez, UNEX 14346. Almonte, Laguna de Santa Olalla, 2-V-1990, S. García \& F.M. Vázquez, UNEX 14352 (Holótipo). Almonte, Laguna de Tarafe, 18-V1977, E. Valdés Bermejo, MA 291373. Almonte, Pilar Porquera del Fraile, 24-III-1966, E.F. Galiano \& J. Novo, MA 205484.

Stipa tirsa: ESPAÑA PENINSULAR. Lugar no precisado del cuadrante Centro-Oriental, $M$. Lagasca, MA 146661.

Material estudiado no cartografiado. ALEMANIA. BOHEMIA: Leitmeritz, mot basaltique Radobyl, 26-VI-1887, J. Freyn, Exsicc. Fl. Selecta Ch. Magnier n. 2099, MA 4984. Lorrach, 7-VI-1905, sin recolector, MA 4980. FRANCIA. COT'DOR: Fontainebleau, VI1944, sin recolector, MA 149133. REPÚBLICA CHECA. MORAVIA: Monte Bile Kappate, 20V-1932, F. Weber, MA 4987. Hluk-Uh Brod, 30VI-1927, Jos, MA 4986. Vyskov, stepposo «Vetrniky», VI-1921, Richauer, MA 4983. UCRANIA: Kaltfgik, campo Maeotico, sin fecha, Graff, H 1065655 (Lectótipo). TURQUíA: Steppe auj Eruptirgestein, Kars Susuz, 30-VI1988, M. Nydegger, KAS 43532.

Nassella mucronata: ESPAÑA PENINSULAR. MADRID: Aranjuez, VII-1892, J. Mas y Guindal, MAF 62737.

PORTUGAL PENINSULAR. BEIRA LITORAL: Coimbra, cerca del Seminario, 3-V-1945, 
P. Povoa dos Reis, COI s/n.

Material estudiado no cartografiado: FRANCIA. Montpellier, V-1925, J. Daveau, Exsicc. Fl. Francaise, Dufour, n. 5074, MA 466726.

\section{ÍNDICE DE NOMBRES CIENTÍFICOS}

Los nombres de los taxones de Stipa y Nassella aceptados en el tratamiento taxonómico, y su número de orden en la revisión, aparecen en negrita. El resto de los nombres corresponden a sinónimos, seguidos de números y letras, que indican el taxón en el que quedan incluidos.

Achnatherum Beauv.

I,I.G.

Achnatherum sect. Aristella (Trin.)Tzvelev I.H.

Achnatherum bromoides (L.)Beauv.

Achnatherum calamagrostis (L.)Beauv.

Achnatherum papposum (Nees)Barkworth

Agrostis bromoides $\mathrm{L}$.

Agrostis calamagrostis $\mathrm{L}$.

Antistirrhia glauca Desf.

Aristella (Trin.)Bertol.

Aristella bromoides (L.)Bertol.

Avena cavanillesii Lag.

17.1

Calamagrostis plumosa Sprengel

Jarava Ruiz \& Pavón

I,I.F.

Lasiagrostis bromoides (L.)Nevski \& Roshev. 15

Lasiagrostis calamagrostis (L.) Link

Lasiagrostis gigantea (Link)Trin. \& Rupr.

Lasiagrostis Link

Lasiagrostis tenacissima (L.)Trin. \& Rupr.

Macrochloa arenaria (Brot.)Kunth

Macrochloa gigantea (Link)Hackel

Macrochloa Kunth

Macrochloa tenacissima (L.)Kunth

Nassella Desv.

17

I,I.G.

16

17.1

17

I,I.J.,I.K.

16

II

Nassella mucronata (Humb. Bonpl. \& Kunth)Pohl II.1 Nassella neesiana (Trin. \& Rupr.)Barkworth II.1 Stipa L.

Stipa «a» Aristella Trin.

Stipa sect. Aristella (Trin.)Hackel

Stipa sect. Barbatae Junge

Stipa sect. Leiostipa Dumort.

Stipa sect. Leiostipa ser. Bromoides (Martinovsky)Moraldo
Stipa sect. Leiostipa ser. Capillatae

(Roshev.)Moraldo

I.C.

Stipa sect. Giganteae (Martinovsky)F.M.Vázquez \& Devesa

I.K.

Stipa sect. Jarava (Ruiz \& Pavón)F.M.Vázquez \& Devesa

I.F.

Stipa sect. Inaequiglumes (Bor)F.M.Vázquez \& Devesa

I.D.

Stipa sect. Lasiagrostis (Link)Hackel I.G.

Stipa sect. Macrochloa (Kunth)F.M.Vázquez \& Devesa

I.J.

Stipa sect. Stipa

I.A.

Stipa sect. Stipa «gr.» Leiostipa (Dumort.)Freitag

Stipa sect. Stipella Tzvelev I.E

Stipa ser. Bromoides Martinovsky I.H.

Stipa ser. Barbatae Roshev. I.B.

Stipa ser. Capillatae Roshev. I.C.

Stipa ser. Giganteae Martinovsky I.K.

Stipa ser. Inaequiglumes Bor I.D.

Stipa ser. Pennatae Roshev. I.A.

Stipa ser. Pseudocapillatae Roshev. I.A.

Stipa ser. Pulcherimae Martinovsky I.A.

Stipa ser. Pulcherimae Martinovsky subser.

Eriocaules Martinovsky I.A.

Stipa ser. Tirsae Martinovsky I.A.

Stipa ser. Tortiles Roshev. I.E.

Stipa subgen. Aristella (Trin.)Trin. \& Rupr. I.H.

Stipa subgen. Jarava (Ruiz \& Pavón)Trin. \& Rupr.

Stipa subgen. Lasiagrostis (Link)Steud. I.G.

Stipa subgen. Macrochloa (Kunth)Steud. I.J.

Stipa subgen. Eriocaules Martinovsky I.A.

S. apertifolia Martinovsky 2

S. apertifolia var. apertifolia 2.a

S. apertifolia var. nevadensis F.M.Vázquez \&

Devesa 2.b

S. arenaria Brot. $\quad 17.1$

S. aristella L. $\quad 15$

S. barbata Desf. 5

S. barbata Desf. var. barbata 5

S. barbata var. brevipila Cosson \& Durieu 5

S. barbata var. hispanica Trin. \& Rupr. 5

S. barbata var. longiaristata Martinovsky 5

I.H. S. bromoides (L.)Dörfler 15

I.H. S. calamagrostis (L.)Wahlenb. 14

I.B. S. calamagrostis var. glabra Ascherson \& Graebner

I.C.

S. capensis Thunb. 12

S. capensis Thunb. var. capensis 12.a 
S. capensis var. pubescens (Ball)Breistr.

12.b

S. capensis var. tortilis (Desf.)Breistr.

S. capillata L.

S. capillatavar. orthopogon Ascherson \& Graebner

6

S. capillata var. ulopogon Ascherson \& Graebner

S. celakovskyi Martinovsky

S. clausa Trabut

S. clausa Trabut subsp. clausa

S. clausa trabut subsp. clausa var. clausa 9.1.a

S. clausa subsp. clausa var. matritensis

F.M.Vázquez \& Devesa

9.1.b

S. clausa subsp. cazorlensis F.M.Vázquez \& Devesa

S. dasyvaginata Martinovsky

S. delilei Steud.

S. eriocaulis auct. pl.

S. eriocaulis Borbás

S. gabesensis Moraldo, Raffaelli \& Ricceri

S. gigantea Lag.

S. gigantea Link

S. gigantea Link subsp. gigantea

S. gigantea subsp. donyanae F.M.Vázquez \& Devesa

S. gigantea fma. pubescens Hackel

S. humilis Brot.

S. iberica Martinovsky

S. iberica subsp. austro-iberica Scholz

S. iberica subsp. pauneroana Martinovsky

S. iberica subsp. pauneroana var. pseudodasyphylla Martinovsky

S. iberica var. austro-iberica (Scholz)F.M.Vázquez \& Devesa

S. iberica var. iberica

S. iberica var. pseudodasyphylla (Martinovsky)F.M.Vázquez \& Devesa 3.b

S. iberica var. pygmaea Martinovsky 3.a

S. iberica var. pygmaea fma. levis Martinovsky

S. ilorcitana Sennen

3.a

S. juncea auct. pl.

11.a

S. juncea Cav.

S. juncea Gouan

S. juncea $L$.

S. juncea L. var. juncea

S. juncea var. cabanasii F.M.Vázquez \& Devesa

8.b

S. juncea var. lagascae (Roemer \& Schultes)Mutel
S. kelibiae Moraldo, Raffaelli \& Ricceri $\quad 16$

S. kralifii Moraldo, Raffaelli \& Ricceri $\quad 16$

S. lagascae auct. hisp. $\quad 8$. a

S. lagascae auct. pl. $\quad 6$

S. lagascae Roemer \& Schultes 7

S. lagascae subsp. clausa (Trabut)Coutinho 9

S. lagascae subsp. normalis Maire 7

S. lagascae subsp. normalis var. embergeri Maire

7.b

S. lagascae subsp. normalis var. oropediorum Maire

7.b

S. lagascae subsp. normalis var. pubescens (Hackel)Maire

S. lagascae subsp. normalis var. pubescens fma. breviaristata Maire

7.a

S. lagascae subsp. normalis var. trabutii Maire

7.b

S. lagascae Roemer \& Schultes var. lagascae 7.a

S. lagascae var. australis Maire 7.b

S. lagascae var. eriophylla Willk. $\quad 7 . \mathrm{a}$

S. lagascae var. hachelii Fiori $\quad 9.1$

S. lagascae var. pubescens fma. latifolia Maire \& Weiller

7.a

S. mucronata Humb., Bonpl. \& Kunth $\quad 19$

S. offneri Breistr. $\quad 10$

S. paleacea Poiret $\quad 12$

S. papposa Nees $\quad 13$

S. parviflora Desf. 11

S. parviflora subsp. contorta (Lange)Malagarriga

S. parviflora var contorta Lange

S. parviflora var. ilorcitana (Sennen)Sennen 11.a

S. parviflora Desf. var. parviflora 11.a

S. parviflora var. pilosa (Chrtek \& Martinovsky) F.M.Vázquez \& Devesa

11.b

S. parviflora fma. pilosa Chrtek \& Martinovsky

$11 . \mathrm{b}$

S. pauneroana (Martinovsky) F.M.Vázquez \& Devesa

S. pennata auct. pl.

1,2

S. pennata subsp. eriocaulis (Borbás)Martinovsky

S. pennata subsp. iberica (Martinovsky)O. Bolòs et al.

S. pennata subsp. mediterranea (Trin. \& Rupr.)Ascherson \& Graebner 3.a

S. pennata subsp. tirsa (Steven)Kneucker $\quad 18$

S. pennata var. mediterranea Trin. \& Rupr. 3.a

S. plumosa Pourret ex Willk. 5

S. pubescens Lag. (16)

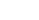
.

(7)

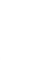


S. retorta Cav.

S. setigera C. Presl

S. stenophylla Czern.

S. tenacissima Loefl. ex L.

S. tenuiflora Phil.

S. tirsa Steven

S. tortilis Desf.

S. tortilis var. pilosa Trabut

S. tortilis var. pubescens Ball

S. trochelaris Nees \& Mey.

Themeda triandra Forsskål

Urachne subgen. Nassella Trin.

AGRADECIMIENTOS. A los doctores Ginés López González (Madrid), Helmut Freitag (Kassel, Alemania), Mary Barkworth (Logan, U.S.A.) y Ana Ortega (Badajoz), por sus sugerencias sobre el manuscrito; al Dr. Ricardo Cabezas de Herrera por la transcripción al latín de las diagnosis; a la $\mathrm{Dr}^{\mathrm{a}}$ Trinidad Ruiz Téllez (Badajoz) por sus orientaciones sobre la ecología de las especies; a todos los Directores y Conservadores de Herbario por la cesión de material, y a dos revisores anónimos cuyos comentarios han servido para mejorar el texto original.

\section{BIBLIOGRAFÍA}

AVDULOV, N. P. -1928- Systematicheskaya Karyologica semeestava Gramineae. Drievnik V. S. Leningrade, 1928: 65-66.

AVDULOV, N. P. -1931-Kario-sistematicheskoye issledovaniye semeystva zlakok. Bull. Appl. Bot. Pl.-Breed. (Leningrad) Suppl., 44: 1-428.

BARKWORTH, M. E. -1990- Nassella (Gramineae, Stipeae). Revised interpretation and nomenclatural changes. Taxon, 33 (4): 597-614.

BARKWORTH, M. E. -1993- North American Stipeae (Gramineae): Taxonomic changes and others comments. Phytologia, 74(1):1-25.

BARKWORTH, M. E. \& J. EVERETT -1987Evolution in the Stipeae: Identification and Relationships of its Monophyletic Taxa. In: T.R. SODERSTROM et al. (eds.) Grass Systematics and Evolution, 251-264. Washington.

BAUHini, C. -1623-Pinax theatri Botanici. Basileae.
BEAUVOIS, A. M. F. J. PALISOT DE -1812-Essai d'une nouvelle Agrosto-graphie. París.

BENTHAM, G. \& J. D. HOOKER fil. -1883Gramineae. In: Genera Plantarum, 3(2): $1074-$ 1215. London.

BERTOLONI, A. -1833-Flora Italic sistemus plantas in Italia et insulis circuncustantibus sponte nascentes, 1. Bologna.

BOCCONE, S. -1697-Museo di Piante rare, 1. Venetia.

BOLÓS, O. DE, R. MASALLES \& J. VIGO -1987Notes sobre monocotiledonies. Collec. Bot. (Barcelona), 17(1): 95-96.

BOR, N. L. -1960- The Grasses of Burma, Ceylon, India and Pakistan. New York.

BORGEN, L. -1970- Chromosome numbers of Macaronesian flowering plants. Nytt. Mag. Bot., 17(3-4): 145-161.

BOWDEN, W. M. \& H. A. SENN -1962Chromosome numbers in 18 grass genera from South America. Canad. Jour. Bot., 40: 1115 1124.

CABRERA, A. \& M. A. TORRES -1968-El género Stipa L. en la prov. de Buenos Aires. Bol. Soc. Argent. Bot., 12: 132-179.

CARO, J. A. -1966- Las especies de Stipa (Gramineae) de la región central Argentina. Kurtziana, 3: 7-119.

CARO, J. A. y E. SÁNCHEZ - 1973-Las especies de Stipa (Gramineae) del subgénero Jarava. Kurtziana, 7: 61-116.

CASASAYAS, T. \& A. FARRAS -1985- Stipa papposa Nees, Eragrostis curvula (Schrad.)Nees i Chenopodium pumilo R.Br.: Tres especies exótiques noves per a Catalunya. Collect. Bot. (Barcelona), 16(1): 161-164.

CAVAnilles, A. J. -1802-Descripción de las plantas. Madrid.

CEBOLlA, C. \& M. A. LóPEZ - 1994- De Stipis matritensibus notulae praecipue chorologicae. Fontqueria, 39: 155-163.

CELAKOVSKY, L. -1883-Ueber einiger Stipen Österr. Bot. Zeitschr., 33: 313-319.

CELAKOVSKY, L. -1884- Nachtragliches uber Stipa tirsa Steven. Österr. Bot. Zeitschr., 34: 318-321.

CHAMBERS, H. L et al., -1979-Aristella In: E.R.FARR, J.A. LEVSSINK \& F.A.STAFLEU (eds.) Index Nominorum Genericorum vol., 1: 129. Utrecht. 
CHRTEK, J. \& J. O. MARTINOVSKY -1969Infraspeziphische taxa von «Stipa parviflora» Desf. und «Stipa hoggarensis» Chrtek et Martinovsky sp. nova. Webbia, 24: 391-399.

CLAYTON, W. D. \& S. A. RENVOIZE -1986Genera graminum. Grasses of the world. London.

CLUSIUS, C. -1601- Historia Rariorum Plantarum, 6. Anvers.

COVAS, G. \& M. BOCKLET -1945- Número de cromosomas de algunas Gramineae-Stipinae de la Flora Argentina. Rev. Argent. Agron., 12: 261-265.

DAHLGREN, R., T. KARLSSON \& P. LASSEN 1971 - Studies on the flora of the Balearic Islands.

I. Chromosome numbers in Balearic Angiosperms. Bot. Not. (Lund), 124: 249-269.

DE WINTER, B. -1965- The South African Stipeae and Aristideae (Gramineae). An anatomical, Cytological, and taxonomic study. Bothalia, 8: 201-404.

DELILE, A. R. -1840- Index Seminum Horti Monspeliensis. Ann. Sci. Nat. Bot. sér., 3, 3:2528.

DELILE, A. R. -1849- Index Seminum Horti Monspeliensis. Ann. Sci. Nat. Bot. sér., 3, 12:364-369.

DESVAUX, E. -1854-Gramíneas. In: C. GAY (ed.), Historia Física y Política de Chile, 6: 23-551. París.

DEVESA, J. A., T. RUIZ, M. C. VIERA, R. TORMO, F. M. VÁZQUEZ, J. P. CARRASCO, A. ORTEGA \& J. PASTOR - 1991- Contribución al conocimiento cariológico de la familia Poaceae en Extremadura (España). III. Bol. Soc. Brot., sér. 2, 64: 35-74.

DIHORU, G. \& N. ROMAN -1969- Une nouvelle espece du genre Stipa. Rev. Roumaine Biol., 14(1): 21-27.

DUMORTIER, P. B. -1823-Observationes sur les gramineés de la Flore Belgique. Turnay.

ELIAS, M. K. -1942- Tertiary prairie Grasses and Other Herbs from the high plains. Geological Society of America Special Paper (Regular Studies), 41: 2-175.

ENDLICHER, S. -1836-1840- Genera Plantarum Secundum Ordines Naturales Disposita. Vindobonae.

EVERETT, J. \& S. W. L. JACOBS -1983- Studies in Australia Stipa (Poaceae). Telopea, 2(4): 391-400.
EVERETT, J. \& S. W. L. JACOBS -1990- Notes on Stipa (Poaceae) in Australia and Easter Island. Telopea, 4(1): 7-11.

FERNANDES, A. \& M. QUEIRÓS -1969Contribution à la connaissance cy totaxonomique des Spermatophyta du Portugal. I. -Gramineae. Bol. Soc. Brot, sér. 2, 43: 20-144.

FREITAG, H. -1975- The genus Piptatherum (Gramineae) in Southwest Asia. Notes Roy. Bot. Gard. Edinburgh, 33(3): 341-408.

FREITAG, H. -1985- The genus Stipa (Gramineae) in Southwest and South Asia. Notes Roy. Bot. Gard. Edinburgh, 42(3): 355-489.

GARCIA, J. -1946- Algunas novidades para a flora Ibérica. Anal. Inst. Bot. Cavanilles, 6(2): 421427.

GERVAIS, C. -1966- Nombres chromosomiques chez quelques Graminées. Bull. Neuchât. Sci. Nat., 89: 87-100.

GODRON, D. A. -1853- Flore Juvenalis. Mém. Acad. Sci. Montpellier, 1: 1-450.

GOULD, F. W. -1970- Stipa. In: A. LÖVE (ed.), Chromosome numbers reports XXV. Taxon, 19(1): 112-113.

GRISLEY, G. -1660- Viridarium Lusitanum, 1. Olyssipone.

HARTLEY, W. -1973- Studies on the origin, evolution, and distribution of the gramineae. V. The subfamily Festucoideae. Aust. Jour. Bot., 21: 201-234.

HITCHCOCK, A. S. -1925- The North America species of Stipa and synopsis of the South American species of Stipa. Contr. USA Nat. Herb., 24(7): 215-289.

HITCHCOCK, A. S. -1935-Manual of the grasses of the Unites States. New York.

HOLMGREN, P. K., W. KEUKEN \& E. K. SCHOFIELD - 1981 - Index Herbariorum I. Regn. Veg., 106: 1-452.

HUGHES, D. K. -1921- A revision of the Australian species of Stipa. Kew Bull., 1921: 1-30.

HUGHES, D. K. -1922- Further notes on the Australian species of Stipa. Kew Bull., 1922: 15-22.

JACOBS, S. W., J. EVERETT \& M. E. BARKWORTH -1995-Clarification of morphological terms used in the Stipeae (Gramineae), and a reassessment of Nassella in Australia. Taxon, 44(1): 33-41.

KERGUÉLEN, M. - 1975- Les Gramineae (Poaceae) 
de la Flore Française. Essai de mise au point taxonomique et nomenclaturale. Lejeunia, 75: 1-343.

KUNTH, C. S. -1829- Stipa. In: Révision des Graminées publiées dans les Nova Genera et Species Plantarum de Humboldt et Bonpland, 1: 179-186. Paris.

LABADIE, J. P. -1979- Étude caryosystematique de quelques especes de la flore d'Algérie. Nat. Monsp., 32: 1-11

LAGASCA, M. -1816-Genera et Species Plantarum quae aut novae sunt aut nondum recte cognoscuntur. Matriti.

LINNEO, C. -1753- Species Plantarum, 1. Holmiae.

LINNEO, C. -1754- Genera Plantarum, ed.5. Holmiae.

LINNEO, C. -1755-Centuria Plantarum I. Upsaliae. LINNEO, C. -1759-Systema Naturae, ed. 10, vol. 2. Holmiae.

LINNEO, C. -1762-Species Plantarum, ed. 2, vol. 1. Holmiae.

LINNEO, C. -1767-Mantissa Plantarum, ed. 2. Holmiae.

LINNEO, C. -1768-Systema Naturae, ed. 12, vol. 3. Holmiae.

LORENZO-ANDREU, A. -1951- Cromosomas de plantas de la estepa de Aragón. III. Anales Est. Exp. Aula Dei, 2(2): 195-203.

LORENZO-ANDREU, A. -1953- Notas sobre cariología. Estudios y experiencias sobre el esparto, 2: 87-91.

LORENZO-ANDREU, A. \& M. P. GARCÍA SANZ -1950- Cromosomas somáticos de plantas espontáneas en la estepa de Aragón. II. Anales Est. Exp. Aula Dei, 2(1): 12-20.

LÖVE, A. \& D. LÖVE-1961- Chromosome numbers of central and northwest European plant species. Op. Bot., 5: 1-581.

LÖVE, A. \& D. LÖVE -1974- Cytotaxonomical atlas of the slovenian flora. Stockholm.

LÖVE, A \& D. LÖVE -1975-Plant Chromosomes. Vaduz.

LOVE, R. M. -1947- Stipa. In: MYERS, W. M. (ed.), Cytology and genetics of forage grasses. Bot. Rev., 13(6): 390-391.

LUNGEANU, I. -1980- Stipa tenacissima. In: A. LÓVE (ed.), Chromosome numbers reports LXVI. Taxon, 29(1): 164.

MARTINOVSKY, J. O. -1965- Stipa rubens P. Smirnov das Rötliche federgras- eine für die
Tschechoslowakei und für Mitteleuropa neu Art. Preslia, 37(2): 156-169.

MARTINOVSKY, J. O. -1966- Zwei neue süderuropäische Federgrassippen IX. Beitrag zur Kenntnis der europäischen Stipa-Sippen. Feddes Repert., 73: 141-152.

MARTINOVSKY, J. O. -1967a- A karpat-medence Stipa-fajai. Bot. Közlem, 54(1): 45-52.

MARTINOVSKY, J. O. -1967b- Neue submediterrane Stipa-Arten und die taxonomische Einteilung der Federgrassippen der Serie Pulcherrimae Martinovsky. Preslia, 39(2): 260-275.

MARTINOVSKY, J. O. -1970a- Zwei neue StipaSippen aus Iraq. XXI Beitrag zur Kenntis der Stipa-Sippen. Preslia, 42(4): 373-377.

MARTINOVSKY, J. O. -1970b- Über drei neue Stipa-Sippen aus dem Verwandtschafstskreis Stipa joannis s.l. XXII. Beitrag zur Kenntnis der Stipa-Sippen. Öster. Bot. Zeischr., 118(10): 171-181.

MARTINOVSKY, J. O. -1970c- Beitrag zur Kenntnis der spanischen und der nordafrikanischen Federgrassippen der Gruppe Pennatae. XV. Anal. Inst. Bot. Cavanilles, 27: 55-85.

MARTINOVSKY, J. O. -1976- Neue Stipa-Sippen und einige Ergänzungen der früher beschriebenen Stipa-Taxa. Preslia, 48(1): 186188.

MARTINOVSKY, J. O. -1980- Stipa. In: T.G. TUTIN et al. (eds.), Flora Europaea, 5: 247252.

MARTINOVSKY, J. O. \& H. SCHOLZ -1968-Stipa bavarica - eine neue federgrasat. XIII. Willdenowia, 4: 317-324.

MARTINOVSKY, J. O. \& V. SKALISCKY -1969Zur Nomenklatur einiger Stipa-Sippen der Pennatae-Gruppe XVI. Beitrag zur Kenntnis der europäischen Federgrassippen. Preslia, 41(3): 327-341.

MATTHEI, O. R. -1965- Estudio crítico de las gramíneas del género Stipa en Chile. Gayana, 13: 1-137.

MORALDO, B. -1986- Il genere Stipa L. (Gramineae) in Italia. Webbia, 40(2): 203-278.

NASH, L. -1913- Stipa. In: N.L.BRITTON \& A.BROWN (eds.), Flore N.U.S., ed. 2, 1: 176. London.

NILES, C. \& A. CHASE -1925- A bibliographic 
study of Beauvois' Agrostographie. Contr. U.S. Nat. Herb., 24(6): 181.

NILSSON, O. \& P. LASSEN -1971- Chromosome numbers of vascular plants from Austria, Mallorca and Yugoslavia. Bot. Not., 124: 270276.

PARODI, L. R. -1946- Gramíneas Bonarienses. Clave para la determinación de los géneros y enumeración de las especies. Buenos Aires.

PARODI, L. R. - 1947- Las especies de gramíneas del género Nassella de la Argentina y Chile. Darwiniana, 7: 369-395.

PARODI, L. R. -1960- Las especies de Stipa del Subgénero Pappostipa de la Argentina y Chile. Rev. Arg. Agr., 27: 65-106.

PAUNERO, E. -1960- ¿Es Stipa tirsa una planta española? Anal. Inst. Bot. Cavanilles, 18: 289 293.

PIGNATTI, S. -1982- Flora d'Italia, 3. Bologna. ‘ POIRET, J. L. -1789- Voyage en Barbarie. Paris.

PRETEL, A. - 1976- Procedimiento para facilitar el estudio de cromosomas en materiales vegetales difíciles. Cuad. Ci. Biol. (Granada), 5: 53-60.

QUEIRÓS, M. -1973-Contribuiçao para o conhecimento citotaxonomico das Spermatophyta de Portugal. Gramineae I. Bol. Soc. Brot., sér. 2, 47: 77-103.

QUEIRÓS, M. -1974- Contribuiçao para o conhecimento citotaxonomico das Spermatophyta de Portugal. Gramineae II. Bol. Soc. Brot., sér. 2, 48: 81-98.

REESE, G. -1957- Über die Polyploidiespektren in der nordsaharrischen Wüstenpflanzen. Flora, 144(4): 598-634.

ROJAS, F. -1994-Revisión de las especies de la tribu Stipeae (Poaceae) en Bolivia. Tesis Magist. Universidad de Concepción. Concepción. Inéd. ROSHEVITS, R. Y. -1934- Stipa. In: V. L. KOMAROV (ed.), Fl. URSS, 2: 79-83. Leningrad.

ROUY, G. -1913- Flore de France, 14: 97-98. París. SCHEUCHZER, J. -1719-Agrostographia. Tiguri. SCHOLZ, H. -1968- Die artengruppe Stipa pennata L. in Frankreich, in der Schweiz und angrenzenden Gebieten. Willdenowia, 4(3): 299315 .

SCHOLZ, H. -1975- Grassland evolution in Europa. Taxon, 24(1): 81-90.

SCHOLZ, H. -1982- Über mikro-und Makrohaare einiger Piptatherum-Uund Stipa-Arten (Stipeae,
Gramineae). Willdenowia, 12(2): 235-240.

SCHOLZ, H. -1985- Stipa. In: P. H. DAVIS (ed.), Flora of Turkey, 9: 541-553. Edinburgh.

SCHOLZ, H. -1988- Eine neue Stipagrostis (Gramineae) aus den Sand-Wüsten Irans und Afghanistans. Willdenowia, 17: 107-109.

SCHOLZ, H. -1989- Neue Taxa der Gattung Stipa sect. Stipa (Gramineae aus dem Mittelmeergebiet). Willdenowia, 19: 127-132.

SCHOLZ, H. -1990- Neue und wenig bekannte mediterrane Gramineen-taxa. Willdenowia, 19: 405-412.

SCHOLZ, H. -1991- Stipa tunetana, eine neue Art aus Tunesien, und das St.lagascae-Aggregat (Gramineae). Willdenowia, 20: 77-80.

SKALINSKA, M., E. POGAN \& A. JANKUN 1968- Dalse badania nad Kariologia flory polskiej CZ VII. Acta Biol. Cracovia, 11(2): 199-224.

SMIRNOW, P. -1925-Die neuen russichen Specierum novarum regni vegetabilis. Feddes Repert., 21: 231-237.

SMIRNOW, P. -1929- Neue Stipen. Feddes Repert., 26: $264-271$

SNOW, R. -1963- Alcoholic hydrochloric acidcarmine as a stain for chromosome in squash preparations. Stain Technol. 38: 9-13.,

SPEGAZZINI, C. -1901- Stipeae Platenses. An. Mus. Nac. Montevideo, 4: 1-173.

STACE, C. A. \& C. E. JARVIS - 1985- Typification of linnacan tax a of annual Poaceae: Poeae related to Vulpia and Desmazeria. Bot. Jard. Linn. Soc., 91: 435-444.

STEBBINS, G. L. -1975- The role of polyploid complexes in the evolution of North American grasslands. Taxon, 24(1): 91-106.

STEBBINS, G. L. \& R. M. LOVE -1941- A cytological study of california forage grasses. Amer. Jour. Bot., 28(5): 371-382.

STEUDEL, E. G. -1854-Stipa. In: Synopsis Plantarum Glumacearum, 1: 120-135. Stuttgartiae.

STEVEN, C. -1857- Vezeichnis der auf der taurischen halbiusel wild wachsenden pflanzen. Bull. Soc. Nat. Moscou, 30(3): 65-133.

STRID, A. \& I. A. ANDERSSON -1985Chromosome numbers of greek mountain plants. An annotated list of 115 species. Bot. Jahrb. Syst., 107: 203-228.

SWALLEN, J. R. -1979- Lasiagrostis, Jarava. In: 
E.R.FARR, J.A. LEVSSINK \& F.A.STAFLEU (eds.), Index Nominorum Genericorum vol. 2. Utrecht.

TALAVERA, S. -1987- Stipa. In: B.VALDÉS, S.TALAVERA \& E.FERNÁNDEZ-GALIANO (eds.), Flora Vascular de Andalucía Occidental, 3: 381-384. Barcelona.

TARNAVSCHI, I. T. -1948- Die chromosomenzahlen der Anthophyten-Flora von Rumänien mit einem Ausblick auf das Polyploidie-problem. Bot. Mus. Bot. Univ. Cluj., 28, suppl. 1-130.

TARNAVSCHI, I. T. -1970- Stipa. In: A. LÖVE (ed.), Chromosome numbers reports XXVII. Taxon ,19(4): 609-610.

THOMASSON, J. R. -1979- Distribution in Pitochaetium (Gramineae-Stipeae) Paleophytogeographical significance. Iselya, 1(4): 161-165.

THOMASSON, J. R. -1980- Paleoeriocoma (Gramineae, Stipeae) from the miocene of Nebraska: Taxonomic and Phylogenetic significance. Syst. Bot., 5(3): 233-240.

TISCHLER, G. -1950-Die chromosomenzahlen der Gefässpflanzen Mitteleuropas. Gravenhage.

TJIO, J. H. \& A. LEVAN -1950- The use of oxyquinoleine in chromosome analysis. Anal. Est. Exp. Aula Dei, 2: 21-64.

TOURNEFORT, J. P. -1700-Institutiones Rei Herbariae, 1. Parisiis.

TORRES, M. A. -1993- Revisión del género Stipa (Poaceae) en la provincia de Buenos Aires. Monogr. Comis. Invest. 12.

TOVAR, O. -1988- Revisión de las especies peruanas del género Stipa L. (Gramineae). Opusc. Bot. Pham. Complutensis, 4: 75-106.

TRINIUS, C. B. - 1820- Fundamenta agrostografica. Viennac.

TRINIUS, K. B. \& F. J. RUPRECHT -1842-Species graminum Stipacearum. Mém. Acad. Sci. Pétersb. sér. 6, 4: 27-96.

TZVELEV, N. N. - 1973- Notae de gramineis Florae URSS. Nov. Syst. Plant. Vasc., 10: 79-98.

TZVELEV, N. N. -1974- Notulae de Tribu Stipeae Dumort. (Fam. Poaceae) in URSS. Nov. Syst. Plant. Vasc., 11: 4-21.

TZVELEV, N. N. -1989- The system of grasses Poaceae and their evolution. Bot. Rev., 55(3): 141-205.

UJHELYI, J. -1961-Data to the systematics of the subsection Glaucae of sectio Bulbosae of the genus Koeleria. Ann. Hist. Nat. Mus. Natl. Hungarici Not., 53: 208-224.

VAN ROYEN, A. -1740-Florae Leydensis prodromus, exhibens plantas quae in Horto academico Lugduno-Batavo aluntur. Lugduni Batavorum.

VÁZQUEZ, F. M., G. LÓPEZ \& J. A. DEVESA 1995- Tipificación de los taxones linneanos del género Stipa (Gramineae) que viven en la Península Ibérica. Anales Jard. Bot. Madrid, 52(2): 179-186.

VÁZQUEZ, F. M. \& J. A. DEVESA -1996- Stipa clausa Trabut. (Stipa Sect. Leiostipa Dumort., Gramineae), una especie olvidada del centro y sur de la Península Ibérica. An. Jard. Bot. Madrid, 54(1): 407-414.

VICKERY, J. W., S. W. JACÓBS \& J. EVERETT 1986- Taxonomic studies in Stipa (Poaceae) in Australia. Telopea, 2(6): 1-132.

VIERA, M. C. \& F. M. VÁZQUEZ-1991-Stipa. In: J. A. DEVESA (ed.), Las gramíneas de Extremadura, 232-238. Serv. Publ. Univ. Extremadura, Monogr.Bot. Badajoz.

Aceptado para su publicación en Julio de 1996

Dirección de los autores. F.M. Vázquez: Dpto. Producción Forestal, Servicio Investigación y Desarrollo Tecnológico, Junta de Extremadura, Apdo. 22. 06080, Badajoz. J.A. Devesa: Departamento de Biología y Producción de los Vegetales (Botánica), Facultad de Ciencias, Universidad de Extremadura, Avda. de Elvas s/n, 06071-Badajoz, España. 